UNIVERSIDADE DE SÃO PAULO - USP

FACULDADE DE ECONOMIA, ADMINISTRAÇÃO E CONTABILIDADE DEPARTAMENTO DE ECONOMIA PROGRAMA DE PÓS-GRADUAÇÃO EM ECONOMIA

UMA AVALIAÇÃO COMPARATIVA DA EFICIÊNCIA DOS GASTOS PÚBLICOS COM SAÚDE NOS MUNICÍPIOS BRASILEIROS

Éverton Gomes Ferreira de Abreu dos Santos

Orientadora: Profa. Dra. Fabiana Fontes Rocha 
Profa. Dra. Suely Vilela

Reitora da Universidade de São Paulo

Prof. Dr. Carlos Roberto Azzoni

Diretor da Faculdade de Economia Administração e Contabilidade

Prof. Dr. Joaquim José Martins Guilhoto

Chefe do Departamento de Economia

Prof. Dr. Dante Mendes Aldrigly

Coordenador do Programa de Pós Graduação de Economia 
ÉVERTON GOMES FERREIRA DE ABREU DOS SANTOS

\section{UMA AVALIAÇÃO COMPARATIVA DA EFICIÊNCIA DOS GASTOS PÚBLICOS COM SAÚDE NOS MUNICÍPIOS BRASILEIROS}

Texto apresentado ao departamento de Economia da Faculdade de Economia Administração e Contabilidade da Universidade de São Paulo como requisito para prova de qualificação para a obtenção do título de Mestre em Economia

Orientadora: Profa. Dra. FABIANA FonTES RochA

SÃO PAULO

2008 


\section{FICHA CATALOGRÁFICA}

Elaborada pela Seção de Processamento Técnico do SBD/FEA/USP

Santos, Éverton Gomes Ferreira de Abreu

Uma avaliação comparativa da eficiência dos gastos públicos com saúde nos municípios brasileiros / Éverton Gomes Ferreira de Abreu dos Santos. -- São Paulo, 2008.

$77 \mathrm{p}$.

Dissertação (Mestrado) - Universidade de São Paulo, 2008 Bibliografia.

1. Gastos em saúde - Eficiência 2. Economia da saúde 3. Econometria I. Universidade de São Paulo. Faculdade de Economia, Administração e Contabilidade II. Título.

CDD -336.39 
Para minha mãe 


\section{AGRADECIMENTOS}

Agradeço antes de tudo à minha mãe que sempre incentivou meus estudos, além de torcer por mim e comemorar com entusiasmo por todas as minhas conquistas. Também agradeço ao meu pai, meus irmãos e todo o resto da minha família pelo suporte e carinho.

Agradeço à professora Fabiana Rocha que além de ter paciência, compreensão e dedicação, se dispôs a ajudar com rapidez sempre que necessário. Não poderia deixar de agradecer também às professoras Verônica Orellano e Basília Aguirre pelos comentários e sugestões feitas durante a qualificação que contribuíram de forma bastante relevante para essa dissertação.

Agradeço aos meus amigos do mestrado pelo enorme companheirismo, tanto nos momentos de descontração como nos de aprendizagem.

Agradeço à Lílian por todo carinho e apoio dado durante toda a elaboração desse trabalho.

E por fim, sou grato à Fipe e à Fapesp pelas bolsas concedidas em boa parte da minha passagem pelo mestrado. 


\section{RESUMO}

Este trabalho tem como objetivo comparar a eficiência dos gastos públicos com saúde dos municípios brasileiros, ou seja, analisar quais deles melhor aproveitam seus recursos investidos nessa área. Em outras palavras, foi comparado o orçamento público total para este setor em cada município, com a qualidade da saúde da sua população - com o cuidado de levar em consideração uma série de outras variáveis que tem impacto sobre a saúde da população, tais como a educação, as condições de saneamento, a renda média, etc. Para tanto, primeiro foi feita uma caracterização geral da qualidade de saúde da população dos municípios, e depois foi construída uma fronteira de possibilidades de produção, utilizando-se da técnica de análise de Fronteiras Estocásticas, sendo a ineficiência dos municípios comparada através da distância de cada um deles em relação a essa fronteira.

Foram analisados também fatores que pudessem explicar a magnitude relativa das ineficiências, na tentativa de encontrar variáveis que expliquem desempenhos melhores e piores, como por exemplo: a intensidade de utilização do capital, que se mostrou negativamente correlacionada com a ineficiência; a cobertura dos programas Saúde da Família e Agentes Comunitários da Saúde, que aparentemente não aumentam a eficiência; a parceira com o setor privado, entre outros.

Os gastos avaliados são referentes ao período entre 1997 e 2000 - anos que antecedem o Censo de onde foram tiradas as principais informações de saúde da população. A fonte utilizada para a obtenção dos dados de gastos com saúde foi o Sistema de Informações Financeiras (SIAFI) do Tesouro Nacional, por isso a amostra de municípios se constitui de todos os municípios brasileiros cujo montante de gastos com saúde no período em questão está discriminado nesse banco de dados ${ }^{1}$. A amostra final contempla 3370 municípios, número que corresponde a $60 \%$ do total nacional.

\footnotetext{
${ }^{1}$ Os municípios que declararam gasto inferior a $\mathrm{R} \$ 5,0$ per capita também não foram considerados
} 


\begin{abstract}
The aim of this work is to compare the efficiency of the public expenses with health among Brazilian municipalities, i.e. analyze which municipality better applied the financial resources on this sector. In order to achieve this goal, each municipality's total public budget for this sector was compared to the local health quality of population - taken into account variables that may affect population's health, such as: education; public utilities; average income; etc. Firstly, the general quality of health for the municipalities was defined and characterized, secondly a Production Possibility Frontier was built, using the method of Stochastic Frontier, where the municipalities' inefficiency is compared through the distance of each of them to the frontier.

The influence of some factors were tested, as they may explain the difference in performance among the municipalities. The main factors are: intensiveness of capital usage, which showed negative correlation with inefficiency; coverage of the public policies Saúde da Família and Agentes Comunitários da Saúde, which did not present evidences of raising the efficiency; private sector partnerships; among others.

The database used was the Sistema de Informações Financeiras (SIAFI), collected from the National Treasury of Brazil, covering the period from 1997 to 2000. The population's data used was from the National Census of 2000. The final sample contains 3370 municipalities, which correspond to $60 \%$ out of the Brazilian total municipalities.
\end{abstract}




\section{SUMÁRIO}

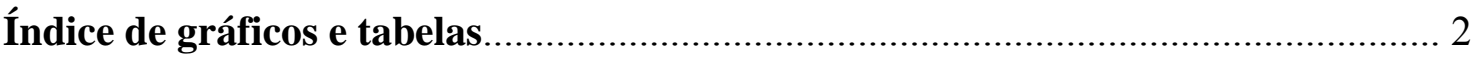

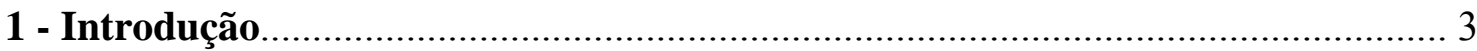

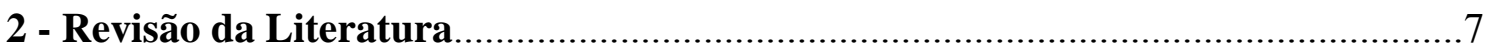

3 - O sistema e as condições de saúde no Brasil.................................................................11

3.1 - O sistema público de saúde brasileiro............................................................11

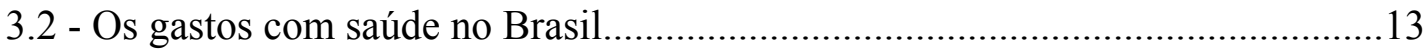

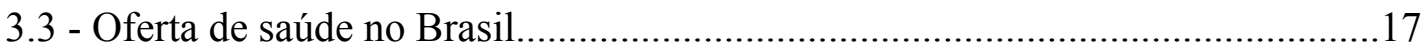

3.4 - Condições de saúde no Brasil.........................................................................21

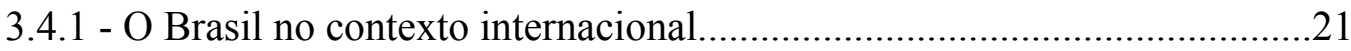

3.4.2 - A desigualdade de qualidade de saúde no Brasil....................................22

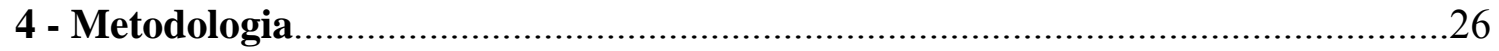

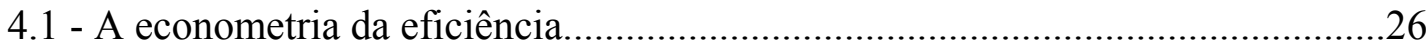

4.2 - Avaliando o sistema de saúde dos municípios brasileiros..................................34

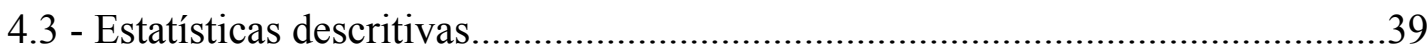

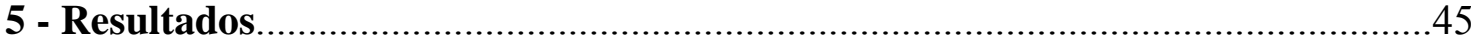

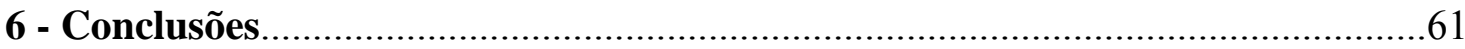

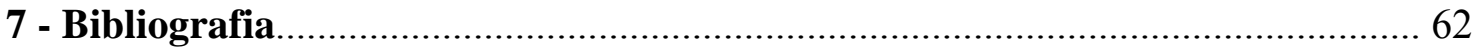

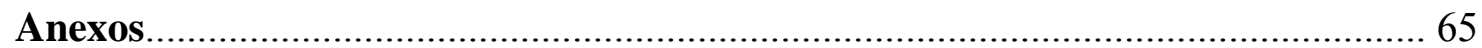




\section{ÍNDICE DE GRÁFICOS E TABELAS}

Gráfico 1 - Expectativa de vida ao nascer 5

Gráfico 2 - Fronteira de possibilidades de produção construída por FDH 27

Gráfico 3 - Fronteira de possibilidades de produção construída por DEA 28

Gráfico 4 - Fronteira de possibilidades de produção construída por COLS 30

Gráfico 5 - Fronteira de um produto "negativo" 55

Tabela 1 - Expectativa de vida ao nascer 6

Tabela 2 - Ranking de expectativa de vida ao nascer (2000) - 30 melhores e piores 7

Tabela 3 - Recursos líquidos para ações e serviços de saúde (1995-2005) 14

Tabela 4 - Evolução do gasto público total per capita com saúde - a preços de $2004 \quad 14$

Tabela 5 - Participação (\%) no total de gastos do governo com saúde 15

Tabela 6 - Participação dos gastos por ente federativo (média entre 2000 e 2004) 15

Tabela 7 - Destino do gastos federais com saúde (\%) 1998-2005 16

Tabela 8 - Destino dos gastos executados pelos municípios (2005) 17

Tabela 9 - Quantidade de leitos por 100000 habitantes (2005) 18

Tabela 10 - Número de estabelecimentos de atendimento a saúde s/ internação 19

Tabela 11 - Número de equipamentos de manutenção da vida 19

Tabela 12 - Pessoal empregado na área de saúde com curso superior 20

Tabela 13 - Proporção da população assistida por plano de saúde privado (\%) 21

Tabela 14 - Indicadores mundiais selecionados $\quad 22$

Tabela 15 - Disparidade de expectativa de vida entre municípios das U.F. 24

Tabela 16 - Mortalidade infantil (por mil nascidos vivos) 25

Tabela 17 - Mortalidade infantil (por mil nascidos vivos)- por faixa populacional 25

Tabela 18 - Descrição das principais variáveis utilizadas (referência ano 2000) 41

Tabela 19 - OLS: Índice de desempenho X Variáveis Selecionadas 43

Tabela 20 - OLS: Mortalidade infantil X Variáveis selecionadas 44

Tabela 21 - OLS: Expectativa de vida X Variáveis Selecionadas 45

Tabela 22 - Fronteiras estimadas para expectativa de vida 47

Tabela 23 - Fronteiras estimadas para a probabilidade de atingir os 60 anos 48

Tabela 24 - Fronteiras estimadas para a mortalidade infantil 48

Tabela 25 - Fronteiras estimadas para a mortalidade até 5 anos 49

Tabela 26 - Fronteira expectativa de vida c/ modelagem da média da Ineficiência $\quad 51$

Tabela 27 - Fronteiras estimadas via pessoal empregado e capital ao invés de gastos $\quad 52$

Tabela 28 - Fronteira mortalidade infantil com mescla de insumos 53

Tabela 29 - Correlação entre rankings dos diferentes produtos 53

Tabela 30 - Ranking de eficiência dos municípios c/ pop. de até dez mil habitantes $\quad 56$

Tabela 31 - Ranking de eficiência dos municípios c/ pop. de 10 a 15 mil habitantes $\quad 57$

Tabela 32 - Ranking de eficiência dos municípios c/ pop. maior de 50000 habitantes $\quad 58$

Tabela 33 - Municípios com melhor e pior classificação por estado 59

Tabela 34 - Eficiência máxima e mínima em cada estado $\quad 60$

Tabela 35 - Ranking completo dos municípios com até 10 mil habitantes 65

Tabela 36 - Ranking completo dos municípios de pop. entre 10 e 15 mil habitantes $\quad 71$

Tabela 37 - Ranking completo dos municípios com mais de 50 mil habitantes $\quad 76$ 


\section{1 - INTRODUÇÃO}

O Governo, em suas diversas esferas, tem como uma de suas principais atribuições o provimento de bens e serviços, objetivando a maximização do bem estar dos seus habitantes e ampliando o máximo possível os indicadores sociais e econômicos da população. À luz da teoria microeconômica sabemos que o papel do Estado é fundamental, sobretudo, na oferta de bens e serviços cujo mercado privado não funciona eficientemente, o que geralmente ocorre devido à presença de falhas de mercado.

Nesse sentido, ganha importância a participação ativa do Governo na oferta de serviços de saúde, uma vez que esse mercado é caracterizado por diversas falhas que dificultam o seu funcionamento. No caso do mercado de seguros de saúde, por exemplo, existem falhas nas relações entre os três principais agentes - que são os segurados, as seguradoras e os provedores de serviços (principalmente médicos e hospitais) -, entre as quais se destacam: (i) informação assimétrica, sobretudo na relação entre seguradoras e segurados; (ii) risco moral dos segurados uma pessoa coberta por um plano de saúde tem incentivo para sobre-utilizar os serviços; e (iii) risco moral do provedor de serviços - o provedor de serviços muitas vezes recebe o seu pagamento de acordo com o número de consultas e, dessa forma, tem incentivo para atender uma quantidade de pacientes acima do ótimo, deixando de se preocupar com a qualidade do serviço. Outra falha corriqueiramente citada nos estudos sobre economia da saúde é a externalidade, uma vez que a qualidade de saúde de um indivíduo depende não só das suas atitudes, mas também do comportamento dos demais, como por exemplo, no caso do controle de epidemias.

Essas falhas de mercado, em conjunto com a importância do estado de saúde para o bem estar da população, explicitam a necessidade da ação do Estado para garantir o acesso da população a um bom sistema. Essa ação pode se dar via regulamentação do mercado; oferta direta dos serviços de saúde; subsídio para os indivíduos que não tem acesso ao mercado privado; ou algum tipo de parceria com o sistema privado. A própria Constituição brasileira de 1988 classifica o acesso à saúde como direito de todo cidadão e dever do Estado.

Entretanto, o alto endividamento dos países em desenvolvimento, somado a um crescente consenso sobre a importância da estabilização econômica para o crescimento sustentado do país, implicam em uma necessidade cada vez maior de contenção dos gastos, limitando ainda mais os já escassos recursos públicos. No caso brasileiro, temos ainda o agravante de que já possuímos uma das maiores cargas tributárias do mundo ${ }^{2}$, o que inviabiliza a atraente solução (do ponto de vista dos governantes, é claro) de recorrer ao aumento dos impostos para implementar o ajuste fiscal.

\footnotetext{
${ }^{2}$ Segundo o IBGE (Instituto Brasileiro de Geografia e Estatística, Sistema de Contas Nacionais) a carga tributária total correspondia a $33,8 \%$ do PIB em 2005.
} 
Sendo assim, tanto em âmbito nacional, através das metas para superávit primário, como nas demais esferas de governo, principalmente por meio da $\mathrm{LRF}^{3}$, existe (ou pelo menos deveria existir) um grande empenho em controlar os gastos.

Com isso, se por um lado o governo tem a obrigação de fornecer bens e serviços com o objetivo de garantir as condições necessárias para o desenvolvimento socioeconômico do país, por outro, deixou de ser viável ampliar sistematicamente os gastos para atingir tais objetivos. Nessas condições, fica evidente a necessidade de administrar com o máximo de eficiência possível o orçamento disponível.

Dentro desse contexto, diversos trabalhos têm sido elaborados visando medir a ineficiência relativa dos países quanto aos seus gastos públicos. Consequentemente, um debate acadêmico sobre qual seria a melhor forma de medir essa ineficiência tem sido travado entre os economistas.

Existe certo consenso a respeito da necessidade da construção de uma fronteira de possibilidades de produção, ou seja, uma função que indique o máximo de produto possível de se atingir para um dado nível de utilização de insumos. Após essa construção, a ineficiência seria medida pela distância entre os dados observados para o país em questão e a fronteira. A maior divergência de opiniões surge no momento de definir a metodologia de calcular essa fronteira, principalmente na escolha entre métodos paramétricos e os não-paramétricos (ver capítulo sobre metodologia).

Tendo em vista a escassez de trabalhos focados nos dados nacionais, e o contraste entre o elevado patamar dos gastos públicos e os indicadores socioeconômicos inferiores aos que seriam desejáveis (indicando uma forte evidência da má administração dos recursos), o presente estudo pretende analisar a eficiência dos gastos públicos em saúde dos municípios brasileiros, com o intuito de compará-los entre si, e examinar possíveis razões para as ineficiências relativas encontradas. Entende-se aqui por eficiência a proximidade à uma fronteira de possibilidades de produção, uma vez que, por definição, essa fronteira mede a quantidade máxima de produto que pode ser atingida para uma dada quantidade de insumo utilizada, e por isso, quanto mais perto da fronteira, mais eficiente é o produtor (no caso desse trabalho, o município).

O grande peso da demanda por serviços de saúde no bem estar da população; a importância da intervenção da administração pública nesse setor; a elevada participação dos

\footnotetext{
${ }^{3}$ Lei assim definida pelo Tesouro Nacional: "A Lei Complementar $n^{\circ} 101$, de 4 de maio de 2000, intitulada Lei de Responsabilidade Fiscal - LRF, estabelece normas de finanças públicas voltadas para a responsabilidade na gestão fiscal, mediante ações em que se previnam riscos e corrijam desvios capazes de afetar o equilíbrio das contas públicas, destacando-se o planejamento, o controle, a transparência e a responsabilização como premissas básicas".
} 
gastos nessa área no orçamento dos estados e municípios ${ }^{4}$; e a situação frágil do estado de saúde dos brasileiros quando comparados ao restante do mundo; por si só justificam a escolha específica do setor de saúde, podendo facilmente o trabalho ser estendido para outros tipos de gasto.

O relatório de Saúde Mundial (World Health Report 2004), produzido pela Organização Mundial da Saúde, estimou a expectativa de vida ajustada (ou expectativa de vida saudável) ${ }^{5}$ brasileira em 59,8 anos, posicionando o País como $100^{\circ}$ colocado (entre os 192 membros) $)^{6}$, indicando uma situação bem preocupante em termos de saúde da população (Tabela 14).

Atenuando um pouco a gravidade da situação, vale observar que a expectativa de vida ao nascer no Brasil, segundo o IBGE, apresentou um avanço significativo nos últimos anos (Gráfico 01), subindo de 66,9 anos em 1991 para 72,1 anos em 2005. Nesse período o número médio de anos vividos aumentou tanto para as mulheres (de 70,9 para 75,9) como para os homens (de 63,2 para 68,4$)$.

Porém, ainda existe uma grande disparidade desse indicador entre as Unidades da Federação (Tabela 01). Em 2005 o Distrito Federal apresentava o melhor índice (74,9 anos), enquanto Alagoas registrava o pior $(66,0)$, totalizando uma expressiva diferença de 9 anos. Se fizermos uma avaliação por regiões, a região Sul aparece com a situação mais favorável, com um índice médio de 74,2 anos, enquanto o Nordeste exibe o pior desempenho, uma média de 69,0 anos.

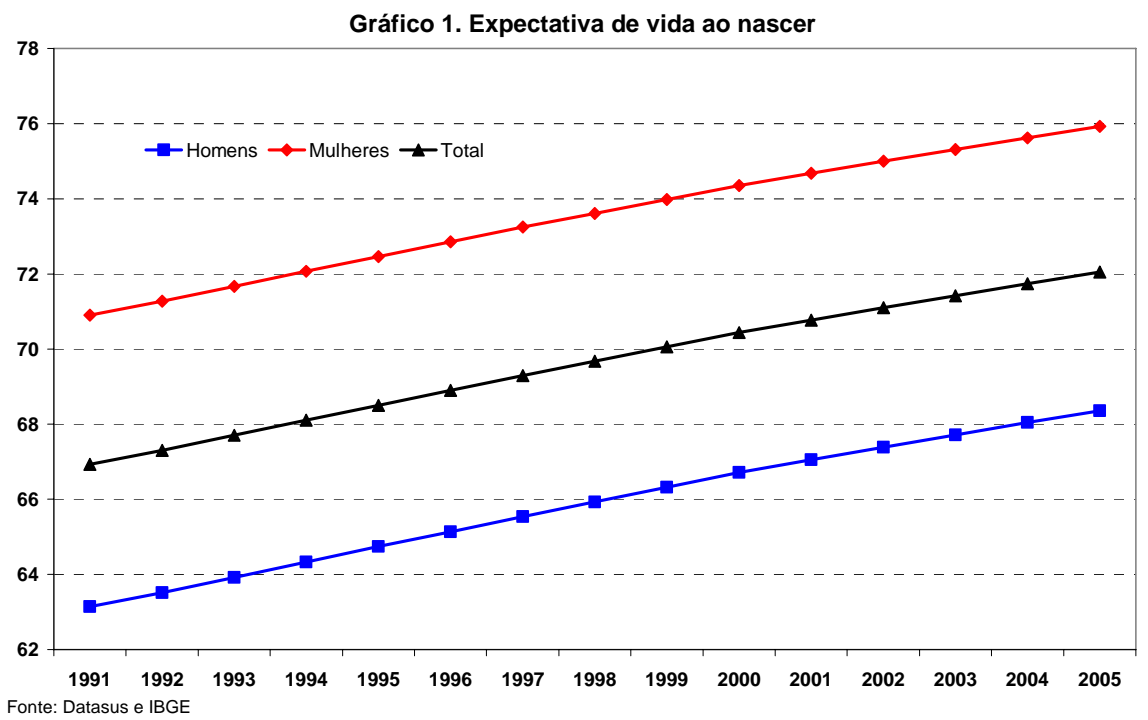

\footnotetext{
${ }^{4}$ Em 2002, segundo o IBGE, o setor respondeu por 9\% das despesas totais dos governos estaduais e $22 \%$ dos municipais, sendo para os municípios o maior destino de recursos, superando a educação que recebeu $21 \%$ dos recursos.

${ }^{5}$ A expectativa de vida saudável (DALE, Disability Adjusted Life Expectancies) é uma estimativa de quantos anos, em média, os indivíduos vivem em perfeitas condições de saúde. A vantagem desse indicador é considerar não só o tempo médio de vida dos indivíduos mas também suas condições de saúde enquanto vivos.

${ }^{6} \mathrm{O}$ país que apresentou o maior índice de expectativa de vida ajustada foi o Japão, atingindo 75,0 anos, ou seja, um indivíduo japonês tem, em média, 15,2 anos de vida saudável a mais do que um brasileiro.
} 
$\mathrm{Na}$ esfera municipal essa disparidade é ainda mais grave - em São Caetano do Sul (SP), que possui o melhor desempenho no indicador de expectativa de vida entre todos os municípios brasileiros, a esperança de vida ao nascer é de 78,2 anos, enquanto em Centro do Guilherme (MA), que possui o pior desempenho do Brasil, essa expectativa é de 54,3 anos, ou seja, a diferença entre o melhor e o pior desempenho é de 23,9 anos (Tabela 2).

Tabela 1. Expectativa de vida ao nascer

\begin{tabular}{|c|c|c|c|}
\hline UF & $\begin{array}{l}\text { Expectativa de } \\
\text { vida ao nascer }\end{array}$ & UF e Regiöes & $\begin{array}{l}\text { Expectativa de } \\
\text { vida ao nascer }\end{array}$ \\
\hline Distrito Federal & 74.9 & Amapá & 69.8 \\
\hline Santa Catarina & 74.8 & Rio Grande do Norte & 69.8 \\
\hline Rio Grande do Sul & 74.5 & Ceará & 69.6 \\
\hline Minas Gerais & 74.1 & Roraima & 69.3 \\
\hline São Paulo & 73.7 & Paraíba & 68.3 \\
\hline Paraná & 73.5 & Piauí & 68.2 \\
\hline Mato Grosso do Sul & 73.2 & Pernambuco & 67.5 \\
\hline Espírito Santo & 73.1 & Maranhão & 66.8 \\
\hline Goiás & 72.8 & Alagoas & 66.0 \\
\hline Mato Grosso & 72.6 & & \\
\hline Rio de Janeiro & 72.4 & & \\
\hline Bahia & 71.4 & Regiẫo Sul & 74.2 \\
\hline Pará & 71.4 & Regiẫo Sudeste & 73.5 \\
\hline Amazonas & 71.0 & Regiẫo Centro-Oeste & 73.2 \\
\hline Acre & 70.8 & Regiẫo Norte & 71.0 \\
\hline Tocantins & 70.7 & Regiẫo Nordeste & 69.0 \\
\hline Rondônia & 70.6 & & \\
\hline Sergipe & 70.3 & Brasil & 72.05 \\
\hline \multicolumn{2}{|l|}{ Fonte: Datasus e IBGE } & & \\
\hline
\end{tabular}




\begin{tabular}{|c|c|c|c|c|c|c|c|}
\hline \multicolumn{2}{|c|}{$\begin{array}{l}\text { Ranking dos UF } \\
\text { melhores }\end{array}$} & \multicolumn{2}{|l|}{ Município } & \multicolumn{2}{|c|}{$\begin{array}{l}\text { Ranking } \\
\text { dos piores }\end{array}$} & \multicolumn{2}{|l|}{ Município } \\
\hline 1 & $\mathrm{SP}$ & São Caetano do Sul & 78,2 & 5478 & $\mathrm{TO}$ & Santa Terezinha do Tocantins & 55,9 \\
\hline 2 & $\mathrm{SC}$ & Antônio Carlos & 77,9 & 5479 & $\mathrm{AL}$ & Poço das Trincheiras & 55,9 \\
\hline 3 & $\mathrm{SC}$ & Planalto Alegre & 77,8 & 5480 & $\mathrm{AL}$ & Porto de Pedras & 55,9 \\
\hline 4 & $\mathrm{SC}$ & Massaranduba & 77,8 & 5481 & $\mathrm{AL}$ & Senador Rui Palmeira & 55,9 \\
\hline 5 & RS & Sã̃o José do Inhacorá & 77,8 & 5482 & AL & Traipu & 55,9 \\
\hline 6 & $\mathrm{SC}$ & Cunhataí & 77,8 & 5483 & MA & Cantanhede & 55,9 \\
\hline 7 & $\mathrm{SC}$ & Luzerna & 77.7 & 5484 & MA & Matôes do Norte & 55,9 \\
\hline 8 & $\mathrm{SC}$ & São Miguel do Oeste & 77,7 & 5485 & $\mathrm{PI}$ & Ilha Grande & 55,9 \\
\hline 9 & $\mathrm{SC}$ & Saudades & 77.7 & 5486 & $\mathrm{Pl}$ & São Joẫo do Arraial & 55,9 \\
\hline 10 & PR & Quatro Pontes & 77,7 & 5487 & $\mathrm{PI}$ & Campo Largo do Piauí & 55,8 \\
\hline 11 & RS & Tucunduva & 77,6 & 5488 & $\mathrm{PI}$ & Milton Brandão & 55,8 \\
\hline 12 & PR & Maripá & 77,5 & 5489 & $\mathrm{PI}$ & Novo Santo Antônio & 55,8 \\
\hline 13 & $\mathrm{SC}$ & Tunápolis & 77,4 & 5490 & $\mathrm{BA}$ & Jussara & 55,8 \\
\hline 14 & $\mathrm{SP}$ & Águas de São Pedro & 77,4 & 5491 & $\mathrm{BA}$ & Andaraí & 55,8 \\
\hline 15 & $\mathrm{RS}$ & Bento Gonçalves & 77,4 & 5492 & MA & Presidente Juscelino & 55,7 \\
\hline 16 & RS & Três de Maio & 77,3 & 5493 & $\mathrm{PE}$ & Manari & 55,7 \\
\hline 17 & $\mathrm{SP}$ & Saltinho & 77,3 & 5494 & MA & Governador Newton Bello & 55,6 \\
\hline 18 & RS & Pareci Novo & 77,3 & 5495 & MA & Brejo de Areia & 55,5 \\
\hline 19 & PR & Entre Rios do Oeste & 77,3 & 5496 & MA & Bom Jardim & 55,4 \\
\hline 20 & $\mathrm{SC}$ & Riqueza & 77,3 & 5497 & $\mathrm{BA}$ & Xique-Xique & 55,4 \\
\hline 21 & RS & Porto Mauá & 77,0 & 5498 & $\mathrm{BA}$ & Inhambupe & 55,4 \\
\hline 22 & $\mathrm{SC}$ & Videira & 77,0 & 5499 & PB & Juripiranga & 55,3 \\
\hline 23 & $\mathrm{SC}$ & Urussanga & 76,9 & 5500 & PB & São Miguel de Taipu & 55,3 \\
\hline 24 & $\mathrm{SP}$ & São Joẫo da Boa Vista & 76,9 & 5501 & PB & Logradouro & 55,3 \\
\hline 25 & MG & São Lourenço & 76,9 & 5502 & TO & Axixá do Tocantins & 55,2 \\
\hline 26 & $\mathrm{SC}$ & Ituporanga & 76,9 & 5503 & PB & Gado Bravo & 55,2 \\
\hline 27 & $\mathrm{SC}$ & Witmarsum & 76,9 & 5504 & PB & Natuba & 55,2 \\
\hline 28 & RS & Osório & 76,9 & 5505 & MA & Araioses & 55,2 \\
\hline 29 & MG & Alfenas & 76,9 & 5506 & MA & Lagoa Grande do Maranhẫo & 54,9 \\
\hline 30 & $\mathrm{RS}$ & Sã̃o José do Hortêncio & 76,8 & 5507 & MA & Centro do Guilherme & 54,3 \\
\hline Fonte: IBGE/ & Censo & demográfico 2000 & & & & & \\
\hline
\end{tabular}

Este trabalho está dividido em 5 capítulos, além dessa introdução. No segundo capítulo será feita uma revisão da literatura sobre eficiência. No terceiro será apresentada uma visão geral das condições e do sistema de saúde no Brasil, estando o capítulo dividido em quatro partes: (i) breve descrição do sistema de saúde brasileiro; (ii) caracterização dos gastos; (iii) condições de acesso aos serviços de saúde nos municípios; e (iv) condições de saúde no Brasil. O quarto capítulo apresentará a metodologia adotada no trabalho, além de explicitar a correlação de algumas variáveis selecionadas com a qualidade de saúde da população. No quinto serão apresentados os principais resultados obtidos. Finalmente, o sexto capítulo apresentará as principais conclusões e sugestões de políticas para a área de saúde que podem ser derivadas dos resultados encontrados.

\section{2 - REVISÃO DA LITERATURA}

Existem poucos trabalhos com foco na eficiência dos gastos públicos, principalmente no que diz respeito ao Brasil, sendo que a maioria deles se utiliza de métodos não-paramétricos de estimação da fronteira de possibilidades de produção. 
Um exemplo de estudo que se utilizou de um método não-paramétrico para a construção de uma fronteira de possibilidades de produção com o intuito de avaliar a eficiência de gastos públicos foi elaborado por membros do FMI (Gupta, Honjo e Verhoeven, 1997), que analisaram a eficiência dos gastos do governo em educação e saúde em 38 países na África entre 1984 e 1995, comparando-os entre si, e com alguns países da Ásia e do hemisfério ocidental (incluindo o Brasil). Os autores optaram por fazer uma análise FDH (Free Disposal Hull) ${ }^{7}$, que consiste basicamente em considerar países que não são explicitamente superados tecnicamente por nenhum outro da amostra (ou seja, não há nenhum outro que produza mais com a mesma quantidade de insumo, ou produza a mesma quantidade com menos insumo) como países de fronteira e os demais como ineficientes. Um interessante resultado deste estudo é que os países com maior patamar de gasto público foram os que apresentaram índices mais baixos de eficiência, reforçando a sugestão de que para melhorar os serviços de educação e saúde, antes de ampliar os gastos, é necessário aumentar a eficiência dos mesmos.

Afonso, Schuknecht e Tanzi (2005) elaboraram um trabalho mais geral, avaliando não só as variáveis de saúde e educação, mas também diversos outros indicadores relacionados à uma boa administração pública. Eles utilizaram uma amostra de 23 países da OCDE e construíram um índice de desempenho do setor público composto por 7 sub-indicadores: (i) qualidade administrativa, que considerava, entre outros, o grau de corrupção e a qualidade do judiciário; (ii) Educação, incluindo matrículas no segundo grau e resultados atingidos em testes; (iii) Saúde, levando em conta a expectativa de vida e a mortalidade infantil; (iv) Infra-estrutura Pública, avaliada pela qualidade da comunicação e pela rede de transportes; (v) Distribuição de renda, medida pela participação na renda total dos $40 \%$ mais pobres; (vi) Estabilidade Macroeconômica, captada pela variância do PIB e pela inflação média em 10 anos; e (vii) Desempenho da economia, considerando o PIB per capita, o crescimento médio do PIB em 10 anos e a taxa de desemprego. Após construir esse índice, os autores utilizaram o método FDH tomando como insumo os gastos públicos totais e como produto esse indicador, comparando dessa forma, a eficiência relativa dos gastos nesses países.

Com base em uma metodologia bastante semelhante, porém utilizando o DEA (Data Envelopmente Analysis, ver capítulo sobre metodologia) ao invés do FDH, Afonso et al. (2006) compararam a ineficiência dos gastos públicos totais dos novos membros da União Européia e de algumas economias emergentes. Na amostra de 24 países, cinco faziam parte ou se situavam bem próximos da fronteira: Chipre, Irlanda, Tailândia, Coréia e Cingapura. O Brasil ficou na penúltima posição $\left(23^{\mathrm{a}}\right)$, ficando à frente apenas da Turquia. A análise sugere que os países poderiam

\footnotetext{
${ }^{7}$ Deprins, Simar e Tulkens (1984) foi o pioneiro na utilização da análise FDH com um trabalho sobre a eficiência relativa dos correios.
} 
utilizar, em média, 45\% menos recursos para atingir o mesmo produto. Após a estimativa dos scores de ineficiência os autores estimaram um modelo Tobit com o intuito de explicar parte dessa ineficiência. Entre as variáveis que se mostraram positivamente correlacionadas com a ineficiência, destacam-se: o PIB per capita; o direito de propriedade; a escolaridade; e a competência dos servidores públicos.

Um estudo paramétrico de destaque foi produzido pela Organização Mundial da Saúde (Evans, Tandon, Murray e Lauer, 2000) focado na eficiência dos gastos públicos na área de saúde, utilizando dados de seus 191 países membros entre 1993 e 1997, tomando como produto a expectativa de vida ajustada e como insumos os gastos totais com saúde e a escolaridade média da população adulta. Para mensurar a ineficiência relativa, os autores calcularam uma regressão com dados em painel, assumindo que o efeito específico de cada país seria sua ineficiência. Segundo os resultados produzidos pelo estudo, o Brasil assumiu a $78^{\circ}$ colocação, com um índice de desempenho igual a 0,767 , enquanto o país com melhor desempenho (Oman) obteve 0,992, e o pior (Zimbabwe) 0,080.

Greene (2003) elaborou uma crítica aos modelos similares ao construído pela Organização Mundial da Saúde, enfatizando o fato de que a existência de uma grande heterogeneidade entre os países da amostra faz com que a análise de dados em painel, através de efeito fixo (ou mesmo aleatório) seja inapropriada para a distinção entre ineficiência e heterogeneidade. $O$ autor basicamente replicou o estudo da WHO, porém utilizando a metodologia da fronteira estocástica ao invés de um painel, encontrando resultados significativamente diferentes. A desigualdade de renda, o produto per capita e uma dummy para países tropicais apareceram como estatisticamente significantes para explicar a ineficiência dos gastos em saúde.

Quanto à literatura nacional, Sousa, Cribari-Neto, Stosic e Borko (2003), utilizaram um método não-paramétrico (DEA) para comparar a eficiência dos serviços públicos oferecidos pelos municípios brasileiros. Os autores utilizaram métodos econométricos de reamostragem (Bootstrap e Jacknife) para tentar isolar apenas o efeito da ineficiência, ou seja, corrigir parte do problema gerado pelos outliers. Após o cálculo dos índices de desempenho dos municípios, foram estimadas regressões que buscavam explicar a ineficiência dos municípios, utilizando-se de variáveis políticas e socioeconômicas.

Nos resultados desse estudo, capitais dos estados se mostraram mais eficientes que os demais municípios, mas as cidades localizadas em regiões metropolitanas não se beneficiam da localização "privilegiada". Já os municípios localizados no Polígono da Seca apresentam uma ineficiência maior, prejudicados por condições climáticas adversas. A análise não sugere que os municípios mais pobres sejam mais ineficientes e aponta que aqueles atendidos pelo projeto 
Alvorada ${ }^{8}$ apresentam desempenho melhor do que a média. Vale ressaltar também que os municípios que recebem quantias significativas de royalties apresentam, em média, gastos mais elevados, mas são menos eficientes. A urbanização e o tamanho da população estão correlacionadas com uma maior eficiência, o que sugere ganhos de escala. Nas variáveis de gestão, o grau de utilização de computadores e a existência do poder de decisão em conselhos municipais, implicam um aumento de eficiência. As variáveis políticas apresentaram resultados distintos, dependendo do modelo estimado.

Outro estudo interessante que utilizou um DEA para medir eficiência dos gastos públicos dos municípios brasileiros foi feito por Boueri (2006). Esse trabalho utiliza como produto o número de matrículas na rede municipal de ensino básico, o número de internações realizadas na rede municipal e o porcentual de cobertura de coleta de lixo. Como insumo foi considerada a despesa orçamentária total de cada município no ano de 2000. As estimativas foram feitas considerando duas variações do DEA, a primeira considerando retornos constantes de escala (modelo CCR) e a segunda permitindo retornos variáveis de escala (modelo BCC). Após estimar a ineficiência foi estimado o desperdício total de recursos dos municípios da amostra. $\mathrm{O}$ modelo CCR apontou um desperdício da ordem de $70 \%$ do gasto total, enquanto o modelo BCC indicou desperdício de $47 \%$. A exemplo do detectado em outros estudos, os resultados indicam que existe correlação positiva entre o tamanho do gasto e o grau de ineficiência, ou seja, quanto maiores os gastos maior a ineficiência. Além disso, os municípios menores apresentam desperdícios proporcionalmente maiores, apesar dos dados apontarem retorno decrescente de escala.

Apesar de não se tratar de um trabalho especificamente sobre eficiência, vale citar o estudo de Pires e Oliveira Neto (2006) que construiu um interessante indicador de qualidade da saúde da população, nomeado pelos autores de índice de vulnerabilidade dos municípios, considerando quatro indicadores de saúde: (i) expectativa de vida ao nascer; (ii) mortalidade infantil; (iii) mortalidade até 5 anos de idade; e (iv) probabilidade de atingir 60 anos de idade. Para ponderar esses indicadores os autores escolheram os pesos de tal forma a maximizar a variância do índice de vulnerabilidade, sujeito à restrição da soma dos pesos se igualar a um. Além disso, eles criaram uma medida de política levando em conta a participação de cada município nos programa de Saúde da Família, Saúde Bucal, Agentes Comunitários e a média de atendimentos básicos habitante/ano. Por fim os autores classificaram os municípios em quatro tipos de perfis, com o melhor incluindo aqueles menos vulneráveis e com maior penetração de políticas e o pior agregando os mais vulneráveis e com menor penetração das políticas.

\footnotetext{
${ }^{8}$ O Projeto Alvorada é uma iniciativa do Governo Federal para tentar reduzir as desigualdades regionais. O indicador utilizado para selecionar os locais mais carentes foi o Índice de Desenvolvimento Humano (IDH).
} 


\section{3 - O SISTEMA E AS CONDIÇÕES DE SAÚDE NO BRASIL}

\section{1 - O SISTEMA PÚLICO DE SAÚDE BRASILEIRO}

A explicação para a escolha dos municípios como unidade de análise na maior parte dos estudos que tem como objetivo avaliar a eficiência dos gastos públicos com saúde no Brasil, ou mesmo a qualidade da saúde da população, remete as próprias diretrizes do sistema público de saúde brasileiro. Isso porque desde a promulgação da Constituição de 1988 (que universalizou o atendimento à saúde no Brasil) tem havido um esforço na direção da descentralização do sistema, tendo em vista que os estados e, principalmente, os municípios, tem informações mais completas sobre as necessidades e preferências dos seus habitantes, o que, ao menos em teoria, viabilizaria melhor planejamento, gestão, avaliação e controle. As cinco principais diretrizes do sistema, que vem sendo perseguidas desde a nova Constituição são: i) universalidade, ou seja, a possibilidade de acesso de toda a população; ii) integralidade, que consiste em uma oferta completa, ou seja, de todos os tipos de serviços voltados à promoção da saúde, prevenção de doenças, tratamento e reabilitação; iii) eqüidade, fornecendo ajuda a cada indivíduo de forma proporcional às suas necessidades; iv) regionalização e hierarquização de serviços, facilitando mecanismos de integração; e v) descentralização.

Essas diretrizes estão implícitas em dois artigos da referida Constituição:

No Artigo 196: A saúde é direito de todos e dever do Estado, garantido mediante políticas sociais e econômicas que visem à redução do risco de doença e de outros agravos e ao acesso universal e igualitário às ações e serviços para sua promoção, proteção e recuperação.

E no Artigo 198: As ações e serviços públicos de saúde integram uma rede regionalizada e hierarquizada e constituem um sistema único, organizado de acordo com as seguintes diretrizes:

I - descentralização, com direção única em cada esfera de governo;

II - atendimento integral, com prioridade para as atividades preventivas, sem prejuízo dos serviços assistenciais;

III - participação da comunidade;

Um aspecto que viabilizou a reestruturação do sistema foi a definição de um órgão central em cada esfera do Governo para gerir o sistema, sendo eles: o Ministério da Saúde no âmbito federal, e as Secretarias Estaduais e Municipais da Saúde nos estados e municípios. Além disso, conforme sugerido no artigo 198 citado acima é importante ressaltar a importância da participação da comunidade, que foi organizada por meio de Conferências e Conselhos.

Além da Constituição, o SUS é regido basicamente por duas leis (Lei $n^{\circ} 8.080$ - Lei Orgânica da Saúde e Lei n ${ }^{\circ} 8.142$ - que dispõe sobre participação da comunidade e transferências 
intergovernamentais) e pelas normas operacionais - Normas Operacionais Básicas (NOBs) e Normas Operacionais de Assistência à Saúde (Noas).

O boletim de acompanhamento e análise de políticas sociais (2007, volume número 13, edição especial) do Instituto de Pesquisa Econômica Aplicada (IPEA) traz um resumo esclarecedor de como ficaram definidas as competências de cada esfera administrativa de acordo com o arcabouço legal citado acima:

a) à esfera federal, a formulação da política nacional de saúde; a regulação nacional do Sistema Único de Saúde, a elaboração de normas técnicas, o financiamento e cooperação técnica com estados e municípios, a regulação da relação público-privado, regulação de padrões $e$ registro de produtos destinados à assistência médico-hospitalar e de bens de consumo que se relacionam com a saúde, coordenação nacional do sistema de informações, o acompanhamento e avaliação das tendências da situação sanitária nacional e do desempenho do sistema nacional de saúde, apoio ao desenvolvimento científico e tecnológico e ao de recursos humanos, regulação de aspectos éticos de pesquisas e articulação intersetorial no plano federal;

b) à esfera estadual, a formulação da política estadual de saúde; o planejamento, a coordenação e o estabelecimento de modelos de atenção à saúde; a supervisão, financiamento $e$ cooperação técnica com as secretarias municipais de saúde; a coordenação de redes de serviços especializados e a responsabilidade pelo desenvolvimento de recursos humanos; $e$

c) à instância municipal, a formulação da política local, o planejamento, contratação (quando for o caso), avaliação e controle dos estabelecimentos de saúde e a execução direta dos serviços. O município é o único ente federativo com a competência constitucional explícita (art. 30, VII) para "prestar, com a cooperação técnica e financeira da União e do Estado, serviços de atendimento à saúde da população”.

As NOBs (principalmente de 1991, 1992, 1993 e 1996) tiveram papel fundamental no desenho da estrutura do sistema, uma vez que introduziram mecanismos de repasse que condicionavam os recursos ao cumprimento de certos critérios, de modo que foram criados incentivos para que a organização se aproximasse daquela definida nas diretrizes, com os gestores estaduais e municipais assumindo suas competências e ganhando autonomia. Dessa forma, o caminho estava pavimentado para a descentralização do sistema. Além disso, vale observar que foi na ocasião da NOB de 1996 que foi fortalecida a recomendação de que o município deveria ser o responsável pela atenção básica à saúde, e nesse contexto é que foi criado o Programa de Saúde da Família e o Programa de Agentes Comunitários da Saúde, além do Piso de Atenção Básica (instrumento financeiro utilizado para financiar os procedimentos de atenção básica à saúde de responsabilidade geralmente municipal). É importante frisar que também foi descentralizada a vigilância epidemiológica e o controle de doenças infecciosas e parasitárias. 
Com o contínuo esforço pela descentralização havia a preocupação com aqueles municípios que não tinham escala suficiente para produzir certos serviços de maior complexidade. Para lidar com isso os municípios deveriam estabelecer parcerias, negociadas pelos seus gestores e intermediadas pelos estados.

$\mathrm{Na}$ prática os municípios de médio e grande porte ainda colocavam certas restrições ao atendimento a residentes de outras localidades, por isso as duas Normas Operacionais de Assistência à Saúde (Noas) implementadas na seqüência, em 2001 e 2002, enfatizaram o dever de atendimento universal, definindo de maneira mais clara e objetiva a regulamentação do acesso.

Por fim, ainda em fase de implementação, merece ser destacado também o "Pacto pela Saúde”, publicado em fevereiro de 2006, que trouxe duas inovações principais: (i) o fim da necessidade de "habilitação" de municípios e estados a alguma condição de gestão - esses critérios foram criados para "induzir" à estruturação do sistema na direção das diretrizes definidas desde a implementação da nova Constituição, mas com o sistema já estruturado a sua necessidade se reduziu, o que abriu espaço para uma maior flexibilização, sendo que as estruturas poderiam se adequar às necessidades específicas de cada região; e (ii) os repasses federais passaram a ser automáticos, condicionados apenas a autorização da CIB (Comissão Intergestores Bipartite) de cada estado.

Após essa breve descrição da organização do sistema, a próxima seção trará um retrato sobre o perfil do gasto público com saúde no Brasil, e as duas posteriores analisarão a desigualdade do acesso à saúde e a qualidade da saúde da população brasileira.

\section{2 - OS GASTOS COM SAÚDE NO BRASIL}

Antes de avaliar a oferta de serviços de saúde, é importante explicitar a magnitude dos recursos que são investidos nessa área no Brasil. Nesse sentido, a primeira estatística de interesse é o montante de gastos do Ministério da Saúde. Esse gasto foi em média de R \$ 39,7 bilhões entre 1995 e 2005 (em termos reais, a preços de dezembro de 2005), mas a série apresentou uma volatilidade considerável, atingindo um pico (nesse período considerado) de R \$ 41,9 bilhões em 2001 e um piso de R\$35,0 bilhões em 2003 (Tabela 3). Contudo, os recursos disponíveis para ações e serviços de saúde foram inferiores a esses, uma vez que devem ser descontados os Encargos Previdenciários da União (EPU), os dispêndios com encargos da dívida interna e externa e as despesas com o Fundo de Combate e Erradicação a Pobreza, de forma que o resultado líquido nesse período é em média de $\mathrm{R} \$ 34,7$ bilhões. 


\begin{tabular}{|c|c|c|c|c|c|c|}
\hline Ano & Gasto Total & EPU & Dívida & $\begin{array}{c}\text { FCEP + transf. de } \\
\text { renda }\end{array}$ & $\begin{array}{l}\text { Açöes e serv. } \\
\text { públ. saúde }\end{array}$ & $\begin{array}{l}\text { Açỏes e serv. } \\
\text { públ.saúde / } \\
\text { Gasto Total (\%) }\end{array}$ \\
\hline 1995 & $41.760,2$ & $3.688,2$ & $3.761,9$ & 0,0 & $34.310,1$ & 82,2 \\
\hline 1996 & $36.239,1$ & $3.722,5$ & $1.251,0$ & 0,0 & $31.265,6$ & 86,3 \\
\hline 1997 & $43.509,7$ & $3.635,5$ & $3.687,0$ & 0,0 & $36.187,2$ & 83,2 \\
\hline 1998 & $39.645,1$ & $3.948,5$ & $1.251,1$ & 0,0 & $34.445,5$ & 86,9 \\
\hline 1999 & $40.809,1$ & $3.732,7$ & 310,6 & 0,0 & $36.765,7$ & 90,1 \\
\hline 2000 & $40.279,9$ & $3.610,7$ & 96,3 & 0,0 & $36.572,9$ & 90,8 \\
\hline 2001 & $41.860,1$ & $3.309,5$ & 376,2 & $1.787,1$ & $36.387,3$ & 86,9 \\
\hline 2002 & $39.361,6$ & $2.985,5$ & 518,2 & 688,8 & $35.169,1$ & 89,3 \\
\hline 2003 & $34.983,7$ & $2.601,3$ & 485,5 & 416,5 & $31.480,4$ & 90,0 \\
\hline 2004 & $38.536,1$ & $2.804,3$ & 514,7 & $1.198,0$ & $34.019,1$ & 88,3 \\
\hline 2005 & $40.211,4$ & $2.818,9$ & 337,7 & $2.186,2$ & $34.868,7$ & 86,7 \\
\hline
\end{tabular}

Fonte: SIAFI/SIDOR. Extraída do Boletim de acompanhamento e análise de Políticas Sociais (No 13) do IPEA

Além de apresentar uma volatilidade elevada no tempo, os gastos per capita com saúde no Brasil diferem bastante entre as regiões, unidades da federação e municípios. Tomando o período entre 2000 e 2004 como exemplo, o gasto total com saúde das três esferas do governo foi em média de R\$ 488 per capita no Acre (o maior na média do período), mas de apenas R\$ 181 per capita no Maranhão (o menor na mesma comparação).

Tabela 4. Evolução do gasto público total per capita com saúde - a preços constantes de 2004

\begin{tabular}{|c|c|c|c|c|c|c|}
\hline UF & 2000 & 2001 & 2002 & 2003 & 2004 & $\begin{array}{l}\text { Média do } \\
\text { período }\end{array}$ \\
\hline Acre & 497 & 597 & 428 & 423 & 496 & 488 \\
\hline Alagoas & 205 & 226 & 267 & 244 & 263 & 241 \\
\hline Amapá & 431 & 397 & 510 & 440 & 431 & 442 \\
\hline Amazonas & 315 & 383 & 409 & 402 & 406 & 383 \\
\hline Bahia & 188 & 207 & 222 & 224 & 244 & 217 \\
\hline Ceará & 216 & 227 & 243 & 234 & 246 & 233 \\
\hline Distrito Federal & 376 & 426 & 515 & 413 & 406 & 427 \\
\hline Espírito Santo & 272 & 305 & 290 & 299 & 314 & 296 \\
\hline Goiás & 232 & 244 & 269 & 267 & 284 & 259 \\
\hline Maranhã̃o & 157 & 169 & 190 & 181 & 206 & 181 \\
\hline Mato Grosso & 236 & 295 & 321 & 322 & 360 & 307 \\
\hline Mato Grosso do Sul & 241 & 274 & 313 & 296 & 304 & 286 \\
\hline Minas Gerais & 221 & 258 & 252 & 244 & 257 & 247 \\
\hline Pará & 177 & 204 & 214 & 204 & 212 & 202 \\
\hline Paraíba & 210 & 280 & 279 & 245 & 249 & 253 \\
\hline Paraná & 218 & 238 & 269 & 262 & 290 & 256 \\
\hline Pernambuco & 227 & 251 & 273 & 251 & 269 & 254 \\
\hline Piauí & 182 & 212 & 215 & 218 & 259 & 217 \\
\hline Rio de Janeiro & 366 & 385 & 423 & 412 & 440 & 405 \\
\hline Rio Grande do Norte & 279 & 295 & 311 & 306 & 304 & 299 \\
\hline Rio Grande do Sul & 286 & 305 & 297 & 304 & 309 & 300 \\
\hline Rondônia & 306 & 332 & 325 & 330 & 314 & 321 \\
\hline Roraima & 538 & 573 & 512 & 491 & 474 & 518 \\
\hline Santa Catarina & 243 & 260 & 266 & 299 & 332 & 280 \\
\hline São Paulo & 328 & 349 & 398 & 359 & 383 & 364 \\
\hline Sergipe & 196 & 234 & 265 & 272 & 297 & 253 \\
\hline Tocantins & 294 & 350 & 371 & 361 & 379 & 351 \\
\hline Total & 284 & 308 & 332 & 319 & 359 & 320 \\
\hline Fonte: Datasus/SIOP & & & & & & \\
\hline
\end{tabular}


Quanto à participação dos entes federativos no total de gastos públicos, é importante mencionar que o Governo federal contribui com a maior parte dos gastos públicos no setor de saúde: em 2004, por exemplo, os gastos federais representavam 50,2\% dos gastos totais (Tabela 5), enquanto os municípios contribuíam com $25,1 \%{ }^{9}$ e os estados com o restante $(24,6 \%)$.

Tabela 5. Participação (\%) no total de gastos do governo com saúde

\begin{tabular}{|l|l|l|l|l|l|}
\hline & $\mathbf{2 0 0 0}$ & $\mathbf{2 0 0 1}$ & $\mathbf{2 0 0 2}$ & $\mathbf{2 0 0 3}$ & $\mathbf{2 0 0 4}$ \\
\hline Federal & 59,8 & 56,1 & 52,1 & 51,3 & 50,2 \\
\hline Estadual & 18,5 & 20,7 & 22,6 & 23,1 & 24,6 \\
\hline Municipal & 21,7 & 23,2 & 25,3 & 25,6 & 25,1 \\
\hline
\end{tabular}

Fonte: Datasus / SIOPS

Tabela 6. Participaçäo dos gastos por ente federativo (média entre 2000 e 2004)

\begin{tabular}{|c|c|c|c|c|}
\hline UF & Federal & Estadual & Municipal & Total \\
\hline Acre & 43,2 & 49,3 & 7,5 & 100,0 \\
\hline Alagoas & 58,6 & 22,6 & 18,8 & 100,0 \\
\hline Amapá & 38,0 & 53,7 & 8,3 & 100,0 \\
\hline Amazonas & 31,2 & 52,7 & 16,1 & 100,0 \\
\hline Bahia & 53,3 & 24,5 & 22,2 & 100,0 \\
\hline Ceará & 56,7 & 21,7 & 21,6 & 100,0 \\
\hline Distrito Federal & 45,7 & 38,7 & 15,6 & 100,0 \\
\hline Espírito Santo & 41,4 & 32,7 & 25,9 & 100,0 \\
\hline Goiás & 51,8 & 26,0 & 22,3 & 100,0 \\
\hline Maranhẫo & 64,4 & 15,6 & 20,0 & 100,0 \\
\hline Mato Grosso & 45,3 & 25,5 & 29,2 & 100,0 \\
\hline Mato Grosso do Sul & 48,5 & 20,2 & 31,2 & 100,0 \\
\hline Minas Gerais & 49,0 & 17,4 & 33,6 & 100,0 \\
\hline Pará & 55,5 & 25,8 & 18,7 & 100,0 \\
\hline Paraiba & 61,4 & 20,2 & 18,4 & 100,0 \\
\hline Paraná & 51,6 & 15,8 & 32,6 & 100,0 \\
\hline Pernambuco & 59,4 & 23,0 & 17,7 & 100,0 \\
\hline Piauí & 62,7 & 19,1 & 18,2 & 100,0 \\
\hline Rio de Janeiro & 62,8 & 14,4 & 22,8 & 100,0 \\
\hline Rio Grande do Norte & 47,2 & 30,5 & 22,3 & 100,0 \\
\hline Rio Grande do Sul & 55,3 & 16,8 & 27,9 & 100,0 \\
\hline Rondônia & 51,6 & 30,0 & 18,4 & 100,0 \\
\hline Roraima & 43,7 & 45,8 & 10,5 & 100,0 \\
\hline Santa Catarina & 44,1 & 26,6 & 29,3 & 100,0 \\
\hline Sã̃o Paulo & 37,1 & 28,5 & 34,4 & 100,0 \\
\hline Sergipe & 53,4 & 27,8 & 18,8 & 100,0 \\
\hline Tocantins & 42,3 & 37,4 & 20,3 & 100,0 \\
\hline Fonte: Datasus/SIOPS & & & & \\
\hline
\end{tabular}

\footnotetext{
${ }^{9}$ A participação dos municípios cresceu bastante com o esforço pró descentralização dos anos 90, em 1995 a contribuição dos municípios era próxima de $17 \%$.
} 
Contudo, a distribuição dos gastos entre as três esferas administrativas também é bastante dispersa nas diferentes unidades da federação: enquanto os municípios contribuíram com 34,4\% dos gastos per capita no estado de São Paulo (na média entre 2000 e 2004), no Acre essa contribuição foi de apenas 7,5\% (Tabela 6). É importante frisar que essa diferença está associada não só a decisões políticas, mas também às restrições orçamentárias dos municípios, de forma que em municípios com dotação orçamentária menor, é natural que a participação federal (ou estadual) seja maior.

Vale ressaltar que apesar dos municípios contribuírem, em média, com apenas 25\% dos gastos públicos em saúde, o montante de recursos administrados por eles é maior do que esse, uma vez que além dos recursos próprios os municípios recebem repasses dos estados e, principalmente, da União. Em 2004, por exemplo, aproximadamente 41\% dos gastos federais em saúde foram com transferências para os municípios (Tabela 7), Com isso, ao somar os recursos repassados pelo governo federal, os gastos executados pelos municípios se aproximaram de $47 \%$ dos gastos totais daquele ano ${ }^{10}$.

\begin{tabular}{|c|c|c|c|c|c|c|c|c|}
\hline Itens de gasto & 1998 & 1999 & 2000 & 2001 & 2002 & 2003 & 2004 & 2005 \\
\hline Pessoal & 14,2 & 13,0 & 12,6 & 11,4 & 11,4 & 13,3 & 12,4 & 11,4 \\
\hline Outras despesas correntes & 48,5 & 42,7 & 36,8 & 34,6 & 31,9 & 27,7 & 19,1 & 17,6 \\
\hline Outros gastos diretos & 5,3 & 5,4 & 5,5 & 5,4 & 5,4 & 4,6 & 5,1 & 4,5 \\
\hline Transferência a estados e DF & 5,9 & 7,0 & 11,0 & 12,4 & 14,1 & 16,8 & 23,0 & 25,6 \\
\hline Transferência a municípios & 26,0 & 31,9 & 34,6 & 36,8 & 37,3 & 38,2 & 41,0 & 40,9 \\
\hline Total & 100,0 & 100,0 & 100,0 & 100,0 & 100,0 & 100,0 & 100,0 & 100,0 \\
\hline
\end{tabular}

Analisando o destino dos recursos executados pelos municípios - tomando como exemplo os gastos totais com saúde e saneamento em 2005 -, nota-se que três rubricas principais se destacam: (i) assistência hospitalar (38\% desses gastos); (ii) atenção básica à saúde (35\%) e (iii) saneamento $(10 \%)$.

Essa composição, contudo, apresenta diferenças significativas entre as unidades da federação. Essa diversidade pode ser ilustrada por dois exemplos extremos: os municípios no Acre gastaram em média 71\% dos seus recursos com atenção básica e 3\% com assistência hospitalar (no ano de 2005), ao passo que no Rio de Janeiro, no mesmo ano, o gasto médio dos municípios

\footnotetext{
${ }^{10}$ Uma estimativa mais precisa da participação dos gastos efetivamente executados pelos municípios deveria incluir também as transferências dos estados para os municípios. Contudo, o montante de repasse estadual para os municípios é relativamente baixo, se situando ao redor de $1 \%$ do valor repassado pela União, de forma que a aproximação considerando apenas o repasse federal não implica em um erro muito acentuado.
} 
com atenção básica foi de apenas $20 \%$ do total enquanto o gasto com assistência hospitalar foi de $55 \%$ (Tabela 8).

\begin{tabular}{|c|c|c|c|c|c|c|c|c|c|}
\hline UF & $\begin{array}{l}\text { Atençäo } \\
\text { Básica }\end{array}$ & $\begin{array}{l}\text { Assistência } \\
\text { Hospitalar }\end{array}$ & $\begin{array}{c}\text { Suporte } \\
\text { Profilático }\end{array}$ & $\begin{array}{c}\text { Vigilância } \\
\text { Sanitária }\end{array}$ & \begin{tabular}{c|} 
Vigilância \\
Epidemiológica
\end{tabular} & $\begin{array}{c}\text { Alimentaçäo } \\
\text { e Nutriçäo }\end{array}$ & $\begin{array}{l}\text { Demais } \\
\text { Subfunçöes } \\
\text { de Saúde }\end{array}$ & Saneamento & Total \\
\hline ACRE & 71,2 & 3,4 & 1,5 & 0,8 & 1,7 & 0,0 & 4,7 & 16,7 & 100,0 \\
\hline ALAGOAS & 57,7 & 28,8 & 1,8 & 0,3 & 3,0 & 0,2 & 4,2 & 4,0 & 100,0 \\
\hline AMAPA & 33,8 & 23,9 & 1,1 & 1,6 & 3,5 & 0,0 & 33,8 & 2,3 & 100,0 \\
\hline AMAZONAS & 27,9 & 43,5 & 0,3 & 0,0 & 0,5 & 0,1 & 20,1 & 7,6 & 100,0 \\
\hline BAHIA & 45,0 & 29,7 & 1,8 & 0,5 & 1,3 & 1,6 & 15,8 & 4,3 & 100,0 \\
\hline CEARA & 27,9 & 54,3 & 0,6 & 0,4 & 1,8 & 0,1 & 11,7 & 3,2 & 100,0 \\
\hline ESPIRITO SANTO & 34,7 & 19,4 & 1,5 & 0,8 & 2,5 & 0,1 & 30,4 & 10,6 & 100,0 \\
\hline GOIAS & 21,6 & 51,2 & 0,2 & 0,1 & 0,5 & 0,8 & 12,0 & 13,5 & 100,0 \\
\hline MARANHAO & 33,5 & 39,6 & 0,3 & 1,7 & 1,1 & 0,8 & 19,6 & 3,6 & 100,0 \\
\hline MATO GROSSO & 37,7 & 27,1 & 1,0 & 0,4 & 1,6 & 0,2 & 23,5 & 8,5 & 100,0 \\
\hline MATO GROSSO DO SUL & 47,7 & 42,7 & 0,7 & 1,0 & 1,3 & 0,1 & 4,4 & 2,0 & 100,0 \\
\hline MINAS GERAIS & 22,7 & 37,4 & 1,2 & 0,6 & 1,6 & 0,6 & 21,6 & 14,3 & 100,0 \\
\hline PARA & 28,6 & 32,8 & 0,9 & 0,6 & 3,1 & 0,6 & 28,1 & 5,3 & 100,0 \\
\hline PARAIBA & 45,9 & 40,5 & 1,4 & 0,5 & 2,1 & 0,6 & 7,2 & 1,9 & 100,0 \\
\hline PARANA & 53,0 & 37,5 & 1,2 & 1,1 & 1,3 & 0,3 & 3,6 & 1,9 & 100,0 \\
\hline PERNAMBUCO & 28,8 & 39,5 & 1,1 & 0,7 & 1,7 & 0,4 & 24,3 & 3,7 & 100,0 \\
\hline PIAUI & 36,5 & 36,2 & 2,2 & 0,7 & 2,1 & 0,5 & 12,9 & 8,9 & 100,0 \\
\hline RIO DE JANEIRO & 20,3 & 55,3 & 0,9 & 0,8 & 0,9 & 0,2 & 15,6 & 6,0 & 100,0 \\
\hline RIO GRANDE DO NORTE & 65,6 & 19,7 & 0,3 & 1,2 & 2,3 & 2,3 & 5,7 & 3,0 & 100,0 \\
\hline RIO GRANDE DO SUL & 34,7 & 31,6 & 0,6 & 0,6 & 0,4 & 0,2 & 11,5 & 20,5 & 100,0 \\
\hline RONDONIA & 28,3 & 35,6 & 1,0 & 1,2 & 3,2 & 0,1 & 28,8 & 1,8 & 100,0 \\
\hline RORAIMA & 34,6 & 7,5 & 0,3 & 0,2 & 4,3 & 1,8 & 44,8 & 6,5 & 100,0 \\
\hline SANTA CATARINA & 58,7 & 22,6 & 0,4 & 0,3 & 0,4 & 0,8 & 5,2 & 11,6 & 100,0 \\
\hline SAO PAULO & 33,3 & 37,9 & 0,4 & 0,5 & 0,6 & 1,0 & 12,8 & 13,5 & 100,0 \\
\hline SERGIPE & 61,3 & 29,5 & 0,0 & 0,8 & 0,0 & 0,0 & 7,4 & 0,8 & 100,0 \\
\hline TOCANTINS & 44,6 & 40,8 & 1,1 & 0,9 & 0,7 & 1,3 & 8,5 & 2,2 & 100,0 \\
\hline Média & 34,2 & 38,2 & 0,8 & 0,6 & 1,1 & 0,7 & 14,3 & 10,1 & 100,0 \\
\hline
\end{tabular}

Fonte: Sistema de Administraçẫo Financeira do Tesouro Nacional (SIAFI) / Finanças Brasileiras (Finbra)

\section{3 - OFERTA DE SAÚDE NO BRASIL}

Tendo em vista que um dos princípios do sistema de saúde nacional é a equidade, para uma caracterização geral do sistema é importante uma análise da configuração geográfica da oferta de serviços de saúde, com o intuito de avaliar se os indivíduos têm a sua disposição os serviços dos quais necessitam. Como esse não é o foco desse trabalho, será feita apenas uma breve descrição de alguns indicadores selecionados, que serão: o número de leitos de internação, de estabelecimentos sem internação, de equipamentos de manutenção da vida e do pessoal empregado em saúde.

Segundo a pesquisa de Assistência Médico-Sanitária (AMS) de 2005, elaborada pelo IBGE, no Brasil existiam naquele ano 240,6 leitos de internação para cada 100.000 habitantes (Tabela 9) - número inferior ao recomendado pela OMS, que sugere uma média de 300 leitos para cada 100.000 habitantes $^{11}$. Desse total, $212,0^{12}(88,1 \%)$ são públicos ou particulares que prestam atendimento ao SUS. A maior parte desses estabelecimentos é particular, mas a maioria deles presta serviço ao SUS $-82,1 \%$ do total dos leitos privados estão localizados em estabelecimentos

\footnotetext{
${ }^{11}$ No entanto, vale ressaltar que não há um consenso a respeito da validade da comparação com o número recomendado pela OMS, uma vez que o número ideal pode variar bastante de um país para outro devido a particularidades de cada um.

${ }^{2}$ Sempre considerando por 100.000 habitantes
} 
que prestam serviços ao SUS. Considerando apenas os públicos, aproximadamente $47 \%$ são administrados pelos municípios.

A Região Sul possui o maior número de leitos por habitante, $276,4^{13}$, enquanto a Região Norte apresenta a maior escassez, com 184,8. É importante frisar que nenhum dos estados da região norte possui um número superior ou mesmo igual à média nacional. Entre a unidade da federação com a maior oferta de serviços de internação - que é o Rio de Janeiro, com 292,9 leitos - e o Amapá, que possui o menor número de leitos (124,8), a diferença totaliza 135\%, o que ilustra a grande disparidade de oferta de serviços de saúde no Brasil.

Tabela 9. Quantidade de leitos por 100000 habitantes (2005)

\begin{tabular}{|c|c|c|c|c|c|c|c|}
\hline \multirow{2}{*}{$\begin{array}{c}\text { UF e Grandes } \\
\text { Regiöes }\end{array}$} & \multirow{2}{*}{ Total } & \multirow{2}{*}{$\begin{array}{l}\text { Total público } \\
+ \text { privado c/ } \\
\text { atendimento } \\
\text { ao SUS }\end{array}$} & \multicolumn{3}{|c|}{ Público } & \multicolumn{2}{|c|}{ Privado } \\
\hline & & & Federal & Estadual & Municipal & sus & sem sus \\
\hline Brasil & 240,6 & 212,0 & 9,3 & 33,5 & 38,0 & 131,2 & 28,6 \\
\hline Norte & 184,8 & 166,4 & 6,0 & 55,5 & 45,1 & 59,8 & 18,4 \\
\hline Rondônia & 200,6 & 157,1 & - & 34,2 & 102,8 & 20,1 & 43,5 \\
\hline Acre & 233,1 & 221,4 & 3,0 & 173,7 & 5,7 & 39,1 & 11,6 \\
\hline Amazonas & 156,0 & 144,0 & 13,2 & 102,9 & 13,7 & 14,3 & 11,9 \\
\hline Roraima & 153,3 & 140,8 & 1,3 & 90,0 & 47,3 & 2,3 & 12,5 \\
\hline Pará & 191,8 & 174,3 & 4,6 & 18,0 & 48,8 & 102,8 & 17,5 \\
\hline Amapá & 124,8 & 115,4 & 16,1 & 71,1 & 6,7 & 21,4 & 9,4 \\
\hline Tocantins & 212,3 & 192,8 & 1,4 & 85,0 & 72,0 & 34,4 & 19,5 \\
\hline Nordeste & 227,1 & 213,6 & 7,0 & 39,3 & 56,6 & 110,7 & 13,5 \\
\hline Maranhão & 226,7 & 215,3 & 7,1 & 14,0 & 110,2 & 83,9 & 11,4 \\
\hline Piauí & 246,9 & 238,2 & 2,5 & 128,6 & 23,3 & 83,7 & 8,7 \\
\hline Ceará & 214,2 & 203,1 & 9,4 & 19,1 & 61,3 & 113,3 & 11,1 \\
\hline Rio Grande do Norte & 239,4 & 227,3 & 15,9 & 52,9 & 48,1 & 110,5 & 12,1 \\
\hline Paraíba & 251,4 & 240,5 & 10,3 & 50,4 & 53,7 & 126,0 & 10,9 \\
\hline Pernambuco & 253,1 & 231,1 & 6,9 & 53,6 & 56,5 & 114,1 & 22,0 \\
\hline Alagoas & 197,4 & 190,6 & 2,8 & 30,4 & 37,4 & 120,0 & 6,8 \\
\hline Sergipe & 181,1 & 174,6 & 2,8 & 32,1 & 8,6 & 131,1 & 6,5 \\
\hline Bahia & 218,7 & 203,4 & 5,4 & 31,2 & 51,1 & 115,8 & 15,2 \\
\hline Sudeste & 244,0 & 203,1 & 10,4 & 30,3 & 27,3 & 135,0 & 40,9 \\
\hline Minas Gerais & 240,6 & 217,9 & 8,7 & 20,3 & 26,3 & 162,7 & 22,6 \\
\hline Espírito Santo & 224,3 & 194,7 & 8,5 & 44,0 & 14,6 & 127,6 & 29,6 \\
\hline Rio de Janeiro & 292,9 & 235,2 & 35,8 & 24,2 & 51,8 & 123,3 & 57,7 \\
\hline São Paulo & 228,7 & 184,6 & 1,8 & 36,3 & 19,6 & 127,0 & 44,1 \\
\hline Sul & 276,4 & 251,7 & 11,1 & 19,9 & 24,1 & 196,6 & 24,7 \\
\hline Paraná & 276,2 & 251,1 & 7,5 & 18,6 & 33,4 & 191,6 & 25,1 \\
\hline Santa Catarina & 266,2 & 248,3 & 5,0 & 43,4 & 18,6 & 181,2 & 17,9 \\
\hline Rio Grande do Sul & 282,2 & 254,1 & 17,7 & 8,4 & 18,3 & 209,6 & 28,1 \\
\hline Centro-0este & 262,5 & 229,3 & 119 & 33,4 & 509 & 1332 & 33,2 \\
\hline Mato Grosso do Sul & 2735 & 2452 & 19.6 & 94 & 36.8 & 1794 & 28,3 \\
\hline Mato Grosso & 239,2 & 217,1 & 8,1 & 11,0 & 65,4 & 132,6 & 22,1 \\
\hline Goiás & 290,2 & 259,3 & 5,7 & 16,5 & 70,4 & 166,7 & 30,9 \\
\hline Distrito Federal & 213,0 & 156,4 & 24,1 & 124,0 & - & 8,3 & 56,6 \\
\hline
\end{tabular}

Fonte: IBGE / Pesquisa de Assistência Médica e Sanitária (AMS)

Já o número de estabelecimentos sem internação possui uma distribuição mais homogênea nas diferentes regiões geográficas do país: no Sudeste, onde há o menor número proporcional de

\footnotetext{
${ }^{13}$ Nota-se que mesmo a Região Sul, que é a mais bem servida em termos de número de leitos, possui uma quantia inferior à sugerida pela OMS.
} 
estabelecimentos com essa característica, existiam em 2005 21,0 por 100.000 habitantes, e no Sul, que possui a maior quantidade proporcional, esse número é de 28,8 (Tabela 10). A média nacional é de 25,0 estabelecimentos sem internação por 100.000 habitantes, e desse total, 18,2 (ou $73 \%$ ) são administrados pelos municípios, o que reflete a importância dos municípios na atenção básica à saúde.

\begin{tabular}{|c|c|c|c|c|c|c|c|}
\hline Regiäo/UF & Total Geral & $\begin{array}{c}\text { Total público + } \\
\text { privado que } \\
\text { atende o sus }\end{array}$ & $\begin{array}{l}\text { Público } \\
\text { federal }\end{array}$ & $\begin{array}{l}\text { Público } \\
\text { estadual }\end{array}$ & $\begin{array}{l}\text { Público } \\
\text { municipal }\end{array}$ & $\begin{array}{c}\text { Privado } \\
\text { (atende o SUS) }\end{array}$ & $\begin{array}{c}\text { Privado } \\
\text { (näo atende } \\
0 \text { SUS) }\end{array}$ \\
\hline Brasil & 25,0 & 19,8 & 0,3 & 0,5 & 18,2 & 0,9 & 5,2 \\
\hline Região Norte & 26,7 & 24,9 & 1,3 & 1,5 & 21,4 & 0,7 & 1,8 \\
\hline Regiẫo Nordeste & 28,6 & 24,2 & 0,1 & 0,3 & 22,5 & 1,3 & 4,4 \\
\hline Região Sudeste & 21,0 & 15,0 & 0,1 & 0,3 & 13,9 & 0,7 & 6,1 \\
\hline Região Sul & 28,8 & 23,2 & 0,2 & 0,2 & 21,8 & 1,0 & 5,6 \\
\hline Região Centro-Oeste & 24,7 & 18,4 & 0,7 & 1,1 & 16,1 & 0,6 & 6,3 \\
\hline
\end{tabular}

Fonte: Datasus / IBGE (AMS 2002)

Quanto à aparelhagem, a maior disponibilidade se situa na região Sudeste, sendo a dispersão bastante expressiva. O número de equipamentos classificados como de manutenção da vida $^{14}$, por exemplo, é de 178,0 por 100.000 habitantes na região Sudeste e de apenas 70,8 na região Norte (Tabela 11).

Tabela 11. Número de equipamentos de manutenção da vida (por 100000 habitantes) - 2005

\begin{tabular}{|c|c|c|c|c|}
\hline & Total & Público & $\begin{array}{c}\text { Privado } \\
\text { (total) }\end{array}$ & $\begin{array}{c}\text { Privado } \\
\text { (atende SUS) }\end{array}$ \\
\hline Brasil & $\mathbf{1 3 5 , 8}$ & $\mathbf{4 4 , 6}$ & $\mathbf{9 1 , 2}$ & $\mathbf{5 3 , 3}$ \\
\hline Norte & 70,8 & 41,6 & 29,2 & 15,9 \\
\hline Nordeste & 81,3 & 31,6 & 49,7 & 32,5 \\
\hline Sudeste & 178,0 & 56,0 & 122,0 & 63,3 \\
\hline Sul & 150,7 & 36,1 & 114,7 & 84,5 \\
\hline Centro-Oeste & 137,7 & 48,5 & 89,1 & 52,0 \\
\hline Fonte: IBGE / AMS 2005 & & & & \\
\hline
\end{tabular}

Entre os indicadores relacionados à oferta de serviços de saúde levantados nesse trabalho, o total de pessoal empregado na área de saúde com formação superior é o indicador que apresenta o maior contraste regional. Em média existiam 472,5 profissionais da saúde com curso superior

\footnotetext{
${ }^{14}$ Doze tipos de aparelho se enquadram nessa classificação: berço aquecido; desfibrilador; equipamento de fototerapia; incubadora; marcapasso temporário; monitor de ECG; monitor de pressão invasivo; monitor de pressão não-invasivo; oxímetro; reanimador pulmonar; respirador/ventilador adulto; e respirador/ventilador infantil.
} 
para cada 100.000 habitantes no Brasil no ano de 2005 (Tabela 12). No Distrito Federal esse número era de 815,5 , mas no Pará se situava em 197,2, ou seja, uma diferença superior a $300 \%{ }^{15}$.

Tabela 12. Pessoal empregado na área de Saúde com curso superior (por 100000 habitantes)

\begin{tabular}{|c|c|c|c|c|c|}
\hline & Total & Federal & Estadual & Municipal & Privado \\
\hline Brasil & 472,5 & 19,3 & 59,1 & 161,1 & 232,9 \\
\hline Norte & 266,3 & 12,7 & 82,8 & 103,8 & 67,0 \\
\hline Rondônia & 283,3 & 1,0 & 59,9 & 126,9 & 95,5 \\
\hline Acre & 292,5 & 4,6 & 133,5 & 91,5 & 62,9 \\
\hline Amazonas & 364,6 & 26,1 & 166,9 & 115,1 & 56,5 \\
\hline Roraima & 382,0 & 32,5 & 160,7 & 111,2 & 77,7 \\
\hline Pará & 197,2 & 10,5 & 39,3 & 84,0 & 63,4 \\
\hline Amapá & 283,4 & 8,6 & 96,4 & 98,7 & 79,7 \\
\hline Tocantins & 316,4 & 5,2 & 78,3 & 161,2 & 71,6 \\
\hline Nordeste & 361,2 & 14,4 & 55,9 & 146,6 & 144,3 \\
\hline Maranhẫo & 221,6 & 15,3 & 22,9 & 127,0 & 56,3 \\
\hline Piauí & 337,6 & 3,5 & 75,8 & 160,5 & 97,8 \\
\hline Ceará & 328,4 & 17,0 & 40,0 & 148,4 & 123,1 \\
\hline Rio Grande do Norte & 485,3 & 30,9 & 83,9 & 201,5 & 169,1 \\
\hline Paraíba & 447,9 & 29,3 & 58,6 & 217,5 & 142,6 \\
\hline Pernambuco & 423,9 & 12,2 & 85,3 & 149,1 & 177,2 \\
\hline Alagoas & 378,1 & 14,4 & 68,9 & 155,6 & 139,2 \\
\hline Sergipe & 423,2 & 10,2 & 74,4 & 160,7 & 177,9 \\
\hline Bahia & 346,9 & 9,4 & 45,5 & 115,1 & 176,9 \\
\hline Sudeste & 570,0 & 22,1 & 63,7 & 184,1 & 300,1 \\
\hline Minas Gerais & 505,6 & 21,5 & 30,7 & 192,6 & 260,9 \\
\hline Espírito Santo & 525,9 & 18,5 & 56,7 & 177,5 & 273,2 \\
\hline Rio de Janeiro & 694,7 & 74,7 & 74,8 & 224,4 & 320,7 \\
\hline São Paulo & 557,0 & 2,6 & 75,7 & 165,4 & 313,2 \\
\hline Sul & 505,2 & 20,4 & 22,4 & 168,0 & 294,4 \\
\hline Paraná & 466,7 & 16,2 & 28,6 & 153,6 & 268,4 \\
\hline Santa Catarina & 496,9 & 6,0 & 35,7 & 196,6 & 258,5 \\
\hline Rio Grande do Sul & 546,2 & 32,2 & 9,3 & 166,2 & 338,5 \\
\hline Centro-Oeste & 486,6 & 27,2 & 93,7 & 130,2 & 235,5 \\
\hline Mato Grosso do Sul & 558,3 & 37,7 & 124,4 & 171,2 & 225,0 \\
\hline Mato Grosso & 388,5 & 12,4 & 26,5 & 188,9 & 160,7 \\
\hline Goiás & 370,0 & 12,7 & 39,8 & 138,2 & 179,2 \\
\hline Distrito Federal & 815,5 & 69,6 & 274,5 & 0,4 & 470,9 \\
\hline
\end{tabular}

Por fim, outra estatística de interesse aqui é o porcentual da população coberta por um plano de saúde privado, indicador que não tem relação com a oferta de serviços do sistema público, mas se relaciona intimamente ao acesso a serviços de saúde da população, ainda que tenha influência apenas sobre a camada da população com poder aquisitivo relativamente mais elevado. A média de cobertura da população brasileira é de 19,9\%, mas assim como nos demais indicadores de acesso a disparidade é bastante elevada, com os estados da região Norte e Nordeste apresentando indicadores bem inferiores à média (Tabela 13). Em São Paulo a população assistida

\footnotetext{
${ }^{15}$ A recomendação da OMS é de 100 médicos e 200 enfermeiros para cada 100.000 habitantes, mas não há uma sugestão geral para o total do pessoal empregado na área da saúde.
} 
por plano privado se aproxima de $40 \%$, enquanto no eixo Norte-Nordeste apenas o Amazonas $(10,3 \%)$, o Rio Grande do Norte $(10,6 \%)$ e o Pernambuco $(12,4 \%)$ registram cobertura maior que $10 \%$.

Tabela 13. Prop.população assistida por plano de saúde privado (\%) - 2005

\begin{tabular}{|l|c|l|c|}
\hline Unidade da Federaçäo & $\mathbf{2 0 0 5}$ & Unidade da Federação & $\mathbf{2 0 0 5}$ \\
\hline Rondônia & 4,6 & Sergipe & 8,9 \\
\hline Acre & 5,9 & Bahia & 8,6 \\
\hline Amazonas & 10,3 & Minas Gerais & 19,2 \\
\hline Roraima & 2,3 & Espírito Santo & 21,4 \\
\hline Pará & 7,7 & Rio de Janeiro & 31,9 \\
\hline Amapá & 5,3 & São Paulo & 38,5 \\
\hline Tocantins & 3,3 & Paraná & 18,3 \\
\hline Maranhẫo & 3,8 & Santa Catarina & 17,9 \\
\hline Piauí & 4,2 & Rio Grande do Sul & 16,3 \\
\hline Ceará & 9,3 & Mato Grosso do Sul & 14,1 \\
\hline Rio Grande do Norte & 10,6 & Mato Grosso & 8,8 \\
\hline Paraiba & 8,2 & Goiás & 8,8 \\
\hline Pernambuco & 12,4 & Distrito Federal & 26,0 \\
\hline Alagoas & 5,8 & Brasil & $\mathbf{1 9 , 9}$ \\
\hline Fonte: Ministério da Saúde / Datasus & & \\
\hline
\end{tabular}

\section{4 - CONDIÇÕES DE SAÚDE NO BRASIL}

\subsection{1 - O BRASIL NO CONTEXTO INTERNACIONAL}

Antes de comparar as condições de saúde dos estados e municípios entre si, vale a pena localizar o Brasil no quadro mundial. Nesse sentido, conforme já foi mencionado na introdução desse trabalho, é importante frisar que o Brasil foi o $100^{\circ}$ colocado no critério de expectativa de vida saudável, segundo relatório produzido pela Organização Mundial da Saúde, com uma expectativa ao nascer de 59,8 anos de vida saudável. Na comparação com os demais países da América do Sul, o Brasil ficou à frente apenas do Suriname $\left(112^{\circ}\right)$, da Guiana $\left(126^{\circ}\right)$ e da Bolívia $\left(133^{\circ}\right)$. Já o Chile foi o melhor colocado entre os países dessa região, ficando na $35^{\mathrm{a}}$ posição com uma média de 67,3 anos de vida saudáveis (Tabela 14). Serra Leoa é o país com a pior colocação, com uma expectativa de apenas 28,6 anos de vida saudável.

Quando usa-se para a comparação o critério de mortalidade infantil, o Brasil é superado inclusive pelo Suriname, ou seja, dos países da América do Sul, apenas a Guiana e a Bolívia registram taxas de mortalidade infantil superiores às brasileiras. Quanto à mortalidade materna, indicador também bastante utilizado para medir a qualidade do sistema de saúde de um país, a estimativa da OMS para o Brasil é de 260 casos por cem mil nascidos vivos, valor bastante superior ao dos países mais bem colocados no ranking (que apresentam números próximos de 0 ). 
Na comparação com os demais países da América do Sul, somente o Peru e a Bolívia registram números piores do que os brasileiros. Já em relação ao número de mortes por HIV, o Brasil apresenta índices relativamente baixos, com menos de 10 mortes por 100.000 habitantes, aproximando-se dos índices dos países desenvolvidos.

Em linhas gerais, na comparação com os 12 países da América do Sul listados no relatório, com a exceção do número de mortes por HIV, o Brasil se situa entre os quatro últimos colocados em todos os indicadores aqui selecionados, apresentando um desempenho expressivamente inferior aos países com a situação mais favorável na região, que são: Chile, Uruguai, Argentina e Venezuela. Assim, mesmo limitando a comparação a países com características relativamente semelhantes às nossas, é notável o espaço que existe para a evolução dos indicadores domésticos.

\begin{tabular}{|c|c|c|c|c|c|c|}
\hline $\begin{array}{l}\text { Ranking do } \\
\text { DALE }\end{array}$ & Países & $\begin{array}{c}\text { Expectativa de } \\
\text { vida saudável ao } \\
\text { nascer (DALE) }\end{array}$ & $\begin{array}{l}\text { Expectativa de } \\
\text { vida ao nascer }\end{array}$ & $\begin{array}{c}\text { Mortalidade } \\
\text { infantil por } 1000 \\
\text { nascidos vivos }\end{array}$ & $\begin{array}{c}\text { Mortalidade } \\
\text { materna por } 100000 \\
\text { nascidos vivos }\end{array}$ & $\begin{array}{l}\text { Número de } \\
\text { mortes por HIV } \\
\text { por } 100000 \\
\text { habitantes }\end{array}$ \\
\hline & Ano de referência & 2002 & 2004 & 2004 & 2000 & 2003 \\
\hline 1 & Japan & 75,0 & 82,5 & 3,0 & 10 & $<1$ \\
\hline 2 & San Marino & 73,4 & 81,5 & 3,0 & & \\
\hline 3 & Sweden & 73,3 & 80,5 & 3,0 & 8 & $<10$ \\
\hline 4 & Switzerland & 73,2 & 80,5 & 4,0 & 7 & $<10$ \\
\hline 5 & Monaco & 72,9 & 81,5 & 3,0 & $\ldots$ & \\
\hline 6 & Iceland & 72,8 & 81,0 & 2,0 & 0 & 34,6 \\
\hline 7 & Italy & 72,7 & 81,0 & 4,0 & 5 & $<10$ \\
\hline 8 & Australia & 72,6 & 80,5 & 5,0 & 6 & $<10$ \\
\hline 9 & Spain & 72,6 & 80,0 & 4,0 & 5 & $<10$ \\
\hline 10 & Andorra & 72,2 & 80,0 & 6,0 & $\ldots$ & \\
\hline 11 & Canada & 720 & 80.5 & 50 & 5 & $<10$ \\
\hline 12 & France & 72,0 & 79,5 & 4,0 & 17 & $<10$ \\
\hline 35 & Chile & 67,3 & 77,5 & 8,0 & 30 & $<10$ \\
\hline 40 & Uruguay & 66,2 & 75,0 & 12,0 & 20 & 14,6 \\
\hline 45 & Argentina & 65,3 & 74,5 & 16,0 & 70 & $<10$ \\
\hline 54 & Venezuela (Bolivarian Republic of & 64,2 & 75,0 & 16,0 & 78 & 15,9 \\
\hline 71 & Colombia & 62,0 & 72,5 & 18,0 & 130 & $<10$ \\
\hline 74 & Ecuador & 61,9 & 72,5 & 23,0 & 130 & 13,2 \\
\hline 75 & Paraguay & 61,9 & 72,0 & 21,0 & 170 & 10,2 \\
\hline 90 & Peru & 61,0 & 71,0 & 24,0 & 410 & 15,5 \\
\hline 100 & Brazil & 59.8 & 70,5 & 32,0 & 260 & $<10$ \\
\hline 112 & Suriname & 58,8 & 67,5 & 30,0 & 110 & 112,7 \\
\hline 126 & Guyana & 55,2 & 630 & 470 & 170.0 & 146,9 \\
\hline 133 & Bolivia & 54,4 & 64,5 & 54,0 & 420 & $<10$ \\
\hline 192 & Sierra Leone & 28,6 & 38,5 & 165,0 & 2000 & . \\
\hline
\end{tabular}

\subsection{2 - A DESIGUALDADE DE QUALIDADE DE SAÚDE NO BRASIL}

O sistema de informações do Ministério da Saúde disponibiliza uma série de informações que incluem dados sobre mortalidade e taxas de incidências de doenças, com periodicidade anual ou até mesmo mensal para alguns dados, que poderiam ser utilizadas para avaliar as condições de saúde dos diferentes municípios. Contudo, para alguns Estados, principalmente no Norte e no Nordeste, existe um grau de sub-registro muito elevado, de tal forma que os indicadores subestimam os índices de mortalidade e de incidência de doença, sobretudo nas regiões mais 
carentes, o que viesaria a análise desses dados. Assim, como o intuito desse trabalho é fazer uma análise com abrangência nacional da eficiência dos gastos públicos em saúde, são necessários dados que podem ser comparáveis entre os municípios de qualquer localidade, por isso esses indicadores não foram utilizados. Dessa forma, para viabilizar a análise comparativa, serão utilizados os dados divulgados pelo IBGE no último censo demográfico, que são referentes ao ano de 2000 .

Sendo assim, a avaliação da qualidade da saúde da população será feita observando as quatro variáveis que se relacionam à saúde disponíveis no censo: (i) mortalidade infantil; (ii) mortalidade até cinco anos de idade; (iii) expectativa de vida ao nascer; e (iv) probabilidade de chegar aos 60 anos de vida.

Iniciando a análise pela expectativa de vida ao nascer, um primeiro ponto que deve ser ressaltado é que o contraste desse indicador não se verifica apenas entre unidades da federação ou entre municípios localizados em diferentes Estados, sendo evidente também entre municípios localizados na mesma unidade da federação - em Pernambuco, por exemplo, a diferença entre o município com a menor expectativa de vida (Manari, com 55,7 anos) e aquele com o melhor desempenho (Fernando de Noronha, com 75,1 anos) é de aproximadamente 35\% (Tabela 15). Assim, dentro de um mesmo estado existem municípios com índice de expectativa de vida similar ao dos países desenvolvidos e outros com índices que se aproximam aos dos países mais carentes. Em São Paulo, outro exemplo de disparidade bastante elevada, o município de São Caetano do Sul apresenta uma esperança de vida ao nascer de 78,2 anos, o que o aproxima do Reúno Unido, que é o $25^{\circ}$ colocado nesse critério entre os 192 países listados pela OMS, enquanto em Ribeirão Branco a esperança de vida é de 61,0 anos, nível idêntico ao do Nepal, que é o $138^{\circ}$ país no ranking de expectativa de vida ao nascer. 
Tabela 15. Disparidade de expectativa de vida entre os municípios das unidades da federação (2000)

\begin{tabular}{|c|c|c|c|c|c|}
\hline UF & $\begin{array}{l}\text { Município com melhor } \\
\text { desempenho nessa UF }\end{array}$ & $\begin{array}{l}\text { Expectativa } \\
\text { de Vida }\end{array}$ & $\begin{array}{c}\text { Município com pior } \\
\text { desempenho nessa UF }\end{array}$ & $\begin{array}{l}\text { Expectativa } \\
\text { de Vida }\end{array}$ & $\begin{array}{c}\text { Diferença } \\
(\mathrm{em} \%)\end{array}$ \\
\hline$\overline{\mathrm{AC}}$ & Senador Guiomard & 68,4 & Santa Rosa do Purus & 63,2 & 8,2 \\
\hline $\mathrm{AL}$ & Satuba & 68,9 & Traipu & 55,9 & 23,3 \\
\hline $\mathrm{AM}$ & Barcelos & 70,8 & Tapauá & 58,8 & 20,3 \\
\hline $\mathrm{AP}$ & Ferreira Gomes & 70,2 & Pedra Branca do Amaparí & 60,8 & 15,4 \\
\hline $\mathrm{BA}$ & Salvador & 69,6 & Inhambupe & 55,4 & 25,8 \\
\hline CE & Limoeiro do Norte & 72,0 & Croatá & 58,5 & 23,1 \\
\hline ES & Santa Teresa & 74,8 & Água Doce do Norte & 62,5 & 19,7 \\
\hline $\mathrm{GO}$ & Palmelo & 75,7 & Flores de Goiás & 61,1 & 24,0 \\
\hline MA & São Luís & 69,2 & Centro do Guilherme & 54,3 & 27,3 \\
\hline$M G$ & São Lourenço & 76,9 & Montezuma & 59,3 & 29,7 \\
\hline MS & Nova Andradina & 73,0 & Miranda & 65,1 & 12,3 \\
\hline MT & Nova Ubiratẫ & 74,4 & Luciára & 62,9 & 18,3 \\
\hline PA & Novo Progresso & 73,3 & Sẫo Joẫo do Araguaia & 60,9 & 20,4 \\
\hline PB & Sẫo Domingos do Cariri & 70,5 & Natuba & 55,2 & 27,8 \\
\hline PE & Fernando de Noronha & 75,1 & Manari & 55,7 & 34,8 \\
\hline $\mathrm{PI}$ & Eliseu Martins & 69,2 & Novo Santo Antônio & 55,8 & 24,1 \\
\hline PR & Quatro Pontes & 77,7 & Mato Rico & 60,6 & 28,1 \\
\hline RJ & Quatis & 74,1 & Varre-Sai & 62,2 & 19,1 \\
\hline RN & Caicó & 73,3 & Pureza & 57,6 & 27,2 \\
\hline $\mathrm{RO}$ & Espigã̃o D'Oeste & 70,1 & Nova Mamoré & 63,1 & 11,1 \\
\hline $\mathrm{RR}$ & Mucajaí & 70,2 & Uiramutẫ & 59,9 & 17,2 \\
\hline RS & Sẫo José do Inhacorá & 77,8 & Benjamin Constant do Sul & 64,1 & 21,4 \\
\hline $\mathrm{SC}$ & Antônio Carlos & 77,9 & Timbó Grande & 65,9 & 18,2 \\
\hline SE & Moita Bonita & 70,3 & Brejo Grande & 56,5 & 24,4 \\
\hline $\mathrm{SP}$ & São Caetano do Sul & 78,2 & Ribeirẫo Branco & 61,0 & 28,2 \\
\hline TO & Cariri do Tocantins & 72,1 & Axixá do Tocantins & 55,2 & 30,5 \\
\hline
\end{tabular}

Fonte: IBGE / Censo demográfico de 2000

Quando se avalia o indicador de mortalidade infantil, o município com o melhor desempenho também é São Caetano do Sul, com 5,4 mortes a cada mil nascidos vivos. Assim, também por esse critério o município se aproxima do nível dos países mais desenvolvidos do mundo. Já no município de Manari, em Pernambuco, foi registrado o maior número de mortes por mil nascidos vivos de todo o Brasil, 109,7 (Tabela 16).

Comparando os municípios por faixas populacionais, não há diferenças significativas nos resultados. A média simples de todos os municípios que se enquadram nas três faixas selecionadas é relativamente similar e os municípios com os melhores desempenhos em cada uma delas também apresentam resultados parecidos (Tabela 17). A diferença mais significativa está no município com pior desempenho de cada uma das faixas: entre os considerados pequenos (até 9999 habitantes) o maior índice de mortalidade infantil é em Jucati em Pernambuco, com 96,4 mortes por mil nascidos vivos. Já entre os considerados grandes (acima de 49999 habitantes) a maior mortalidade é em Codó no Maranhão, com 77,4 casos por mil nascidos vivos (Manari, já citado como o pior desempenho entre todos os municípios, com 109,7 mortes, se enquadra entre os municípios de médio porte, entre 10000 e 49999). 
Tabela 16. Mortalidade Infantil (por 1000 nascidos vivos) - Melhores e piores municipios

\begin{tabular}{|c|c|c|c|c|}
\hline UF & Melhor município & $\begin{array}{l}\text { Mortalidade } \\
\text { Infantil }\end{array}$ & Pior município & $\begin{array}{l}\text { Mortalidade } \\
\text { Infantil }\end{array}$ \\
\hline$\overline{\mathrm{AC}}$ & Senador Guiomard & 25,5 & Capixaba & 41,6 \\
\hline $\mathrm{AL}$ & Satuba & 30,5 & Poço das Trincheiras & 85,1 \\
\hline $\mathrm{AM}$ & Barcelos & 27,4 & Ipixuna & 75,3 \\
\hline $\mathrm{AP}$ & Ferreira Gomes & 24,1 & Itaubal & 56,3 \\
\hline $\mathrm{BA}$ & Santo Antônio de Jesus & 28,1 & Inhambupe & 83,3 \\
\hline CE & Sẫo Joăo do Jaguaribe & 26,9 & Croatá & 81,6 \\
\hline $\mathrm{DF}$ & - & 14,4 & - & 14,4 \\
\hline $\mathrm{ES}$ & Santa Teresa & 12,9 & Agua Doce do Norte & 47,1 \\
\hline $\mathrm{GO}$ & Palmelo & 9,8 & Buritinópolis & 50,1 \\
\hline MA & Sã̃o Luís & 27,4 & Centro do Guilherme & 88,7 \\
\hline$M G$ & São Lourenço & 11,3 & Curral de Dentro & 71,8 \\
\hline MS & Nova Andradina & 17,7 & Dois Irmãos do Buriti & 41,6 \\
\hline MT & Nova Ubiratẫ & 14,8 & Luciára & 49,2 \\
\hline $\mathrm{PA}$ & Nowo Progresso & 19,0 & Faro & 62,5 \\
\hline PB & São Domingos do Cariri & 25,5 & Gado Bravo & 84,3 \\
\hline $\mathrm{PE}$ & Fernando de Noronha & 20,3 & Manari & 109,7 \\
\hline $\mathrm{Pl}$ & Eliseu Martins & 290 & Campo Largo do Piauí & 81,1 \\
\hline PR & Quatro Pontes & 6,0 & Mato Rico & 45,3 \\
\hline RJ & Quatis & 11,0 & Varre-Sai & 38,7 \\
\hline RN & Timbaúba dos Batistas & 22,5 & Pureza & 83,6 \\
\hline RO & Espigão D'Oeste & 20,2 & Candeias do Jamari & 39,9 \\
\hline $\mathrm{RR}$ & Mucajaí & 23,1 & Caroebe & 57,0 \\
\hline RS & São José do Inhacorá & 7,0 & Benjamin Constant do Sul & 37,9 \\
\hline $\mathrm{SC}$ & Antônio Carlos & 8,1 & Bela Vista do Toldo & 39,3 \\
\hline $\mathrm{SE}$ & Moita Bonita & 26,0 & Brejo Grande & 77,4 \\
\hline $\mathrm{SP}$ & São Caetano do Sul & 5,4 & Barra do Chapéu & 42,4 \\
\hline TO & Cariri do Tocantins & 22,2 & Axixá do Tocantins & 86,8 \\
\hline \multicolumn{4}{|c|}{ Fonte: IBGE / Censo demográfico 2000} & \\
\hline
\end{tabular}

\begin{tabular}{|l|c|c|l|c|c|c|c|c|}
\hline \multicolumn{1}{|c|}{ Tabela 17. Mortalidade infantil (por mil nascidos vivos) - por faixa populacional } \\
\hline \multicolumn{1}{|c|}{ Populaçäo } & Média* & UF & $\begin{array}{c}\text { Município com } \\
\text { melhor } \\
\text { desempenho }\end{array}$ & $\begin{array}{c}\text { Mortalidade } \\
\text { infantil }\end{array}$ & UF & $\begin{array}{c}\text { Município } \\
\text { com pior } \\
\text { desempenho }\end{array}$ & $\begin{array}{c}\text { Mortalidade } \\
\text { infantil }\end{array}$ \\
\hline Até 9999 & 32,8 & PR & Quatro Pontes & 6,0 & PE & Jucati & 96,4 \\
\hline de 10000 a 49999 & 37,1 & SP & Cordeirópolis & 7,1 & PE & Manari & 109,7 \\
\hline Acima de 49999 & 26,7 & SP & Sẫo Caetano do Sul & 5,4 & MA & Codó & 77,4 \\
\hline
\end{tabular}

Fonte: IBGE / Censo. Elaboraçẫo Própria. * Média simples do número de cada município

Com apenas 6,2 mortos até 5 anos de idade por mil nascidos vivos, e 93,1\% de probabilidade de se atingir 60 anos de idade, São Caetano do Sul também lidera os outros dois indicadores de qualidade de saúde da população considerados nesse trabalho. Já o município de Centro de Guilherme (no Maranhão) apresenta o pior desempenho de todo o país nesses dois indicadores, com 53,3\% de probabilidade de se atingir 60 anos de idade e com 134,8 mortos até cinco anos de idade por mil nascidos vivos. Aliás, o Município de Centro do Guilherme só não é o pior colocado no critério de mortalidade infantil, no qual é superado por Manari. 


\section{4 - METODOLOGIA}

Este capítulo está dividido em duas seções, sendo que a primeira apresenta uma resenha teórica dos métodos de estimação de fronteiras de produção, e a segunda trata de aspectos específicos da avaliação do sistema de saúde nacional.

\section{1 - A ECONOMETRIA DA EFICIÊNCIA}

Um primeiro ponto a se destacar é a definição do conceito de eficiência, que pode ser dividido em duas categorias:

1 - Eficiência Técnica: Esse tipo de eficiência está ligado ao processo de produção em si, considerando eficiente o processo que, para uma dada quantidade de insumos, extrai a maior quantidade possível de produto, ou seja, utiliza-se de toda a capacidade produtiva, não havendo desperdício de recursos.

2 - Eficiência Alocativa: A teoria microeconômica nos ensina que uma unidade tomadora de decisões aloca eficientemente seus recursos, quando a razão do produto marginal dos insumos, conhecida na literatura como taxa marginal de substituição técnica, é igual a razão de seus custos marginais (preços), caso contrário, haveria um ganho em aumentar a utilização do insumo que, ponderado pelo seu custo marginal, possui um benefício marginal maior, e diminuir a utilização dos demais, reduzindo assim, o custo total do processo. Sendo assim, temos que o custo de produção só pode ser mínimo se estivermos no ponto de eficiência alocativa.

Tendo em vista que dificilmente as informações de preços dos insumos estão disponíveis, boa parte da literatura sobre eficiência concentra seus esforços na eficiência técnica. Entretanto, alguns trabalhos consideram os gastos totais como um dos insumos, incluindo desta maneira o conceito de eficiência alocativa, uma vez que, conforme argumentado acima, seria impossível minimizar os gastos sem estar no ponto de alocação ótimo. O presente trabalho pretende incluir entre os insumos o gasto total com o setor de saúde, abordando portanto, ambos os conceitos de eficiência.

Definido o conceito de eficiência, passamos agora para uma breve discussão sobre algumas das principais técnicas de mensuração da mesma, que conforme dito anteriormente, podem ser divididas em dois grupos, paramétricas e não-paramétricas.

Um dos métodos não-paramétricos mais simples é o FDH (Free Disposal Hull), que consiste primeiramente em estabelecer uma fronteira de possibilidades de produção, através de uma combinação das observações de melhor desempenho da amostra, e posteriormente medir a distância de cada observação até esta fronteira, tomando essa distância como a ineficiência. 
Uma vantagem dessa abordagem é a imposição de restrições fracas para a tecnologia de produção. A única hipótese assumida é o free disposal (livre descarte), ou seja, com a mesma quantidade de insumos é possível diminuir o produto, ou com a mesma quantidade de produto, aumentar os insumos. Essa propriedade garante a existência da continuidade da fronteira de possibilidades de produção construída por FDH.

Essa análise considera uma observação eficiente, se não existe nenhuma outra na amostra que produza a mesma quantidade com menos insumo, ou produza mais, com a mesma quantidade de insumo. Pontos que não atendam essa descrição de eficiência são considerados ineficientes.

De acordo com os critérios estabelecidos, podemos notar no gráfico abaixo (Gráfico 2), que $\mathrm{A}, \mathrm{C}$ e D são pontos eficientes, enquanto B é ineficiente, uma vez que está localizado abaixo e a direita de A, ou seja, produz uma quantidade menor de produto com uma quantidade maior de insumos.

\section{Gráfico 2: Fronteira de Possibilidades de Prod ua ão construida por FDH}

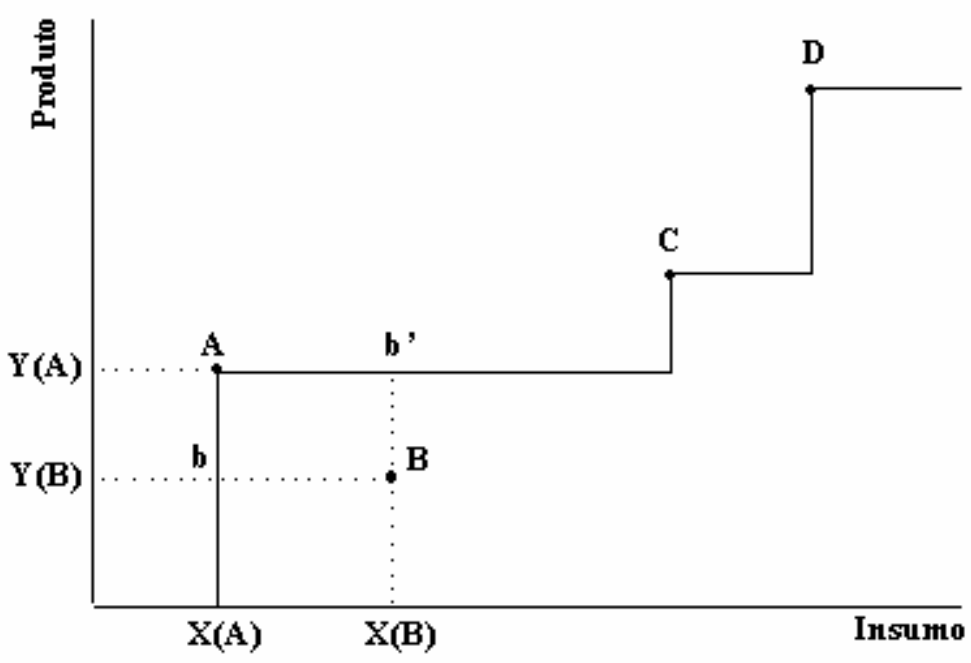

Por fim, para calcular a magnitude da ineficiência de B, a análise FDH sugere dois métodos alternativos.

1 - Score de eficiência de insumo: Medido pela distância bB, ou pelo quociente $\mathrm{X}(\mathrm{A}) / \mathrm{X}(\mathrm{B})$, representando a ótica do insumo;

2 - Score de eficiência de produto: Medido pela distância Bb', ou pelo quociente $\mathrm{Y}(\mathrm{B}) / \mathrm{Y}(\mathrm{A})$, representando a ótica do produto.

Ambas as medidas são iguais a um para pontos de fronteira, e menores do que esse valor para pontos abaixo da mesma. Nesse sentido, quanto menor for o score de uma determinada observação, maior é a sua ineficiência. 
Adicionando a hipótese de que a tecnologia de produção é convexa, temos que qualquer combinação linear das observações de melhor desempenho está abaixo da fronteira de possibilidades de produção (ou faz parte da mesma). Este pressuposto é a base de um método nãoparamétrico alternativo, o DEA (Data Envelopment Analysis).

Resumidamente, podemos dizer que o DEA consiste em definir as combinações lineares das observações de melhores desempenhos como a fronteira de possibilidades de produção, classificando qualquer observação abaixo da mesma como ineficiente. De acordo com os critérios do DEA, o ponto $\mathrm{C}$, anteriormente classificado como eficiente, passa a ser considerado ineficiente, uma vez que se situa abaixo da nova fronteira de possibilidades (Gráfico 3).

\section{Gráfico 3: Fronteira de Possib ilid ad es de Prod ução construida p or DEA}

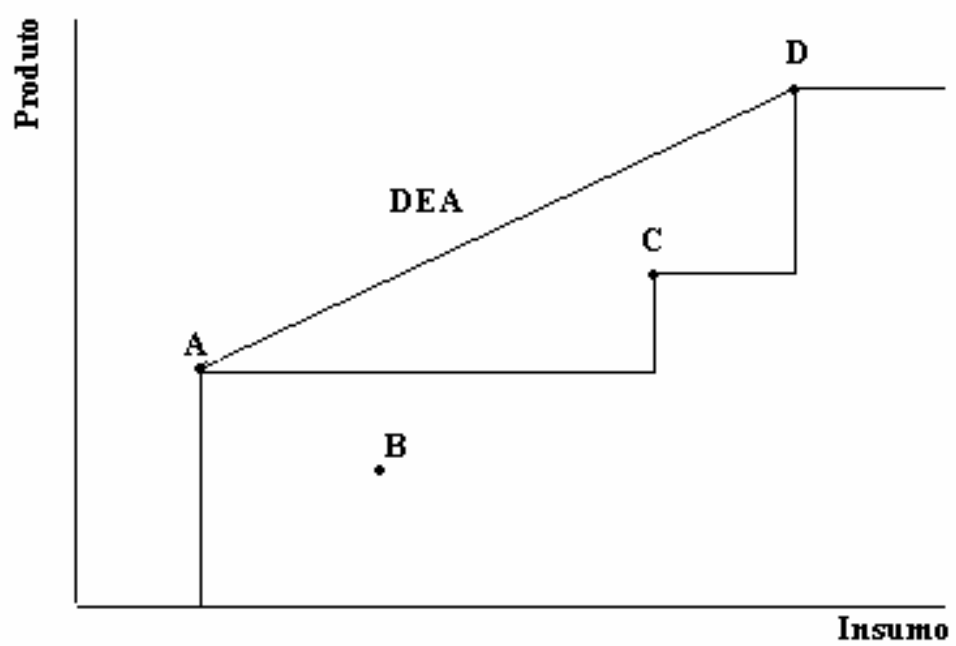

A principal fraqueza de métodos não-paramétricos, como o FDH e o DEA, reside no fato de que esse tipo de análise não distingue o que é ineficiência, do que é erro (perturbação estatística). Em outras palavras, toda a distância entre a observação e a fronteira é considerada ineficiência, o que provavelmente superestima a mesma, uma vez que parte desta distância pode ser explicada por um fator aleatório pontual. Assim, a necessidade de fazer essa distinção, pode ser considerada o principal argumento a favor da utilização de métodos paramétricos.

Uma maneira paramétrica de modelar esse problema foi aplicada por Evans, Tandon, Murray e Lauer, 2000. Os autores utilizaram dados em painel com efeito fixo para distinguir a ineficiência do erro. Em termos gerais a equação estimada por eles foi a seguinte:

$$
\mathrm{Y}_{\mathrm{it}}=\left(\alpha-\mu_{\mathrm{i}}\right)+\mathrm{X}^{\prime}{ }_{\mathrm{it}} \mathrm{B}+\mathrm{v}_{\mathrm{it}}=\alpha_{\mathrm{i}}+\mathrm{X}_{\mathrm{it}} \mathrm{B}+\mathrm{v}_{\mathrm{it}}
$$

Onde: $X_{i t}$ é o vetor de insumos, $v_{i t}$ é o termo de erro com média zero, e $\mu_{i}$ é o efeito específico de cada país, considerado pelos autores como a ineficiência.

Estimando essa equação por OLS, através da inclusão de uma dummy para cada grupo (no estudo em questão seriam Países), encontramos o intercepto de cada um deles $\left(\alpha_{\mathrm{i}}\right)$. Considerando 
o máximo de ai como referência, podemos calcular a ineficiência de cada um da seguinte maneira:

$\mu_{\mathrm{i}}=\operatorname{Max}\left(\alpha_{\mathrm{i}}\right)-\alpha_{\mathrm{i}}$

Apesar de separar o erro da ineficiência, o método descrito acima apresenta algumas inconveniências:

1 - Se existe uma heterogeneidade fixa no tempo entre as unidades produtoras, a mesma será captada pelo $\alpha_{i}$ e, consequentemente, será avaliada como ineficiência.

2 - Essa modelagem não permite que o fator de ineficiência varie no tempo.

3 - Necessita de dados em painel.

As duas primeiras restrições podem ser contornadas através da utilização de uma outra metodologia paramétrica: a fronteira estocástica de produção. Entretanto, no presente trabalho os dados disponíveis não estão em painel, por isso a descrição da metodologia de fronteira estocástica será feita com o foco na sua especificação para cross section.

Antes de apresentar o método de fronteiras estocásticas, é válido descrever, devido às suas semelhanças, o método dos mínimos quadrados corrigidos. O ponto de partida deste modelo, assim como nos de fronteira estocástica, é o score de eficiência do produto, que mede a eficiência técnica do produtor. Ou seja, a eficiência de um produtor $i$ que utiliza $x_{i}$ insumos para produzir $y_{i}$ produtos é medida através da fórmula $\mathrm{TE}_{\mathrm{i}}=\mathrm{y}_{\mathrm{i}} / \mathrm{f}\left(\mathrm{x}_{\mathrm{i}}\right)$, onde $\mathrm{f}\left(\mathrm{x}_{\mathrm{i}}\right)$ é a maior produção possível, ou seja, faz parte da fronteira de possibilidades de produção. Note que quanto mais eficiente for o produtor, mais $\mathrm{y}_{\mathrm{i}}$ se aproximará de $\mathrm{f}\left(\mathrm{x}_{\mathrm{i}}\right)$, e consequentemente TEi se aproximará de 1 . No sentido oposto, uma maior ineficiência implica em um $\mathrm{y}_{\mathrm{i}}$ reduzido em comparação com $\mathrm{f}\left(\mathrm{x}_{\mathrm{i}}\right)$, o que aproxima $\mathrm{TE}_{\mathrm{i}}$ de zero. Assim, $\mathrm{TE}_{\mathrm{i}}$ assume valores entre 0 e 1.

Com um simples rearranjo na fórmula comentada acima, temos: $\mathrm{y}_{\mathrm{i}}=\mathrm{TE}_{\mathrm{i}} * \mathrm{f}\left(\mathrm{x}_{\mathrm{i}}\right)$. Que também pode ser escrita como:

$$
\mathrm{y}_{\mathrm{i}}=\mathrm{TE}_{\mathrm{i}} * \mathrm{f}\left(\mathrm{x}_{\mathrm{i}}, \beta\right)
$$

onde $\mathrm{f}\left(\mathrm{x}_{\mathrm{i}}, \beta\right)$ é a função determinística que define qual é a maior quantidade de produto possível de se obter com a utilização de $\mathrm{x}_{\mathrm{i}}$ insumos e $\beta$ é o vetor de parâmetros da função a ser estimada.

Através de uma transformação logarítmica em 4.1 obtemos a seguinte equação:

$$
\operatorname{Lny}_{i}=\operatorname{Lnf}\left(x_{i}, \beta\right)+\operatorname{LnTE}_{i}
$$

que é equivalente à: $\quad \operatorname{Lny}_{\mathrm{i}}=\operatorname{Lnf}\left(\mathrm{x}_{\mathrm{i}}, \beta\right)-\mathrm{u}_{\mathrm{i}}$

onde $u_{i}=-\operatorname{LnTE}_{i} \geq 0$, que é uma medida de ineficiência técnica, por se aproximar de (1 $\mathrm{TE}_{\mathrm{i}}$ ), ou seja, se aproxima de um menos o coeficiente de eficiência, por isso pode ser considerado uma medida de ineficiência.

Temos então que a eficiência técnica do produtor $i$ é igual a: $\mathrm{TE}_{\mathrm{i}}=\mathrm{e}^{-\mathrm{ui}}$ 
Assumindo que $\mathrm{f}(\mathrm{x})$ seja linear nos logaritmos dos insumos, como por exemplo no caso da função Cobb-Douglas, chegamos ao seguinte modelo de regressão:

$\operatorname{Lny}_{\mathrm{i}}=\beta_{0}+\beta_{1} \operatorname{Lnx}_{1 \mathrm{i}}+\beta_{2} \operatorname{Lnx}_{2 \mathrm{i}}+\ldots+\beta_{\mathrm{n}} \mathrm{LnX}_{\mathrm{ni}}+\varepsilon_{\mathrm{i}}$, sendo $\varepsilon_{\mathrm{i}}=-\mathrm{u}_{\mathrm{i}}$

Admite-se que $\varepsilon_{i}$ possui todas as propriedades de um resíduo de uma regressão linear clássica, exceto média igual a zero (pois $\mathrm{E}\left(\varepsilon_{\mathrm{i}}\right)<0$ ). Então, para ajustar a equação para o formato de uma regressão linear clássica adota-se o seguinte procedimento:

$\operatorname{Lny}_{\mathrm{i}}=\beta_{0}+\mathrm{E}\left(\varepsilon_{\mathrm{i}}\right)+\beta_{1} \operatorname{Lnx}_{1 \mathrm{i}}+\beta_{2} \operatorname{Lnx}_{2 \mathrm{i}}+\ldots+\beta_{\mathrm{n}} \operatorname{Lnx}_{\mathrm{ni}}+\varepsilon_{\mathrm{i}}-\mathrm{E}\left(\varepsilon_{\mathrm{i}}\right)$

ou também: $\operatorname{Lny}_{\mathrm{i}}=\beta_{0}{ }^{*}+\beta_{1} \operatorname{Lnx}_{1 \mathrm{i}}+\beta_{2} \operatorname{Lnx}_{2 \mathrm{i}}+\ldots+\beta_{\mathrm{n}} \operatorname{Lnx}_{\mathrm{ni}}+\varepsilon_{\mathrm{i}}{ }^{*}$

onde: $\beta_{0}{ }^{*}=\beta_{0}+\mathrm{E}\left(\varepsilon_{\mathrm{i}}\right)$; e $\varepsilon_{\mathrm{i}}{ }^{*}=\varepsilon_{\mathrm{i}}-\mathrm{E}\left(\varepsilon_{\mathrm{i}}\right)$

Com isso, $\varepsilon_{i}^{*}$ segue uma distribuição normal, e a equação 4.5 pode ser estimada por OLS de forma consistente. Para que a fronteira envolva todas as observações da amostra, e inclua o produtor mais eficiente, o intercepto é reajustado até que todos os resíduos, exceto o do produtor mais eficiente, sejam negativos.

Na prática o intercepto e o erro corrigido se igualam a:

$$
\begin{aligned}
& \beta_{0}{ }^{\mathrm{COLS}}=\beta_{0}{ }^{*}+\max \left(\varepsilon_{\mathrm{i}}{ }^{*}\right) \\
& \varepsilon_{\mathrm{i}}^{\mathrm{COLS}}=\varepsilon_{\mathrm{i}}{ }^{*}-\max \left(\varepsilon_{\mathrm{i}}^{*}\right)
\end{aligned}
$$

E a estimativa da eficiência do produtor i é: $\mathrm{TE}_{\mathrm{i}}=\mathrm{e}^{\text {eiCOLS }}$

Gráfico 4. Fronteira de Possibilidades de Produção construída por COLS

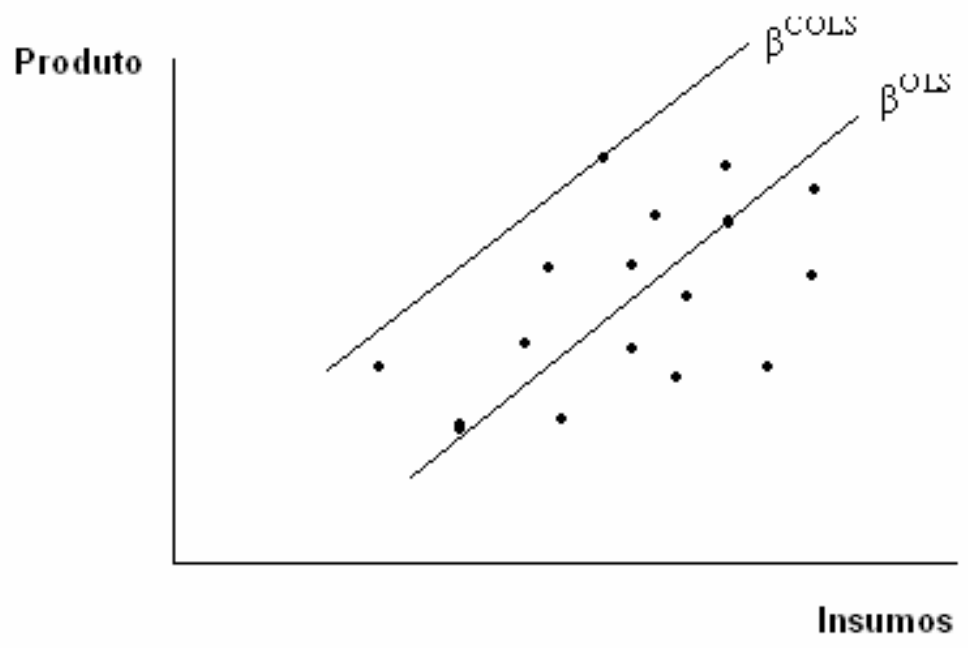

O método de mínimos quadrados corrigidos é uma metodologia paramétrica facilmente aplicável, mas apresenta dois problemas principais:

(i) a estimativa da fronteira feita por esse método não passa de um deslocamento paralelo da reta central estimada pelo método de OLS comum, o que é uma hipótese excessivamente restritiva e forte; e

(ii) a exemplo do que ocorre nos métodos não paramétricos, essa estimativa não separa o que é um choque aleatório comum do que de fato é ineficiência. 
O modelo de fronteira estocástica resolve esses dois problemas. Esse método foi simultaneamente, e independentemente, introduzido por Aigner, Lovell \& Schimidt (ALS, 1977) e Meeusen \& van den Broeck (MB, 1977). Reconhecendo que o produto pode ser afetado também por um choque aleatório, esses modelos reformulam a equação 4.1 da seguinte maneira:

$$
y_{i}=T_{i} * f\left(x_{i}, \beta\right) e^{v i}
$$

onde $\mathrm{e}^{\mathrm{vi}}$ é um termo cuja finalidade é captar o efeito do choque aleatório, permitindo separar o termo de erro do termo de eficiência $\left(\mathrm{TE}_{\mathrm{i}}\right)$.

Como sabemos pela equação $4.3, \mathrm{TE}_{\mathrm{i}}=\mathrm{e}^{-\mathrm{ui}}$, por isso podemos substituir 4.3 na $4.7 \mathrm{e}$ rearranja-la da seguinte maneira: $y_{i}=f\left(x_{i}, \beta\right) e^{\text {vi-ui }}$.

Isolando o termo de eficiência técnica a partir da equação 4.7:

$\mathrm{TE}_{\mathrm{i}}=\mathrm{y}_{\mathrm{i}} / \mathrm{f}\left(\mathrm{x}_{\mathrm{i}}\right) \mathrm{e}^{\mathrm{vi}}$

Esse termo compara o produto do i-ésimo produtor $\left(\mathrm{y}_{\mathrm{i}}\right)$, com o máximo que poderia ser produzido com a utilização dos seus insumos $\left(\mathrm{x}_{\mathrm{i}}\right)$, levando em consideração a existência do termo de erro $\mathrm{e}^{\mathrm{vi}}$.

Admitindo que os parâmetros de $\mathrm{f}\left(\mathrm{x}_{\mathrm{i}}, \beta\right)$ são lineares, e aplicando a transformação logarítmica na equação (4.7) obtemos a estrutura básica da equação que deverá ser estimada:

$\operatorname{Lny}_{\mathrm{i}}=\beta_{0}+\beta_{1} \operatorname{Lnx}_{1 \mathrm{i}}+\beta_{2} \operatorname{Lnx}_{2 \mathrm{i}}+\ldots+\beta_{\mathrm{n}} \operatorname{Lnx}_{\mathrm{ni}}+\operatorname{LnTE}_{\mathrm{i}}+\mathrm{v}_{\mathrm{i}, \text { ou então, fazendo }}$

$\operatorname{LnTE}_{\mathrm{i}}=-\mathrm{u}_{\mathrm{i}} \geq 0$, obtemos Lny $\mathrm{i}_{\mathrm{i}}=\beta_{0}+\beta_{1} \operatorname{Lnx}_{1 \mathrm{i}}+\beta_{2} \operatorname{Lnx}_{2 \mathrm{i}}+\ldots+\beta_{\mathrm{n}} \operatorname{Lnx}_{n \mathrm{i}}+\mathrm{v}_{\mathrm{i}}-\mathrm{u}_{\mathrm{i}}$,

Então, na equação 4.10 fica explícito que a distância de um ponto em relação a fronteira determinística se deve a uma combinação de duas componentes:

$\mathrm{v}_{\mathrm{i}}$, um erro aleatório simétrico, que captura o efeito de qualquer choque aleatório;

$\mathrm{u}_{\mathrm{i}}$, um componente que assume apenas valores não negativos e que capta $\mathrm{o}$ efeito da ineficiência.

Fazendo $\varepsilon_{\mathrm{i}}=\mathrm{v}_{\mathrm{i}}-\mathrm{u}_{\mathrm{i}}$, obtemos Lny $\mathrm{i}_{\mathrm{i}}=\beta_{0}+\beta_{1} \operatorname{Lnx}_{1 \mathrm{i}}+\ldots+\mathrm{B}_{\mathrm{n}} \mathrm{LnX}_{\mathrm{ni}}+\varepsilon_{\mathrm{i}}$

Assumimos que $\mathrm{v}_{\mathrm{i}}$ seja i.i.d. (independente e identicamente distribuído) e que possua distribuição normal, mas $u_{i}$ possui distribuição assimétrica (pois assumi apenas valores não negativos), portanto $\varepsilon_{\mathrm{i}}$ que é composto por esses dois termos, também possui distribuição assimétrica. Geralmente utiliza-se uma distribuição semi-normal para $u_{i}$, então podemos resumir as hipóteses da seguinte maneira:

$$
\begin{aligned}
& \mathrm{H} 1-\mathrm{v}_{\mathrm{i}} \sim \operatorname{iid~N}\left(0 ; \sigma_{\mathrm{v}}^{2}\right) \\
& \mathrm{H} 2-\mathrm{u}_{\mathrm{i}} \sim \text { iid } \mathrm{N}^{+}\left(0 ; \sigma^{2} \mathrm{u}\right) \text {, que é a semi-normal não negativa } \\
& \mathrm{H} 3-\mathrm{u}_{\mathrm{i}} \text { é independente de } \mathrm{v}_{\mathrm{i}} \\
& \mathrm{H} 4-\mathrm{v}_{\mathrm{i}} \text { e } \mathrm{u}_{\mathrm{i}} \text { são independentes de } \mathrm{x}_{\mathrm{i}}
\end{aligned}
$$


Após assumir as hipóteses sobre as distribuições, através do método de máxima verossimilhança estimamos os valores de $\sigma_{v}^{2}, \sigma^{2} u$ e dos parâmetros $\beta$.

Vale citar que para facilitar a maximização da função de máxima verossimilhança, e para tornar seus parâmetros mais intuitivos, Batesse e Cora (1977) reparametrizaram a função em termos de $\sigma^{2}=\sigma_{\mathrm{v}}^{2}+\sigma^{2} \mathrm{u}$ e de $\lambda=\sigma_{\mathrm{ut}} / \sigma^{2}$ (que por construção oscila entre 0 e 1 ). Nota-se que se $\lambda=0, \sigma^{2}=\sigma^{2}{ }_{\mathrm{v}}$ e, portanto, não existe ineficiência uma vez que toda a distância em relação a fronteira se deve a choques aleatórios. Já se $\lambda=1, \sigma^{2}=\sigma^{2} u$ e o desvio da fronteira se deve inteiramente à ineficiência.

Após estimar os parâmetros é necessário separar a ineficiência do erro, desagregando $\varepsilon_{\mathrm{i}}$. Para tanto, Jondrow et. al (Kumbhakar \& Lovell, 2000) sugeriram estimar $\mathrm{u}_{\mathrm{i}}$ como sendo a média (ou a moda) da seguinte função de distribuição condicionada:

$$
f(u / \varepsilon)=\frac{f(u, \varepsilon)}{f(\varepsilon)}=\frac{1}{\sqrt{2 \pi} \sigma_{*}} e^{\left[-\frac{\left(\mu-\mu_{*}\right)^{2}}{2 \sigma_{*}^{2}}\right] /\left[1-\Phi\left(\frac{\mu_{*}}{\sigma_{*}}\right)\right]} \Rightarrow u_{i} \mid \varepsilon_{i} \sim N^{+}\left(\mu_{*}, \sigma_{*}\right)
$$

Onde: $\mu_{*}=-\frac{\varepsilon \sigma_{u}^{2}}{\sigma^{2}}$ e $\sigma_{*}^{2}=\frac{\sigma_{u}^{2} \sigma_{v}^{2}}{\sigma^{2}}$

e $\emptyset$ e $\Phi$ são, respectivamente, a função densidade e a função de distribuição acumulada de uma normal padrão.

Então, a estimativa pontual de $\mathrm{u}_{\mathrm{i}}$ é definida pela média de $f(u / \varepsilon)$ :

$$
\hat{u}_{i}=E\left(u_{i} / \varepsilon_{i}\right)=\mu_{*_{i}}+\sigma_{*}\left[\frac{\phi\left(-\mu_{*_{i}} / \sigma_{*}\right)}{1-\Phi\left(-\mu_{*_{i}} / \sigma_{*}\right)}\right]=\sigma_{*}\left[\frac{\phi\left(\varepsilon_{i} \lambda / \sigma\right)}{1-\Phi\left(\varepsilon_{i} \lambda / \sigma\right)}-\frac{\varepsilon_{i} \lambda}{\sigma}\right]
$$

Dessa forma obtemos então a estimativa de $u_{i}$, e consequentemente, lembrando que $\mathrm{u}_{\mathrm{i}}=-\mathrm{LnTE}_{\mathrm{i}}$, obtemos a estimativa da ineficiência do produtor $\mathrm{i}$ através da fórmula:

$$
\mathrm{TE}_{\mathrm{i}}=\mathrm{e}^{-\hat{\mathrm{u} i}}
$$

Uma maneira de levar em consideração a heterogeneidade dos grupos seria substituir a média de $u_{i}$ (considerada igual a zero na primeira especificação) por:

$\mathrm{E}\left[\mathrm{u}_{\mathrm{i}}\right]=\mathrm{u}_{\mathrm{i}}=\delta_{0}+\mathrm{h}_{\mathrm{i}}{ }_{\mathrm{i}} \delta$, onde $\mathrm{h}_{\mathrm{i}}$ é um vetor de variáveis que capturam as heterogeneidades de cada grupo.

Conforme demonstrado, para a estimação do método de fronteiras estocásticas é necessário assumir hipóteses distributivas sobre o termo de ineficiência. Nesse sentido, diversas distribuições assimétricas têm sido utilizadas, sendo as mais populares a distribuição semi-normal (utilizada no modelo acima), distribuição normal-truncada, distribuição exponencial e distribuição gama. Entretanto, diferentes autores, fazendo hipóteses sobre distribuições diferentes, chegaram a resultados muito similares, sugerindo que essas restrições são pequenas quando comparadas às 
desvantagens de se utilizar um método não-paramétrico ou um COLS. Além disso, como a escolha da distribuição de u tem um impacto bastante reduzido sobre os resultados, usualmente é utilizada a distribuição semi-normal, observando o principio da parcimônia, devido a sua relativa simplicidade.

Sendo assim, pelos motivos expostos acima, o método de análise de fronteiras estocásticas foi o instrumental escolhido para o presente estudo.

Uma outra abordagem de análise paramétrica que pode ser aplicada na avaliação da eficiência de gastos públicos é a estimativa da fronteira estocástica de custos, metodologia muito similar à análise de fronteira estocástica de produção, mas, como o próprio nome sugere, com o foco nos custos. Através desse instrumental pode ser feita uma estimativa do total de recursos desperdiçados em algum período considerado. Intuitivamente a idéia é medir a ineficiência do produtor i através da comparação do total de gasto desse produtor (aqui denominado por $\mathrm{E}_{\mathrm{i}}$ ) com o gasto mínimo com o qual seria possível produzir $\mathrm{y}_{\mathrm{i}}$. A fronteira de custos estima esse gasto mínimo para a produção de $\mathrm{y}_{\mathrm{i}}$, e mais uma vez a medida de ineficiência é obtida a partir da distância a essa fronteira - quanto mais distante (mas dessa vez para acima) da fronteira o ponto estiver, maior está sendo o desperdício de recursos e, consequentemente, maior a ineficiência.

Basicamente a transformação do modelo de fronteira estocástica de produção para o modelo de custo se dá através da troca do sinal do erro $u_{i}$. Isso porque aqui a ineficiência não significa estar abaixo da fronteira, mas sim acima dela. A equação básica do modelo é a seguinte: $\mathrm{E}_{\mathrm{i}}=\mathrm{C}\left(\mathrm{y}_{\mathrm{i}}, \mathrm{w}_{\mathrm{i}}, \beta\right) \mathrm{e}^{\mathrm{vi}+\mathrm{ui}}$

Onde: $\mathrm{w}_{\mathrm{i}}$ é o vetor de preços dos insumos, $\beta$ é o vetor de parâmetros de tecnologia de produção, $\mathrm{y}_{\mathrm{i}}$ é o vetor de produtos, $\mathrm{x}_{\mathrm{i}}$ é o vetor de insumos, $\mathrm{E}_{\mathrm{i}}=\mathrm{w}_{\mathrm{i}}^{\mathrm{T}} \mathrm{x}_{\mathrm{i}}$ é o custo total incorrido pelo i-ésimo produtor, e $\mathrm{C}\left(\mathrm{y}_{\mathrm{i}}, \mathrm{w}_{\mathrm{i}}, \beta\right) \mathrm{e}^{\mathrm{vi}}$ é a fronteira estocástica de custo. Da mesma forma que no modelo anterior, $v_{i}$ captura o efeito de choques aleatórios e $u_{i}$ mede a ineficiência, ambas com características idênticas às do modelo anterior. A medida de eficiência é a razão entre o menor custo possível, estimado pela fronteira de custo, e $\mathrm{E}_{\mathrm{i}}$, o custo do i-ésimo produtor:

$\mathrm{CE}_{\mathrm{i}}=\mathrm{C}\left(\mathrm{y}_{\mathrm{i}}, \mathrm{w}_{\mathrm{i}}, \beta\right) \mathrm{e}^{\mathrm{vi}} / \mathrm{E}_{\mathrm{i}}$

O que equivale a dizer que $\mathrm{CE}_{\mathrm{i}}=\mathrm{e}^{\text {-ui }}$

Assumindo uma função Cobb-Douglas, chegamos a seguinte especificação:

$\mathrm{LnE}_{\mathrm{i}=} \beta_{0}+\beta_{\mathrm{y}} \operatorname{Lny}+\beta_{1} \operatorname{Lnw}_{1 \mathrm{i}}+\ldots . .+\beta_{\mathrm{n}} \mathrm{Lnw}_{\mathrm{ni}}+\mathrm{v}_{\mathrm{i}}+\mathrm{u}_{\mathrm{i}}$

Sendo $u_{i}=-\operatorname{LnCE}_{i} \geq 0$

Antes de estimar o modelo deve-se impor a restrição de que a soma dos parâmetros de tecnologia de produção se iguale a 1 , ou seja: $\beta_{k}=1-\sum_{\substack{j=1 \\ j \neq k}}^{n} \beta_{j}$

Assumindo essa restrição o modelo resultante é: 


$$
\operatorname{Ln} \frac{E_{i}}{W_{k i}}=\beta_{0}+\beta_{y} \operatorname{Lny}_{i}+\sum_{\substack{j=1 \\ j \neq k}}^{n} \beta_{j} \frac{W_{j i}}{W_{k i}}+v_{i}+u_{i}
$$

A despeito de algumas mudanças de sinal, esse modelo pode ser estimado da mesma forma que o modelo de fronteira estocástica de produção, estimando os parâmetros por máxima verossimilhança e posteriormente recorrendo ao procedimento de Jondrow et al para decompor o erro em choque aleatório e em ineficiência, obtendo no final das contas a seguinte estimativa para a ineficiência: $\mathrm{CE}_{\mathrm{i}}=\mathrm{e}^{\text {-ûi }}$

Por fim, é importante frisar que com a mesma adaptação que a feita no modelo de fronteira de produção, o modelo de custos permite o controle da heterogeneidade.

Apesar de ser um instrumental bastante útil e complementar a fronteira estocástica de produção, o modelo de fronteira estocástica de custos infelizmente não pode ser utilizado nesse trabalho, uma vez que os preços dos insumos não são conhecidos.

\section{2 - AVALIANDO O SISTEMA DE SAÚDE DOS MUNICÍPIOS BRASILEIROS}

A principal esfera administrativa avaliada nesse trabalho é o município. A despeito da dificuldade prática de analisar o grande número de municípios brasileiros, a lógica do atual modelo de atenção a saúde no Brasil (SUS) - no qual a descentralização é uma das diretrizes principais - torna praticamente obrigatória a utilização dos municípios como unidade de análise. Ademais, conforme já foi comentado na seção sobre gastos desse trabalho, apesar de financiarem com recursos próprios aproximadamente $25 \%$ dos investimentos públicos totais em saúde, a participação municipal no total de recursos executados é bem maior, uma vez que os municípios recebem transferências de recursos dos estados e da União.

Definida a unidade de análise, temos agora que definir uma medida para comparar a qualidade da saúde entre elas, que será utilizada como produto na estimativa da fronteira de possibilidades de produção.

Nesse sentido, as duas principais medidas que usualmente aparecem nos estudos sobre saúde são a expectativa de vida e a taxa de mortalidade infantil. Apesar da enorme importância desses indicadores para o bem estar da população, ambos apresentam os mesmos problemas: o primeiro é que são medidas que avaliam a longevidade média da população, mas não as condições de saúde dos indivíduos enquanto vivos; e o segundo é que não colaboram para diagnosticar as principais causas de doenças causadoras da perda de bem estar.

Para resolver o primeiro problema a expectativa de vida ajustada seria ideal. Contudo, para a construção desse indicador seriam necessários dados confiáveis do estado de saúde dos indivíduos vivos. Os indicadores de taxa de incidências de doenças poderiam ser uma boa base 
para a construção desse índice, porém, esses indicadores apresentam índices de sub-registro elevados, principalmente nas regiões mais carentes, onde muitas vezes, por falta de atendimento, a doença não chega nem a ser diagnosticada. Assim, a utilização dos mesmos geraria um viés de amostragem.

Uma alternativa adotada em alguns estudos é a construção do índice de anos de vida perdidos (AVP), que indica o número de anos que deixaram de ser vividos em virtude de uma morte precoce. Esse indicador também não avalia a qualidade da saúde dos indivíduos em vida. Contribui, contudo, para diagnosticar as principais doenças causadoras de perda de bem estar, uma vez que mensura aquelas que têm maior impacto sobre a expectativa de vida dos indivíduos e que por isso devem ser combatidas com maior rigor. Sendo assim, o AVP pode ser um importante balizador para o direcionamento dos recursos de saúde. A fórmula básica desse indicador é a seguinte:

$$
\text { AVPjt }=\sum_{i=0}^{L} \frac{E(i) * d i j t}{\text { Pit }} \quad \text {,onde: }
$$

$\mathrm{AVP}_{\mathrm{jt}}=$ Anos de vida perdidos no período t devido a causa $\mathrm{j}$;

$\mathrm{L}=$ idade máxima considerada na amostra

$\mathrm{E}(\mathrm{i})=$ Esperança de vida dado que o indivíduo atingiu a idade $\mathrm{i}$

$\mathrm{d}_{\mathrm{ijt}}=$ número de indivíduos da idade $\mathrm{i}$, que faleceram no período $\mathrm{t}$, devido a causa $\mathrm{j}$

$\mathrm{P}_{\text {its }}=$ número total de indivíduos com idade i no período $\mathrm{t}$

Entretanto, apesar de servir como guia para direcionamento de recursos, o AVP também não poderá ser utilizado para a construção da fronteira estocástica proposta nesse trabalho. Isso pela mesma razão pela qual a expectativa de vida ajustada não pode ser construída: o sub-registro em algumas localidades, principalmente no Norte e no Nordeste, é muito elevado, de tal forma que falta informação confiável para que os dados sejam comparáveis entre os municípios.

Com a exclusão da possibilidade de utilização dos dois principais indicadores de qualidade de saúde usualmente utilizados na literatura (a expectativa de vida ajustada e o índice de anos de vida perdidos), restou apenas a alternativa de utilizar um indicador mais simples, mas de cobertura mais ampla. Para tanto, foi construído um índice de desempenho que resume quatro índices de importância indiscutível para a qualidade de saúde da população, que guardam relação considerável com a estrutura ofertada em cada município, e de razoável confiança:

(i) Expectativa de vida ao nascer;

(ii) Mortalidade até 1 ano de idade;

(iii) Mortalidade até 5 anos de idade;

(iv) Probabilidade de atingir os 60 anos de idade. 
Antes de agregar o índice geral, as quatro variáveis foram normalizadas, para que ficassem representadas por valores entre 0 e 1, pela seguinte fórmula tradicional de normalização:

$$
X i=\frac{X i-M I N(X i)}{M A X(X i)-M I N(X i)}
$$

Depois de normalizadas, para que pudessem ser comparadas com as demais, as duas variáveis de mortalidade foram ajustadas, de forma que o valor considerado foi 1 - valor normalizado. Isso porque quanto maior a mortalidade pior é o desempenho dos municípios, e como quanto maior a mortalidade mais a sua normalização se aproxima de 1, mais o seu valor ajustado (1 - valor normalizado) se aproximará de 0 , o que implica em um índice de desempenho ruim (quanto maior o índice melhor é o desempenho). O peso considerado para que as variáveis fossem agregadas foi igual para todas, assim a equação que resume o índice de desempenho é a seguinte ${ }^{16}$ :

ID $=0,25 *($ exp_vida $)+0,25 *(1$ - mort_infant $)+0,25 *(1$ - mort_5anos $)+0,25 *($ prob60 $)$

A escolha da construção do índice de desempenho com ponderação idêntica para todas as variáveis se deve ao fato de que não existe um consenso na literatura sobre qual seria a variável mais apropriada (ou que deveria receber maior importância) para avaliar a qualidade da saúde da população, ao menos quando a intenção é medir a eficiência do sistema de saúde. Cada variável tem vantagens e desvantagens - a mortalidade infantil, por exemplo, depende bastante de um sistema de saúde eficaz, contudo afeta apenas uma parcela restrita da população (além de estar muito relacionada às condições de saneamento básico), sendo uma medida incompleta, portanto, da qualidade da saúde como um todo; já a expectativa de vida é mais geral, porém é muito afetada por causas externas como violência ou freqüência de acidentes, além de levar mais tempo para reagir a mudanças de gestão em saúde.

Apesar de ser útil na comparação da qualidade de saúde como um todo, e ter sido algumas vezes citado ao longo do restante desse trabalho, não foi gerada uma fronteira estocástica com o indicador de desempenho como produto - isso porque algumas variáveis apresentaram sinais contra-intuitivos, e os parâmetros não mostravam robustez em relação a diferentes especificações escolhidas, de modo que a alternativa preferida foi estimar as fronteiras para cada um dos indicadores de saúde isoladamente, com o intuito de testar a robustez dos resultados para diferentes medidas de qualidade, avaliando se esses resultados são similares independentemente da decisão da variável de produto.

Após definições a respeito do produto, passemos a uma discussão acerca dos insumos que serão incluídos. O principal insumo que será utilizado na construção da fronteira de possibilidades

\footnotetext{
${ }^{16}$ A metodologia de construção desse índice foi inspirada no indicador de vulnerabilidade dos municípios utilizado por Pires e Oliveira Neto (2006).
} 
de produção será o total de gastos públicos per capita com saúde executados pelos municípios ${ }^{17}$. Como o investimento em saúde leva algum tempo para se refletir em melhores condições de saúde da população, serão considerados os gastos públicos municipais per capita do período de quatro anos finalizado em 2000 (ano de referência do Censo). Os municípios que não declararam os gastos para algum desses quatro anos foram excluídos da amostra, e com isso sobraram 3421 municípios. Além disso, foram excluídos também os municípios que declaram gastos inferiores a $\mathrm{R} \$ 5,0$ per capita, uma vez que um valor inferior a esse é um indício grande de algum erro dos dados. Após esse último tratamento restaram 3370 municípios (60,5\% do total). Para tornar os valores financeiros comparáveis, antes de serem somados, os dados de gastos foram deflacionados pelo IPCA, de modo a serem expressos a preços constantes do ano de 2000.

Também serão considerados como insumos os gastos com saneamento. Isso se justifica pois é consensual nos estudos de economia da saúde a relevância do impacto de boas condições de saneamento sobre as condições de saúde da população. Além disso, não parece exagerado supor que a principal finalidade dos gastos com saneamento é a melhora da qualidade de saúde da população. Ademais, um motivo prático torna obrigatória a inclusão dessa variável como insumo: no período que será analisado nesse trabalho, no banco de dados do sistema de informações financeiras do tesouro nacional (fonte desses dados) não há distinção entre os gastos com saúde e com saneamento. Dessa forma, na prática, ambos terão que ser considerados conjuntamente, como se fossem apenas um tipo de insumo.

Além dos gastos municipais, diversas outras variáveis de controle foram incluídas no modelo. Vale dizer que essas variáveis poderiam ter sido utilizadas para modelar a média da ineficiência, ou seja, tratadas apenas como heterogeneidade ao invés de insumos. Contudo, a opção aqui adotada foi tratar todas como insumos, o que na prática significa permitir que essas variáveis influenciem no formato da fronteira de produção ao invés de apenas explicar a distância dos pontos em relação a mesma. Essas variáveis de controle testadas no modelo podem ser divididas em quatro grupos distintos: (i) outras fontes de gastos; (ii) habitação; (iii) educação; e (iv) causas externas.

Grupo (i) - Apesar dos gastos executados pelos municípios serem preponderantes, devemos considerar também os gastos dos estados, caso contrário estaríamos viesando a análise. Para tanto foram extraídos do Datasus os gastos com internação em hospitais de administração estadual abertos por local de residência dos pacientes. Com a utilização dessa variável, é possível ter uma proxy de quanto de recursos estaduais os habitantes de cada município consomem (sendo

\footnotetext{
${ }^{17}$ Os dados de gastos públicos que serão utilizados nesse trabalho estão disponíveis no site do Tesouro Nacional, no SIAF (Sistema de Administração Financeira)
} 
eles do próprio Estado ou de algum outro Estado). Também para essa variável serão considerados os gastos deflacionados entre 1997 e 2000.

Outra consideração que deverá ser feita é a "importação" de pacientes, uma vez que muitas vezes os indivíduos procuram atendimento em municípios diferentes do local da sua residência. Com o intuito de obter uma proxy dessa variável, foi construído um indicador de "importação" através do quociente entre o total de gasto com procedimentos hospitalares em hospitais municipais em um município dividido pelo total de gastos com procedimentos hospitalares em hospitais municipais com a população desse município. A idéia é que quanto maior o gasto dentro de um município em relação ao gasto com a população desse município, maior é o gasto desse município com indivíduos de outras localidades, portanto, maior é a "importação" de pacientes.

Por fim, como não existem dados anuais para o período de referência de gastos privados em saúde nos municípios, serão incluídas variáveis entre os controles de heterogeneidade que medem a renda per capita, a desigualdade de renda e o porcentual de pessoas abaixo da linha de pobreza, variáveis que são correlacionadas com o montante total de gastos privados com saúde.

Grupo (ii) - Nesse grupo serão testadas: o porcentual de população urbana; porcentual de domicílio com água encanada; domicílios com energia elétrica; domicílios com serviços de coleta de lixo; domicílios subnormais ${ }^{18}$; e distância de cada município à capital estadual.

Grupo (iii) - Para medir o grau de escolaridade serão consideradas: analfabetismo entre pessoas de 15 anos ou mais e média de anos de estudo entre as pessoas com mais de 25 anos. Para ilustrar a importância da educação na saúde da população, vale citar Motta e Mendonça (2005) que elaboraram um interessante estudo divulgado pelo IPEA que ponderou o número de mortes que poderiam ser evitadas com a ampliação de serviços de saúde, educação e saneamento, pelo custo de cada um desses serviços, e chegaram a conclusão de que o meio mais barato de reduzir a mortalidade é ampliando os serviços de educação (reduzindo o analfabetismo). Quanto ao gasto com saúde e com saneamento, esse estudo do IPEA indica que o custo benefício dos dois é similar, com ligeira vantagem para os gastos com saúde.

Grupo (iv) - Por fim, as variáveis utilizadas para mensurar o impacto de causas externas serão: taxa de vítimas de acidente de trânsito; taxa de homicídios; e taxa de suicídios.

Além das variáveis incluídas nesses quatro grupos enumerados acima, o tamanho da população também será testado, uma vez que as variáveis de gastos foram colocadas em termos per capita, mas pode haver algum ganho de escala, de tal forma que dois municípios com o mesmo nível de gasto per capita apresentem resultados diferentes que podem ser em parte

\footnotetext{
${ }^{18}$ Percentual de pessoas que vivem em domicílios localizados em aglomerados subnormais. O que caracteriza um aglomerado subnormal é a ocupação desordenada e, quando de sua implementação, não haver a posse da terra ou o título de propriedade. É também designado por "assentamento informal", como por exemplo mocambo, alagado, barranco de rio, etc. Para obter mais informações metodológicas acesse
} 
explicados pelo montante total do gasto (ou seja, pelo gasto per capita multiplicado pelo tamanho da população).

Por fim, após estimar a ineficiência dos municípios serão testadas variáveis que possivelmente expliquem essa ineficiência, sendo elas: (i) o porcentual da população assistida pelo Programa de Saúde da Família e Agentes Comunitários da Saúde; (ii) participação dos leitos privados que atendem ao SUS em relação ao total de leitos incluindo os localizados em hospitais públicos e em particulares que atendem ao SUS; (iii) participação das transferências no total das receitas dos municípios; (iv) porcentual de enfermeiros com ensino superior; e (v) relação entre capital e trabalho na produção de saúde.

Após as estimativas econométricas, para melhor visualizar os resultados, os municípios foram divididos de acordo com o tamanho da sua população - até 10 mil habitantes; entre 10 mil e 50 mil habitantes; e acima de 50 mil habitantes - e também de acordo com o estado ao qual pertencem.

\section{3 - ESTATÍSTICAS DESCRITIVAS}

Os indicadores de qualidade de saúde da população já foram comentados no capítulo anterior, contudo, também é importante fazer uma breve descrição das demais variáveis, para termos uma idéia completa da amostra considerada. Para isso, a tabela 18 resume as principais variáveis consideradas nesse trabalho. Cada uma delas está acompanhada do seu valor máximo e mínimo, discriminando a localidade onde seus valores extremos se encontram, e a média amostral ponderada pela população.

Quanto ao indicador de desempenho, São Caetano apresenta o melhor resultado, o que faz sentido uma vez que esse município lidera todos os indicadores considerados. O pior desempenho é do município de Manari (PE). Vale ressaltar que o município de Centro de Guilherme (no Maranhão), que é o pior em três dos quatro critérios de qualidade de saúde, não está incluído na amostra final, uma vez que não discriminou os gastos nos quatro anos considerados.

O município com o maior valor médio de gastos com saúde e saneamento per capita no período de 1997 a 2000 foi Goiandira (GO), com R\$ 835,3 por habitante, e o menor foi Sapé (PB), com R\$ 10,8 por habitante, sendo que a média ponderada desses gastos na amostra foi de $\mathrm{R} \$ 95,6$ por habitante. Os gastos com procedimentos hospitalares em estabelecimentos estaduais são bem menores do que esses, ficando em média em R\$17,2 per capita. O município que mais "importa" pacientes nos hospitais de gestão municipal é Nova Lima em Minas Gerais, onde os gastos totais com procedimentos hospitalares realizados em seus hospitais municipais é 7,6 vezes 
maior do que os gastos com procedimentos hospitalares com residentes dessa cidade, ou seja, o município gasta em procedimentos hospitalares 7,6 vezes mais do que seus habitantes utilizam.

A renda per capita média da amostra é de $\mathrm{R} \$ 318,8$ ao mês (a preços de agosto de 2000), e a renda por habitante mais baixa é de Manari (PE, o mesmo com o pior desempenho de qualidade da saúde) com R \$ 30,4 mensais. Já o porcentual médio da população abaixo da linha de pobreza é de $27,9 \%{ }^{19}$, sendo o menor valor em São Caetano do Sul (SP), o que pode explicar parte do seu excelente desempenho nos indicadores de saúde.

É importante frisar que os dados dessa tabela devem ser lidos com algum cuidado, no sentido de que para algumas variáveis o município que está discriminado como máximo ou como mínimo, é apenas um exemplo entre outros que apresentam valor similar. Nos gastos com procedimentos hospitalares em estabelecimentos com gestão estadual, por exemplo, São Gonçalo do Gurguéia (PI) aparece com o menor valor $(0,0)$, mas existem na amostra diversos outros municípios que também apresentam esse valor igual a zero, sendo esse município apenas um exemplo. Isso acontece principalmente nas variáveis cujo mínimo é zero (uma vez que há uma concentração de zeros) ou em variáveis expressas em porcentual e que atingem 100\%. Esse é o caso também das variáveis referentes à habitação: no caso do porcentual de domicílios com água encanada e banheiro, por exemplo, existe mais de um município tanto com 100\% de cobertura como com $0 \%$. Vale notar que, na média, $83,5 \%$ dos domicílios localizados nos municípios incluídos nessa amostra têm acesso a água encanada e a banheiro; $96 \%$ deles tem energia elétrica; e 92,3\% são atendidos por serviços de coleta de lixo.

Ainda em relação às condições de habitação, outra variável de interesse é o porcentual de população que habita domicílios em condições subnormais (o que basicamente equivale a favelas), que atinge 40,1\% em Rio das Ostras (RJ), valor bastante acima da média amostral que é de $4,0 \%$.

Jordão, localizado no Acre, apresenta o pior desempenho nas duas variáveis relacionadas à educação, com apenas 39,3\% da população maior de 15 anos alfabetizada, e uma média de 1 ano de estudo entre as pessoas com mais de 25 anos. A média ponderada na amostra para essas duas variáveis é, respectivamente, de $88,2 \%$ e 6 anos de escolaridade.

Em relação às causas externas de mortalidade, as médias amostrais são: 18,1 vítimas de acidente de trânsito, 28,3 homicídios, e 4,5 suicídios (os três expressos em termos de valor por 100.000 habitantes).

Quanto a variável de penetração dos programas de Saúde da Família e de Agentes Comunitários da Saúde, vale ressaltar que para alguns municípios a cobertura estimada passou de

\footnotetext{
${ }^{19}$ Considerou-se abaixo da linha de pobreza a população com renda abaixo de $\mathrm{R} \$ 75,50$ que equivale a meio salário mínimo vigente em 2000.
} 
$100 \%$, o que sugere que pode ter havido dupla contagem no caso de pessoas inscritas em mais de um programa, ou mesmo alguns erros de contabilização. A média amostral da penetração desses programas é de $31,9 \%$ da população. Entre as demais variáveis vale citar que: o porcentual médio de enfermeiros com curso superior é de $13,6 \%$; de pessoal da saúde como um todo é de 35,3\%; as transferência do SUS equivalem em média a $6,4 \%$ das receitas dos municípios.

Tabela 18. Descriçäo das principais variáveis utilizadas (referência ano 2000) - Amostra de 3370 municípios

\begin{tabular}{|c|c|c|c|c|c|}
\hline Variável & máximo & localização do máximo & mínimo & localizaçäo do minimo & $\begin{array}{l}\text { Média } \\
\text { pond }\end{array}$ \\
\hline População - Pessoa & 10434252 & São Paulo (SP) & 795 & Borá (SP) & \\
\hline Esperança de vida ao nascer - Ano & 78,2 & Sẫo Caetano do Sul (SP) & 55,2 & Axixá do Tocantins (TO) & 69,8 \\
\hline Mortalidade infantil (por mil nascidos vivos) até 1 ano & 109,7 & Manari (PE) & 5,4 & São Caetano do Sul (SP) & 25,4 \\
\hline Mortalidade até cinco anos de idade (por mil nascidos vivos) & 131,9 & Axixá do Tocantins (TO) & 6,2 & São Caetano do Sul (SP) & 31,7 \\
\hline Probabilidade de sobrevivência até 60 anos - (\%) & 93,1 & São Caetano do Sul (SP) & 54,6 & Poço das Trincheiras (AL) & 79,7 \\
\hline Índice de desempenho & 100,0 & São Caetano do Sul (SP) & 5,5 & Manari (PE) & 73,1 \\
\hline Despesas por função - saúde e saneamento - municipal - $\mathrm{R} \$$ per capita & 835,3 & Goiandira (GO) & 10,8 & Sapé (PB) & 95,6 \\
\hline Gasto $\mathrm{c} /$ proced. hospitalares em estabelec. estaduais (per capita) ${ }^{\star}$ & 129,7 & Divinolândia (SP) & 0,0 & São Gonçalo do Gurguéia (PI) & 17,2 \\
\hline Proxy de importação de pacientes nos hospitais municipais* & 7,6 & Nova Lima (MG) & 0,0 & Acrelândia (AC) & 0,5 \\
\hline Renda per capita - $\mathrm{R} \$$ de 2000 & 954,6 & Águas de Sẫo Pedro (SP) & 30,4 & Manari (PE) & 318,8 \\
\hline Renda - desigualdade - índice de Gini & 0,8 & Santa Vitória do Palmar (RS) & 0,4 & Barra do Choça (BA) & 0,6 \\
\hline Pobreza - pessoas pobres $(\mathrm{PO})$ - (\%) & 91,5 & Jordão (AC) & 2,9 & Sẫo Caetano do Sul (SP) & 27,9 \\
\hline Pop Urbana (\%) & 100,0 & Eusébio (CE) & 0,0 & Nova Ramada (RS) & 84,6 \\
\hline Domicílios - com água encanada e banheiro - pessoas - (\%) & 100,0 & Águas de São Pedro (SP) & 0,0 & Jordäo $(\mathrm{AC})$ & 83,5 \\
\hline Domicílios - com água encanada - pessoas - (\%) & 100,0 & Inajá (PR) & 0,3 & Santo André (PB) & 86,9 \\
\hline Domicílios - com energia elétrica - pessoas - (\%) & 100,0 & Indaiatuba (SP) & 16,8 & Jordẫo (AC) & 96,0 \\
\hline Domicílios - com serviço de coleta de lixo - pessoas - (\%) & 100,0 & Cipó (BA) & 0,0 & Nova Ramada (RS) & 92,3 \\
\hline Domicílios - subnormais - pessoas - $(\%)$ & 40,1 & Rio das Ostras (RJ) & 0,0 & Cruzeiro do Sul (AC) & 4,0 \\
\hline Distância à capital para os municíp. & 761,4 & Luciára (MT) & 0,0 & Rio Branco (AC) & 146,6 \\
\hline Alfabetismo - pessoas 15 anos e mais - (\%) & 99,1 & Săo Joẩo do Oeste (SC) & 39,3 & Jordão (AC) & 88,2 \\
\hline Anos de estudo - média - pessoas 25 anos e mais - Ano & 9,1 & Vitória (ES) & 1,0 & Jordẫo $(\mathrm{AC})$ & 6,0 \\
\hline Taxa de vítimas de acidentes de trânsito(100.000 Habitantes) & 339,8 & Santa Cruz da Conceiçẫo (SP) & 0,0 & Acrelândia (AC) & 18,1 \\
\hline Taxa de homicídios(100.000 Habitantes) & 122,9 & Diadema (SP) & 0,0 & Epitaciolândia (AC) & 28,3 \\
\hline Taxa de suicídios(100.000 Habitantes) & 157,7 & Ipueira (RN) & 0,0 & Acrelândia (AC) & 4,5 \\
\hline Enfermeiros residentes com curso superior - (\%) & 99,9 & Prudentópolis (PR) & 0,0 & Campo Formoso (BA) & 13,6 \\
\hline Pessoas cadastradas no PSF ou PACS (\% total população) & 251,3 & Itaóca (SP) & 0,0 & Jordẫo (AC) & 31,9 \\
\hline Particiação dos leitos privados que atendem o SUS (\%) & 100,0 & Palmeira dos Índios (AL) & 0,0 & Acrelândia (AC) & 59,5 \\
\hline Transf SUS (\% da receita total) & 35,8 & Porto Franco (MA) & 0,0 & Acrelândia (AC) & 6,4 \\
\hline Outras Transf (\% da receita total) & 100,0 & Pedro Velho (RN) & 18,6 & Rio das Ostras (RJ) & 62,3 \\
\hline Trans Total ( $\%$ da receita total $)$ & 100,0 & Pedro Velho (RN) & 19,1 & Rio das Ostras (RJ) & 68,7 \\
\hline Pessoal da saúde com curso superior & 100,0 & Álvaro de Carvalho (SP) & 0,0 & Cristópolis (BA) & 35,3 \\
\hline
\end{tabular}

Fontes: IPEA, Datasus, IBGE e Finbra. *Média entre 1998 a 2000. " Média entre 1997 e 2000 . Média amostral ponderada pela populaçẵo

Apenas para ilustrar a correlação de algumas variáveis representativas selecionadas, foram estimadas 3 equações por OLS. A primeira tem como variável explicada o Índice de Desempenho elaborado nesse trabalho, a posterior a taxa de mortalidade infantil (por 100.000 habitantes) e a terceira a expectativa de vida.

A primeira equação mostra que o parâmetro dos gastos públicos executados pelos municípios é positivo e estatisticamente significante mesmo a 1\% de nível de significância, o que sugere que de fato os gastos per capita influenciam positivamente na qualidade de saúde da população. A variável de importação de pacientes apresenta sinal negativo e significante (também a $1 \%$ ), o que pode ser interpretado da seguinte maneira: para um mesmo montante de gasto, quanto maior é o direcionamento desses gastos para residentes de outros municípios, menor é o índice de desempenho dos municípios. Já os gastos com procedimentos hospitalares em estabelecimentos estaduais não foram significativos. A renda apresentou o sinal esperado, 
influenciando positivamente a qualidade de saúde da população, mas se mostrou significante apenas a $10 \%$ (seu pvalor foi 0,0582 , o que significa que a $5 \%$ essa variável está no limite entre ser considerada significante ou não). A proporção da população abaixo da linha de pobreza, por sua vez, se mostrou significante mesmo a 1\%, e também apresentou o sinal correto (negativo, pois quanto maior a taxa de pobreza menor é a qualidade de saúde da população).

A taxa de alfabetização entre os maiores de 15 anos apresentou o sinal positivo (sendo significante a 1\%). Quanto maior a escolaridade melhores são os indicadores de saúde, o que corrobora com os resultados obtidos em diversos trabalhos acadêmicos sobre esse assunto.

As variáveis de condições de habitação também se mostraram relevantes: a incidência de domicílios subnormais apresentou correlação negativa com as condições de saúde, enquanto a proporção de domicílios com água encanada e banheiro apresenta correlação positiva, ambas significantes, a 5\% e 1\%, respectivamente. A variável de grau de urbanização (pop_urb) também se mostrou significativa a $1 \%$, e indicou que regiões mais urbanizadas têm menor qualidade de saúde. Já o tamanho da população e o fato do município ser ou não uma capital, não apresentaram correlação significativa com o indicador de desempenho. A distância da capital estadual mostrouse significativa (a 1\%) e indica que a proximidade da capital não favorece a qualidade da saúde de um município.

Entre as variáveis relacionadas com a estrutura de oferta de serviços de saúde consideradas na equação - porcentual de enfermeiros com curso superior (ENFERM_SUP), pessoal empregado na área da saúde por 100000 habitantes (PESSOAL_PERC), leitos por 100000 habitantes (LEITOS_PERC), e equipamentos por 100000 habitantes (EQUIP) -, apenas o número de equipamentos foi considerado significativo, com um pvalor de 0,0234 , o que mostra a importância de uma aparelhagem satisfatória no bom funcionamento de um sistema de saúde.

As variáveis de causas externas de mortalidade - homicídios e vítimas de acidente de trânsito (AC_TRANS) - não foram significativas, e nem a variável que mede a penetração do programa Saúde da Família (PSF-PACS).

É importante frisar, que todas as variáveis que se mostraram significativas apresentaram sinais intuitivos, exceto a distância da capital estadual e o grau de urbanização que aparentemente não possuem uma interpretação direta. 
Tabela 19. OLS Índice de desempenho X Variáveis Selecionadas

Method: Least Squares Sample: 13370

Date: 03/02/08 Time: 01:52 Included observations: 3368

\begin{tabular}{crrrr}
\hline \hline Variable & Coefficient & Std. Error & t-Statistic & Prob. \\
\hline \hline LOG(GASTO_SAUDE) & 0.954852 & 0.331604 & 2.879497 & 0.0040 \\
IMPORTACAO & -1.647565 & 0.507724 & -3.245000 & 0.0012 \\
LOG(GASTO_HOSP_ESTD) & -0.241183 & 0.216326 & -1.114902 & 0.2650 \\
LOG(RENDA) & 2.124299 & 1.120968 & 1.895058 & 0.0582 \\
POBRES & -0.348123 & 0.028123 & -12.37861 & 0.0000 \\
ALFABETISMO & 0.511558 & 0.033389 & 15.32121 & 0.0000 \\
SUBNORMAL & -0.173923 & 0.088087 & -1.974435 & 0.0484 \\
AGUA_BANH & 0.082579 & 0.013950 & 5.919608 & 0.0000 \\
POP_URB & -9.115332 & 0.856086 & -10.64769 & 0.0000 \\
POPP & $-8.83 E-07$ & $9.00 E-07$ & -0.981325 & 0.3265 \\
CAPITAL & -3.159176 & 2.675385 & -1.180831 & 0.2378 \\
DIST & 0.007523 & 0.001059 & 7.103837 & 0.0000 \\
ENFERM_SUP & 0.016488 & 0.010922 & 1.509614 & 0.1312 \\
PESSOALPERC & $-2.12 E-05$ & 0.000316 & -0.067101 & 0.9465 \\
LEITOS_PERC & 0.000535 & 0.000656 & 0.815825 & 0.4147 \\
EQUIP & 0.001315 & 0.000580 & 2.268620 & 0.0234 \\
HOMICIDIOS & -0.012654 & 0.010298 & -1.228858 & 0.2192 \\
AC_TRANS & 0.010896 & 0.006223 & 1.751111 & 0.0800 \\
PSF_PACS & -0.004466 & 0.003947 & -1.131503 & 0.2579 \\
C C & 24.65933 & 6.652666 & 3.706684 & 0.0002 \\
\hline \hline R-squared & 0.750193 & Mean dependent var & 70.34587 \\
Adjusted R-Squared & 0.748775 & S.D. dependent var & 17.47672
\end{tabular}

Ao substituir a variável explicativa pela mortalidade infantil, não ocorrem mudanças muito significativas. As principais mudanças são que os gastos com procedimentos hospitalares em estabelecimentos estaduais passaram a ser significativos, ao passo que a renda, os domicílios em condições subnormais e os equipamentos perderam significância. 


\begin{tabular}{|c|c|c|c|c|}
\hline $\begin{array}{l}\text { Method: Least Squares } \\
\text { Date: 03/02/08 Time: 02:06 }\end{array}$ & \multicolumn{4}{|c|}{$\begin{array}{l}\text { Sample: } 13370 \\
\text { Included observations: } 3368\end{array}$} \\
\hline Variable & Coefficient & Std. Error & t-Statistic & Prob. \\
\hline LOG(GASTO_SAUDE) & -1.348080 & 0.290241 & -4.644691 & 0.0000 \\
\hline IMPORTĀCAO & 1.219196 & 0.444188 & 2.744772 & 0.0061 \\
\hline LOG(GASTO_HOSP_ESTD) & -0.373877 & 0.189178 & -1.976321 & 0.0482 \\
\hline $\operatorname{LOG}(\bar{R} E N D A)$ & -1.440555 & 0.973294 & -1.480082 & 0.1389 \\
\hline POBRES & 0.303920 & 0.024497 & 12.40633 & 0.0000 \\
\hline ALFABETISMO & -0.529689 & 0.029204 & -18.13728 & 0.0000 \\
\hline SUBNORMAL & 0.076279 & 0.075836 & 1.005831 & 0.3146 \\
\hline AGUA BANH & -0.061815 & 0.012173 & -5.077923 & 0.0000 \\
\hline POP_URB & 6.695552 & 0.745204 & 8.984853 & 0.0000 \\
\hline $\mathrm{PŌP}$ & $6.73 \mathrm{E}-07$ & $7.86 \mathrm{E}-07$ & 0.856366 & 0.3919 \\
\hline CAPITAL & 4.343117 & 2.340819 & 1.855383 & 0.0636 \\
\hline DIST & -0.008556 & 0.000920 & -9.303845 & 0.0000 \\
\hline ENFERM_SUP & -0.015279 & 0.009558 & -1.598496 & 0.1100 \\
\hline PESSOAL PERC & 2.17E-05 & 0.000276 & 0.078670 & 0.9373 \\
\hline LEITOS_P̄ERC & -0.000444 & 0.000574 & -0.773913 & 0.4390 \\
\hline EQŪIP & -0.000656 & 0.000506 & -1.296857 & 0.1948 \\
\hline PSF PACS & 0.000875 & 0.003453 & 0.253305 & 0.8000 \\
\hline $\bar{c}$ & 76.94517 & 5.783494 & 13.30427 & 0.0000 \\
\hline & & & & \\
\hline Adjusted R-squared & 0.764639 & S.D. Uepen & ent var & 5.80546 \\
\hline
\end{tabular}

Por fim, na terceira equação estimada, que tem a expectativa de vida como variável dependente, a alteração mais relevante é que os gastos executados pelos municípios perdem relevância. Já os gastos com procedimentos hospitalares em estabelecimentos estaduais, a exemplo do observado na equação com mortalidade infantil, ficam significativos. De resto, na comparação com a equação com o Índice de desempenho, as mudanças são a perda de relevância da renda (do mesmo modo que ocorreu na equação anterior), e a significância da taxa de homicídios - o que faz sentido uma vez que a taxa de homicídio não interfere na taxa de mortalidade infantil mas tem impacto considerável sobre a expectativa de vida. 


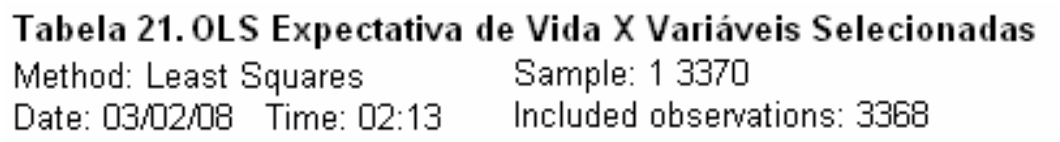

\begin{tabular}{crrrr}
\hline \hline Variable & Coefficient & Std. Error & t-Statistic & Prob. \\
\hline \hline LOG(GASTO_SAUDE) & 0.098287 & 0.093852 & 1.047261 & 0.2951 \\
IMPORTACAO & -0.378525 & 0.143698 & -2.634178 & 0.0085 \\
LOG(GASTO_HOSP_ESTD) & -0.134393 & 0.061225 & -2.195059 & 0.0282 \\
LOG(RENDA) & 0.289132 & 0.317260 & 0.911341 & 0.3622 \\
POBRES & -0.107389 & 0.007959 & -13.49207 & 0.0000 \\
ALFABETISMO & 0.101221 & 0.009450 & 10.71143 & 0.0000 \\
SUBNORMAL & -0.054755 & 0.024931 & -2.196272 & 0.0281 \\
AGUA_BANH & 0.013354 & 0.003948 & 3.382277 & 0.0007 \\
POP_URB & -2.230243 & 0.242292 & -9.204773 & 0.0000 \\
POPP & $-1.71 E-07$ & $2.55 E-07$ & -0.670438 & 0.5026 \\
CAPITAL & -0.475780 & 0.757196 & -0.628345 & 0.5298 \\
DIST & 0.001286 & 0.000300 & 4.291042 & 0.0000 \\
ENFERM_SUP & 0.003731 & 0.003091 & 1.207031 & 0.2275 \\
PESSOAL_PERC & $7.47 E-05$ & $8.94 E-05$ & 0.835474 & 0.4035 \\
LEITOS_PERC & $2.46 E-05$ & 0.000186 & 0.132414 & 0.8947 \\
EQUIP & 0.000435 & 0.000164 & 2.652090 & 0.0080 \\
PSF_PACS & -0.000830 & 0.001117 & -0.742796 & 0.4577 \\
HOMICIDIOS & -0.010886 & 0.002915 & -3.734973 & 0.0002 \\
AC_TRANS & 0.001026 & 0.001761 & 0.582823 & 0.5601 \\
C & 63.47765 & 1.882858 & 33.71345 & 0.0000 \\
\hline \hline R-squared & 0.679849 & Mean dependent var & 69.20208 \\
Adjusted R-Squared & 0.678032 & S.D. dependent var & 4.369251
\end{tabular}

\section{5 - RESULTADOS}

As quatro tabelas posteriores apresentam as equações estimadas para a definição das fronteiras. Nota-se que os resultados encontrados nas equações que determinam as fronteiras são bastante similares aos observados nas equações geradas por OLS no capítulo anterior, fato que torna mais robustos os resultados. A descrição dos parâmetros terá foco nos resultados observados nas fronteiras estimadas utilizando a função de distribuição semi-normal, contudo é importante frisar que os resultados são bastante similares quando utilizadas as distribuições truncada e exponencial, o que pode ser considerado um fator a mais de robustez (Tabelas 22 a 25).

A variável de gasto dos municípios apresentou o sinal esperado (positivo no caso das equações de expectativa de vida e de probabilidade de se atingir 60 anos e negativo nas equações de índices de mortalidade) e mostrou-se significativa a $10 \%$ de significância em todas as equações estimadas, contudo, a $5 \%$ de significância não pode ser considerada estatisticamente diferente de zero nas equações de expectativa de vida e de probabilidade de 
se atingir 60 anos. Já a variável proxy para os gastos estaduais ${ }^{20}$ não mostrou significância em nenhuma das equações (apenas o termo quadrático dessa variável aparece com significância a $5 \%$ na equação de mortalidade infantil.

A taxa de alfabetização é significante a $1 \%$ em todas as equações, sendo, conforme o esperado, positivamente correlacionada com as variáveis de longevidade e negativamente correlacionada com os indicadores de mortalidade. O porcentual de domicílios com água também apresenta o sinal esperado em todas as equações, apesar de não mostrar significância na equação de probabilidade de atingir 60 anos. Já a proporção de domicílios atendidos por serviços de coleta de lixo é relevante apenas na equação de mortalidade até 5 anos. Uma variável que apresentou sinais contraditórios foi a proporção de residências com energia elétrica, uma vez que esteve positivamente correlacionada tanto com as variáveis de longevidade como com as de mortalidade (quando o esperado seria um sinal negativo nas equações de mortalidade), sendo significativa em todas elas. Assim como nas equações estimadas por OLS, a variável que mede a urbanização apresentou-se negativamente correlacionada com a qualidade de saúde das populações, bem como o tamanho da população, indicando que feitos os devidos controles as grandes cidades urbanizadas apresentam piores condições de saúde, o que talvez seja explicado por variáveis mais difíceis de se medir, como por exemplo o nível de stress.

$\mathrm{O}$ índice de pobreza, conforme as expectativas, se mostrou negativamente correlacionado com boas condições de saúde, com significância mesmo a $1 \%$ nas quatro equações. Tanto a renda média como o grau de desigualdade - medido pelo índice de Gini não apresentaram significância nas equações de expectativa de vida e de probabilidade de atingir os 60 anos, mas sim nas equações de mortalidade (com o sinal negativo no caso da renda e positivo no do índice de desigualdade).

Também repetindo os resultados encontrados nas equações estimadas por OLS, a proximidade da capital não parece favorecer a situação da saúde da população, uma vez que a variável distância em relação a capital apresentou significância em todas as equações mostrando sinal negativo nas fronteiras cujo produto são as variáveis de longevidade e positivo nas de mortalidade. A variável proxy para importação de pacientes aparentemente está cumprindo seu papel, uma vez que apresenta sinal que indica que, para um mesmo nível de gasto, quanto maior a importação de pacientes piores são as condições de saúde da população residente.

No caso das variáveis que captam as causas externas de mortalidade, incluídas apenas nas fronteiras de expectativa de vida e de probabilidade de chegar aos 60 anos, o número de vítimas

\footnotetext{
${ }^{20}$ Criada através dos gastos com internação nos hospitais estaduais.
} 
de trânsito não apresenta significância, mas o total de vítimas de homicídios sim (e com o sinal correto, negativo).

Tabela 22 - Fronteiras estimadas para a expectativa de vida

\begin{tabular}{|c|c|c|c|c|c|c|}
\hline Variáveis & \multicolumn{2}{|c|}{ Semi Normal } & \multicolumn{2}{|c|}{ Normal Truncada } & \multicolumn{2}{|c|}{ Exponencial } \\
\hline lexpect & Coef. & P Valor & Coef. & P Valor & Coef. & P Valor \\
\hline Igastos_mun & 0.0239577 & 0.06 & 0.0236243 & 0.06 & 0.02652 & 0.03 \\
\hline Igasto_mun2 & -0.0024818 & 0.09 & -0.0025292 & 0.09 & -0.00282 & 0.05 \\
\hline Igastos_est & -0.0020195 & 0.33 & -0.0020467 & 0.33 & -0.00204 & 0.33 \\
\hline Igasto_est2 & $9.85 \mathrm{E}-06$ & 0.98 & 0.0001441 & 0.77 & 0.00019 & 0.70 \\
\hline alfabetismo & 0.0013763 & 0.00 & 0.0015396 & 0.00 & 0.00154 & 0.00 \\
\hline dom_agua & 0.0001996 & 0.01 & 0.0002467 & 0.00 & 0.00021 & 0.01 \\
\hline dom_coleta_lixo & -0.0000445 & 0.40 & -0.000069 & 0.16 & -0.00005 & 0.31 \\
\hline dom_energia & 0.0001983 & 0.03 & 0.0001689 & 0.05 & 0.00021 & 0.02 \\
\hline popurbana & -0.0326211 & 0.00 & -0.0319401 & 0.00 & -0.03339 & 0.00 \\
\hline pobres & -0.0012817 & 0.00 & -0.0013676 & 0.00 & -0.00132 & 0.00 \\
\hline rendamedia & 0.0000247 & 0.16 & 0.0000342 & 0.07 & 0.00004 & 0.05 \\
\hline desigualdade_gini & -0.0172268 & 0.29 & -0.0127536 & 0.44 & -0.01834 & 0.26 \\
\hline distancia & 0.0000242 & 0.00 & 0.0000248 & 0.00 & 0.00003 & 0.00 \\
\hline vitimas_transito & 0.0000277 & 0.27 & 0.0000252 & 0.33 & 0.00002 & 0.36 \\
\hline homicidios & -0.0001896 & 0.00 & -0.0001691 & 0.00 & -0.00018 & 0.00 \\
\hline importacao & -0.0061952 & 0.00 & -0.0052813 & 0.01 & -0.00479 & 0.02 \\
\hline populacao & $-5.54 \mathrm{E}-09$ & 0.04 & $-5.44 \mathrm{E}-09$ & 0.07 & 0.00000 & 0.06 \\
\hline Cons & 4.145395 & 0.00 & 4.127831 & 0.00 & 4.11123 & 0.00 \\
\hline \multicolumn{7}{|c|}{ Insig2u - Modelo Variância da Ineficiência } \\
\hline psf_pacs & 0.0047261 & 0.00 & \multicolumn{2}{|c|}{ No inefficiency component: } & & \\
\hline tecnologia & -0.4861233 & 0.00 & $z=-3,85$ & Prob $<=z=0$ & & \\
\hline leitos_privad_partic. & -0.0019736 & 0.09 & Prob > chi2 & $=0$ & Observações: & 3244 \\
\hline hosp_privad.partic. & -0.0043312 & 0.17 & & & & \\
\hline enfermeiros & -0.0010111 & 0.68 & \multicolumn{4}{|c|}{ Correlação entre os rankings gerados pelas 3 distribuiçôes: } \\
\hline transfsus_partic. & 0.0062529 & 0.47 & Semi-Normal $X$ & ormal Truncada & & 0.96 \\
\hline outrastransf_partic. & 0.0154931 & 0.00 & Normal Truncad & XExponencial & & 0.97 \\
\hline cons & -7.380955 & 0.00 & Semi-Normal X & xponencial & & 0.97 \\
\hline
\end{tabular}


Tabela 23 - Fronteiras estimadas para a probabilidade de atingir os 60 anos

\begin{tabular}{|c|c|c|c|c|c|c|}
\hline Variáveis & \multicolumn{2}{|c|}{ Semi Normal } & \multicolumn{2}{|c|}{ Normal Truncada } & \multicolumn{2}{|c|}{ Exponencial } \\
\hline Iprob60 & Coef. & $\mathrm{P}$ Valor & Coef. & $\mathrm{P}$ Valor & Coef. & $\mathrm{P}$ Valor \\
\hline Igastos_mun & 0.0363958 & 0.06 & 0.0360718 & 0.07 & 0.03592 & 0.07 \\
\hline Igasto_mun2 & -0.0038427 & 0.08 & -0.003936 & 0.08 & -0.00394 & 0.08 \\
\hline Igastos_est & -0.0029466 & 0.35 & -0.0030819 & 0.35 & -0.00294 & 0.37 \\
\hline Igasto_est2 & $1.02 \mathrm{E}-04$ & 0.89 & 0.0003882 & 0.61 & 0.00034 & 0.66 \\
\hline alfabetismo & 0.0020367 & 0.00 & 0.0023256 & 0.00 & 0.00232 & 0.00 \\
\hline dom_agua & 0.0001404 & 0.23 & 0.0001937 & 0.09 & 0.00020 & 0.09 \\
\hline dom_coleta_lixo & -0.0000471 & 0.56 & -0.0000782 & 0.31 & -0.00007 & 0.34 \\
\hline dom_energia & 0.0004165 & 0.00 & 0.0003629 & 0.01 & 0.00035 & 0.01 \\
\hline popurbana & -0.0479281 & 0.00 & -0.04663334 & 0.00 & -0.04671 & 0.00 \\
\hline pobres & -0.0019777 & 0.00 & -0.0021064 & 0.00 & -0.00211 & 0.00 \\
\hline rendamedia & 0.0000154 & 0.55 & 0.000031 & 0.27 & 0.00004 & 0.21 \\
\hline desigualdade_gini & -0.0052553 & 0.83 & 0.0034668 & 0.89 & -0.00150 & 0.95 \\
\hline distancia & 0.0000362 & 0.00 & 0.0000377 & 0.00 & 0.00004 & 0.00 \\
\hline vitimas_transito & 0.0000754 & 0.05 & 0.0000667 & 0.09 & 0.00006 & 0.12 \\
\hline homicidios & -0.0002789 & 0.00 & -0.0002478 & 0.00 & -0.00026 & 0.00 \\
\hline importacao & -0.0083938 & 0.00 & -0.0064597 & 0.04 & -0.00631 & 0.04 \\
\hline populacao & $-8.02 \mathrm{E}-09$ & 0.03 & $-7.87 \mathrm{E}-09$ & 0.07 & 0.00000 & 0.08 \\
\hline cons & 4.229921 & 0.00 & 4.194608 & 0.00 & 4.18897 & 0.00 \\
\hline \multicolumn{7}{|c|}{ Insig2u - Modelo Variância da Ineficiência } \\
\hline Insig2u & & & \multicolumn{2}{|c|}{ No inefficiency component: } & & \\
\hline psf_pacs & 0.0043198 & 0.00 & $z=-6,4$ & Prob $<=z=0$ & & \\
\hline tecnologia & -0.4561873 & 0.00 & Prob > chi2 & $=0$ & Observaçổes: & 3244 \\
\hline leitos_privad_partic & -0.0019954 & 0.05 & & & & \\
\hline hosp_privad.partic. & -0.0048823 & 0.07 & \multicolumn{4}{|c|}{ Correlaçẫo entre os rankings gerados pelas 3 distribuiçôes: } \\
\hline enfermeiros & -0.0004319 & 0.84 & \multicolumn{3}{|c|}{ Semi-Normal X Normal Truncada } & 0.97 \\
\hline transfsus_partic. & 0.0078909 & 0.30 & \multicolumn{3}{|c|}{ Normal Truncada X Exponencial } & 1.00 \\
\hline outrastransf_partic. & 0.0179584 & 0.00 & \multicolumn{2}{|c|}{ Semi-Normal X Exponencial } & & 0.97 \\
\hline cons & -6.423409 & 0.00 & & & & \\
\hline
\end{tabular}

Tabela 24 - Fronteiras estimadas para a mortalidade infantil

\begin{tabular}{|c|c|c|c|c|c|c|}
\hline \multirow{2}{*}{$\begin{array}{l}\text { Variáveis } \\
\text { Imort1ano }\end{array}$} & \multicolumn{2}{|c|}{ Semi Normal } & \multicolumn{2}{|c|}{ Normal Truncada } & \multicolumn{2}{|c|}{ Exponencial } \\
\hline & Coef. & P Valor & Coef. & P Valor & Coef. & P Valor \\
\hline Igastos_mun & -0.0521511 & 0.00 & -0.0564898 & 0.00 & -0.05628 & 0.00 \\
\hline Igastos_est & -0.0049743 & 0.73 & -0.0037129 & 0.80 & -0.00364 & 0.81 \\
\hline Igasto_est2 & -0.0067898 & 0.05 & -0.0069052 & 0.05 & -0.00689 & 0.05 \\
\hline alfabetismo & $-9.32 \mathrm{E}-03$ & 0.00 & -0.0094989 & 0.00 & -0.00945 & 0.00 \\
\hline dom_agua & -0.0024975 & 0.00 & -0.0025484 & 0.00 & -0.00252 & 0.00 \\
\hline dom_coleta_lixo & 0.0002449 & 0.51 & 0.0003067 & 0.39 & 0.00033 & 0.36 \\
\hline dom_energia & 0.0023541 & 0.00 & 0.0020906 & 0.00 & 0.00206 & 0.00 \\
\hline popurbana & 0.2056421 & 0.00 & 0.2434196 & 0.00 & 0.24605 & 0.00 \\
\hline pobres & 0.011497 & 0.00 & 0.0116024 & 0.00 & 0.01164 & 0.00 \\
\hline rendamedia & -0.0009466 & 0.00 & -0.0009225 & 0.00 & -0.00093 & 0.00 \\
\hline desigualdade_gini & 0.8100726 & 0.00 & 0.8070524 & 0.00 & 0.81158 & 0.00 \\
\hline distancia & -0.0002738 & 0.00 & -0.0002981 & 0.00 & -0.00030 & 0.00 \\
\hline importacao & 0.0259135 & 0.08 & 0.0302565 & 0.04 & 0.03069 & 0.04 \\
\hline populacao & $9.45 \mathrm{E}-08$ & 0.00 & 0.0000001 & 0.00 & 0.00000 & 0.00 \\
\hline cons & 3.683012 & 0.00 & 3.682285 & 0.00 & 3.61241 & 0.00 \\
\hline \multicolumn{7}{|c|}{ No inefficiency component: } \\
\hline$z=-7,474$ & Prob $<=z=0$ & & & & & \\
\hline \multicolumn{7}{|c|}{ Correlaçẫo entre os rankings gerados pelas 3 distribuiçỗes: } \\
\hline Semi-Normal X No & mal Truncada & & 0.99 & & & \\
\hline Normal Truncada) & Exponencial & & 1.00 & & & \\
\hline Semi-Normal XEx & oonencial & & 0.99 & & & \\
\hline
\end{tabular}


Tabela 25 - Fronteiras estimadas para a mortalidade até 5 anos

\begin{tabular}{|c|c|c|c|c|c|c|}
\hline \multirow{2}{*}{$\begin{array}{l}\text { Variáveis } \\
\text { Imort5anos }\end{array}$} & \multicolumn{2}{|c|}{ Semi Normal } & \multicolumn{2}{|c|}{ Normal Truncada } & \multicolumn{2}{|c|}{ Exponencial } \\
\hline & Coef. & P Valor & Coef. & P Valor & Coef. & P Valor \\
\hline Igastos_mun & -0.0602308 & 0.00 & -0.0592333 & 0.00 & -0.05865 & 0.00 \\
\hline Igastos_est & 0.0004801 & 0.98 & -0.0006729 & 0.97 & -0.00141 & 0.93 \\
\hline Igasto_est2 & -0.0048808 & 0.19 & -0.0046672 & 0.21 & -0.00455 & 0.23 \\
\hline alfabetismo & $-1.34 \mathrm{E}-02$ & 0.00 & -0.0134972 & 0.00 & -0.01359 & 0.00 \\
\hline dom_agua & -0.0053813 & 0.00 & -0.0053576 & 0.00 & -0.00532 & 0.00 \\
\hline dom_coleta_lixo & 0.0011453 & 0.00 & 0.0011424 & 0.00 & 0.00114 & 0.00 \\
\hline dom_energia & 0.0015537 & 0.02 & 0.0014857 & 0.02 & 0.00140 & 0.03 \\
\hline popurbana & 0.4125973 & 0.00 & 0.4118213 & 0.00 & 0.41206 & 0.00 \\
\hline pobres & 0.0136235 & 0.00 & 0.0135572 & 0.00 & 0.01347 & 0.00 \\
\hline rendamedia & -0.0008245 & 0.00 & -0.000833 & 0.00 & -0.00084 & 0.00 \\
\hline desigualdade_gini & 0.5311547 & 0.00 & 0.539425 & 0.00 & 0.54665 & 0.00 \\
\hline distancia & -0.0003104 & 0.00 & -0.0003103 & 0.00 & -0.00031 & 0.00 \\
\hline importacao & 0.0589395 & 0.00 & 0.0580236 & 0.00 & 0.05707 & 0.00 \\
\hline populacao & 0.000000128 & 0.00 & 0.0000001 & 0.00 & 0.00000 & 0.01 \\
\hline cons & 4.33741 & 0.00 & 4.295067 & 0.00 & 4.26438 & 0.00 \\
\hline \multicolumn{7}{|c|}{ No inefficiency component: } \\
\hline$z=-6,695$ & Prob $<=z=0$ & & & & & \\
\hline \multicolumn{7}{|c|}{ Correlaçẫo entre os rankings gerados pelas 3 distribuiçốes: } \\
\hline Semi-Normal X No & mal Truncada & & 1.00 & & & \\
\hline Normal Truncada $X$ & Exponencial & & 1.00 & & & \\
\hline Semi-Normal XEx & gonencial & & 1.00 & & & \\
\hline
\end{tabular}

Passando agora o foco para a ineficiência, a primeira questão a ser respondida é se de fato ela existe. Nesse sentido, todas as equações estimadas apresentaram probabilidade de inexistência do fator de ineficiência muito próxima de 0 , deixando clara a sua importância nas equações. Outro ponto importante, por ser muito questionado na utilização da metodologia de fronteira estocástica, é a avaliação da robustez quanto a utilização das diferentes funções de distribuição. Para tanto, foi gerado um ranking de ineficiência dos municípios para cada um dos 4 produtos utilizados (expectativa de vida, probabilidade de atingir 60 anos, mortalidade infantil e mortalidade até 5 anos) utilizando a fronteira obtida por cada uma das funções de distribuição (semi-normal, truncada e exponencial), e posteriormente foi calculada a correlação entre os três rankings obtidos para cada produto. Em outras palavras, foram feitos 12 rankings (4 produtos X 3 distribuições), que foram comparados 3 a 3 - dentro do mesmo produto mas com distribuição diferente.

Esse teste apresentou resultados bastante satisfatórios, indicando que os resultados mostram bastante robustez em relação a escolha da função de distribuição: no caso da função de mortalidade até 5 anos de idade, por exemplo, as correlações entre os rankings gerados são todas iguais a 1,00 (tabela 25). A menor correlação encontrada foi na equação de expectativa de vida, entre as distribuições semi-normal e normal truncada, cujo índice foi de 0,96 , ainda bastante alto (tabela 22). 
Ainda sobre os resultados apresentados nas quatro tabelas anteriores, é importante frisar o impacto das variáveis selecionadas para compor o modelo da variância da ineficiência ${ }^{21}$. Uma primeira variável de interesse é a cobertura dos programas saúde da família e agentes comunitários da saúde. Nota-se que essa variável está positivamente correlacionada com a variância da ineficiência, e é significativa mesmo a $1 \%$ de significância tanto na equação de expectativa de vida como na de probabilidade de sobreviver até os 60 anos $^{22}$, indicando que quanto maior a cobertura desses programas maior é a variância da ineficiência (Tabelas 22 e 23). Já a variável que capta a intensidade da tecnologia aplicada na produção de saúde, definida como a relação equipamentos/pessoal empregado, mostra uma correlação negativa com a variância da ineficiência, e também se mostra significante ao nível de confiança de $1 \%$ nas duas equações, sinalizando que o emprego relativamente maior da tecnologia está associado a uma redução da variância da ineficiência.

Há algum sinal de que a parceria com o setor privado também contribui para reduzir a variância da ineficiência: duas proxies criadas com o intuito de captar esse efeito - a participação tanto dos leitos privados que atendem ao SUS como dos hospitais privados que fazem esse atendimento, em relação ao total de hospitais/leitos que atendem ao SUS (ou seja, a soma dos públicos com os privados que atendem ao SUS) -, apresentam-se significativas a $10 \%$ de significância na equação de probabilidade de chegar aos 60 anos; já na equação de expectativa de vida a participação dos hospitais privados que atendem ao SUS não se mostrou significativa, mas a dos leitos privados sim.

Nem a variável que mede o porcentual de enfermeiros com curso superior nem a participação das transferências do SUS no total de receitas do município se mostraram significativas. Já a participação das demais transferências no total de receitas apresentou correlação positiva com a variância, e significativa a 1\% de significância.

A tabela a seguir (tabela 26) traz uma estimativa da fronteira incluindo a modelagem simultânea da média da ineficiência (ao invés da variância que havia sido estimada nas equações anteriores). Primeiro deve ser ressaltado que os coeficientes das variáveis incluídas na fronteira não sofreram alterações relevantes. Além disso, a correlação do ranking gerado por essa equação (que utiliza a distribuição normal truncada) e o das demais é bastante elevada, chegando, por exemplo, a 0,99 na comparação com o ranking gerado pela distribuição semi normal com modelagem da variância ${ }^{23}$.

\footnotetext{
${ }^{21}$ A modelagem da variância foi feita simultaneamente à estimativa da fronteira que adotou como premissa a função semi-normal.

${ }^{22}$ As equações de mortalidade não foram utilizadas para modelar a variância devido a difícil interpretação uma vez que uma fronteira cujo produto é negativo deve ser interpretada de forma diferente.

${ }^{23} \mathrm{O}$ software utilizado para a estimativa das fronteiras foi o stata, por isso suas limitações foram respeitadas, de forma que a única distribuição que permitiu a modelagem da média da ineficiência foi a normal truncada.
} 
Tabela 26 - Fronteira para a expectativa de vida com modelagem da média da ineficiência

\begin{tabular}{|c|c|c|c|c|c|}
\hline Variáveis & \multicolumn{2}{|c|}{ Normal Truncada } & \multicolumn{3}{|c|}{ Insig2u - Modelo Média da Ineficiência } \\
\hline lexpect & Coef. & P Valor & & & \\
\hline Igastos_mun & 0.0222394 & 0.08 & & & \\
\hline Igasto_mun2 & -0.0023052 & 0.12 & psf_pacs & 0.0005204 & 0.02 \\
\hline lgastos_est & -0.0018742 & 0.37 & tecnologia & -0.0736758 & 0.03 \\
\hline Igasto_est2 & $3.28 \mathrm{E}-06$ & 1.00 & enfermeiros & -0.0003478 & 0.35 \\
\hline alfabetismo & 0.0013395 & 0.00 & outrastransf_partic. & 0.0020317 & 0.04 \\
\hline dom_agua & 0.0001944 & 0.01 & transfsus_partic. & 0.0001362 & 0.91 \\
\hline dom_coleta_lixo & -0.0000443 & 0.40 & hosp_privad.partic. & -0.000378 & 0.43 \\
\hline dom_energia & 0.000202 & 0.03 & leitos_privad_partic. & -0.0002823 & 0.17 \\
\hline popurbana & -0.0320211 & 0.00 & cons -1 & -0.2435872 & 0.07 \\
\hline pobres & -0.0012745 & 0.00 & & & \\
\hline rendamedia & 0.0000314 & 0.08 & & & \\
\hline desigualdade_gini & -0.0210655 & 0.20 & \multicolumn{2}{|c|}{ Correlaçẫo entre os rankings: } & 0.99 \\
\hline distancia & 0.000024 & 0.00 & \multicolumn{3}{|c|}{ Normal truncada com modelagem da média } \\
\hline vitimas_transito & 0.0000245 & 0.33 & & & \\
\hline homicidios & -0.0001914 & 0.00 & \multicolumn{3}{|c|}{ Semi Normal com modelagem da variância } \\
\hline importacao & -0.0062467 & 0.00 & & & \\
\hline populacao & $-5.56 \mathrm{E}-09$ & 0.04 & & & \\
\hline cons & 4.145033 & 0.00 & & & \\
\hline
\end{tabular}

Quanto aos resultados da equação de modelagem da média, nota-se que a cobertura do programa saúde da família e agentes comunitários da saúde parece estar associada a uma maior ineficiência, uma vez que seu coeficiente mostrou-se significativo a 5\% de significância. Já o emprego de um sistema de saúde com maior intensidade em tecnologia, além de reduzir a variância (conforme visto nos modelos anteriores), apresenta correlação negativa com a média da ineficiência, sinalizando que quanto maior a relação capital/trabalho maior é a eficiência da gestão em saúde. As variáveis de proporção de enfermeiros com curso superior, participação de leitos/hospitais que atendem ao SUS em relação ao total de leitos/hospitais com atendimento público e a participação das transferências do SUS no total de receitas dos municípios não apresentaram significância. Já a participação de outras transferências no total de receitas apresenta correlação positiva com a ineficiência (com significância a 5\%), o que sugere que em média os municípios que recebem proporcionalmente mais transferências são menos eficientes. 
Tabela 27 - Fronteiras estimadas via pessoal empregado e capital ao invés de gastos

\begin{tabular}{|c|c|c|c|c|c|}
\hline \multicolumn{3}{|c|}{ Equação Expectativa de Vida } & \multicolumn{3}{|c|}{ Equação Mortalidade Infantil } \\
\hline lexpect & Coef. & $P$ Valor & Imort1ano & & \\
\hline leitos_percapita & -0.0000216 & 0.42 & leitos_percapita & -0.000408 & 0.05 \\
\hline pessoal_percapita & 0.0000354 & 0.02 & pessoal_percapita & -0.000199 & 0.04 \\
\hline equip_percapita & 0.0000116 & 0.67 & equip_percapita & -0.000138 & 0.49 \\
\hline alfabetismo & $1.36 \mathrm{E}-03$ & 0.00 & alfabetismo & -0.009257 & 0.00 \\
\hline dom_agua & 0.0002217 & 0.00 & dom_agua & -0.002583 & 0.00 \\
\hline dom_coleta_lixo & -0.0000557 & 0.29 & dom_coleta_lixo & 0.000068 & 0.86 \\
\hline dom_energia & 0.0001773 & 0.05 & dom_energia & 0.001962 & 0.00 \\
\hline popurbana & -0.0343142 & 0.00 & popurbana & 0.219390 & 0.00 \\
\hline pobres & -0.0013135 & 0.00 & pobres & 0.011973 & 0.00 \\
\hline rendamedia & 0.0000191 & 0.28 & rendamedia & -0.000910 & 0.00 \\
\hline desigualdade_gini & -0.0215397 & 0.19 & desigualdade_gini & 0.805258 & 0.00 \\
\hline distancia & 0.0000257 & 0.00 & distancia & -0.000320 & 0.00 \\
\hline importacao & -0.0054309 & 0.00 & importacao & 0.043059 & 0.00 \\
\hline populacao & $-7.45 \mathrm{E}-09$ & 0.00 & populacao & 0.000000 & 0.00 \\
\hline cons & 4.200037 & 0.00 & cons & 3.456139 & 0.00 \\
\hline \multicolumn{3}{|c|}{ Insig2u - Modelo da Variância da Ineficiência } & \multicolumn{3}{|c|}{ Insig2u - Modelo da Variância da Ineficiência } \\
\hline psf_pacs & 0.0047966 & 0.00 & psf_pacs & 0.0007085 & 0.42 \\
\hline tecnologia & -0.5682271 & 0.00 & tecnologia & 0.2770677 & 0.00 \\
\hline hosp_privad.partic. & -0.0044064 & 0.16 & hosp_privad.partic. & -0.0037269 & 0.25 \\
\hline leitos_privad_partic. & -0.0012653 & 0.28 & leitos_privad_partic. & -0.0008552 & 0.48 \\
\hline transfsus_partic. & 0.0022813 & 0.79 & transfsus_partic. & 0.0019124 & 0.84 \\
\hline outrastransf_partic. & 0.014566 & 0.00 & outrastransf_partic. & 0.0023863 & 0.51 \\
\hline enfermeiros & -0.0007591 & 0.76 & enfermeiros & 0.0081569 & 0.00 \\
\hline _cons & -7.26321 & 0.00 & Cons & -2.855556 & 0.00 \\
\hline \multicolumn{2}{|c|}{ Correlaçẫo entre os rankings: } & & \multicolumn{2}{|c|}{ Correlaçẫo entre os rankings: } & \\
\hline \multicolumn{3}{|c|}{ Semi-Normal (Insumos) X Semi-Normal (Gastos) } & \multicolumn{3}{|c|}{ Semi-Normal (Insumos) X Semi-Normal (Gastos) } \\
\hline 0.99 & & & 0,99 & & \\
\hline
\end{tabular}

A tabela 27 apresenta as estimativas feitas substituindo as variáveis de gasto pelas de insumo de produção de saúde propriamente ditos: pessoal empregado na área de saúde, número de equipamentos e total de hospitais, todas elas por 10.000 habitantes. Esse exercício foi feito para tentar mensurar a possível distorção que poderia ser causada pelo fato de que é de se esperar que em alguns municípios poderia haver um estoque de insumos anterior ao período quando os gastos foram analisados, sendo que quanto maior for esse estoque mais beneficiado o município seria, de forma que esse aparentaria ser mais eficiente. Em outras palavras, para dois municípios com o mesmo nível de gastos no período analisado, aquele que tivesse, por exemplo, um número maior de hospitais construídos em períodos anteriores (o que naturalmente está correlacionado com gastos em períodos anteriores ao da análise), deveria apresentar resultados melhores, o que não necessariamente está correlacionado com uma maior ineficiência.

Porém, o impacto desse efeito parece ser muito baixo, uma vez que a correlação entre o ranking gerado pela equação estimada via insumos propriamente ditos e a estimada via gastos é bastante elevada, sendo da ordem de 0,99 tanto no caso da expectativa de vida como no da 
mortalidade infantil (ambas utilizando a distribuição semi normal). Todavia, vale mencionar os resultados obtidos para esses novos parâmetros: no caso da fronteira de expectativa de vida apenas o pessoal empregado se mostrou significativo; já no caso da equação de mortalidade infantil, além do pessoal empregado, o número de hospitais também apresentou significância (a 5\%).

Ao mesclar as variáveis aqui nomeadas de insumos propriamente ditos com as de gastos, pode ser reforçada ainda mais a hipótese de que o impacto da distorção citada acima é bastante reduzido, uma vez que as variáveis de gasto permanecem significantes enquanto as de pessoal empregado, leitos e número de hospitais perdem relevância (tabela 28).

\begin{tabular}{|l|c|c|}
\hline \multicolumn{2}{|c|}{ Tabela 28 - Fronteira mortalidade infantil com mescla insumos } \\
\hline \multicolumn{1}{|c|}{ Variáveis } & \multicolumn{2}{|c|}{ Semi Normal } \\
\hline \multicolumn{1}{|c|}{ Imort1ano } & Coef. & P Valor \\
\hline Igastos_mun & -0.0457174 & 0.00 \\
\hline Igastos_est & -0.0284226 & 0.00 \\
\hline leitos_percapita & -0.0002609 & 0.22 \\
\hline pessoal_percapita & $-1.19 \mathrm{E}-04$ & 0.23 \\
\hline equip_percapita & 0.00000963 & 0.96 \\
\hline alfabetismo & -0.0094883 & 0.00 \\
\hline dom_agua & -0.0025066 & 0.00 \\
\hline dom_coleta_lixo & 0.0002369 & 0.53 \\
\hline dom_energia & 0.0023035 & 0.00 \\
\hline popurbana & 0.2111068 & 0.00 \\
\hline pobres & 0.0116028 & 0.00 \\
\hline rendamedia & -0.0009196 & 0.00 \\
\hline desigualdade_gini & 0.8103884 & 0.00 \\
\hline distancia & -0.0002821 & 0.00 \\
\hline importacao & 0.0299132 & 0.05 \\
\hline populacao & $9.04 \mathrm{E}-08$ & 0.00 \\
\hline cons & 3.687971 & 0.00 \\
\hline
\end{tabular}

Tabela 29. Correlaçäo entre os rankings dos diferentes produtos

\begin{tabular}{|c|c|c|c|c|}
\hline \multirow{4}{*}{\begin{tabular}{c} 
Exp Vida \\
\cline { 2 - 5 } Prob60 anos
\end{tabular}} & 1.00 & & & \\
\cline { 2 - 5 } Mort 1 ano & 0.99 & 1.00 & & \\
\cline { 2 - 5 } Mort 5 anos & 0.79 & 0.79 & 1.00 & \\
\cline { 2 - 5 } & 0.79 & 0.76 & 0.94 & 1.00 \\
\hline
\end{tabular}

Outro fator que deve ser avaliado é a diferença entre o ranking gerado pelos diferentes produtos escolhidos. Para fazer essa análise foi calculada a correlação entre os rankings gerados pelas fronteiras estimadas (todos utilizando a distribuição semi normal) para cada um dos 4 produtos. Como era de se esperar, devido a semelhança dos indicadores, existem dois pares de 
rankings com correlação elevada: mortalidade infantil X mortalidade até 5 anos; e expectativa de vida X probabilidade de atingir os 60 anos (tabela 29). As demais combinações apresentam baixa correlação, sendo a menor delas de 0,76 (entre mortalidade até 5 anos e probabilidade de atingir 60 anos).

Dada essa razoável divergência de resultados entre diferentes produtos, ganha importância a discussão sobre qual indicador de saúde deveria ser utilizado. Ainda que haja discussões acadêmicas em torno dessa "polêmica", e por isso qualquer decisão pode gerar controversas, no contexto desse trabalho o mais razoável parece ser a utilização de um dos indicadores de mortalidade, devido a duas razões principais: (i) o poder de explicação dos modelos de mortalidade estimados aqui é maior do que os de longevidade - isso pode ser visto, por exemplo, na comparação dos modelos estimados por OLS no capítulo anterior, onde o modelo de expectativa de vida apresentava um $\mathrm{R}^{2}$ ajustado de 0,68 enquanto o modelo de mortalidade infantil apresentou $\mathrm{R}^{2}$ ajustado de 0,76 ; e (ii) o principal insumo a ser avaliado aqui são os gastos, e essa variável apresenta um impacto mais relevante nas equações de mortalidade do que nas de expectativa de vida ou de probabilidade de atingir os 60 anos - em nenhuma das equações de longevidade os gastos mostram significância a 5\% de nível de confiança, e no modelo OLS para expectativa de vida os gastos não apresentam significância nem mesmo a 10\%. Por esses motivos optou-se aqui pela mortalidade infantil como principal produto do sistema de saúde (preferido em relação ao de mortalidade até 5 anos simplesmente por ser mais usualmente utilizado), sendo que o ranking que será comentado a seguir foi gerado pela fronteira cujo produto é esse indicador.

Já que a fronteira aqui escolhida para avaliar a eficiência dos municípios foi a de mortalidade infantil, uma ressalva deve ser feita sobre a elaboração do ranking referente a esse indicador. A característica que torna o ranking gerado por esse indicador peculiar é o fato de que se trata de um "produto negativo", de forma que o desejável é ter o menor índice de mortalidade possível. Ademais, a utilização de uma quantidade maior de insumos reduz a mortalidade infantil. Assim, pode-se dizer que o formato dessa fronteira é o inverso da usual, sendo que a mesma está localizada no $4^{\circ}$ quadrante ao invés de no $1^{\circ}$ (gráfico 4 ). 
Grafico 5 . Fronteira para um "produto negativo".

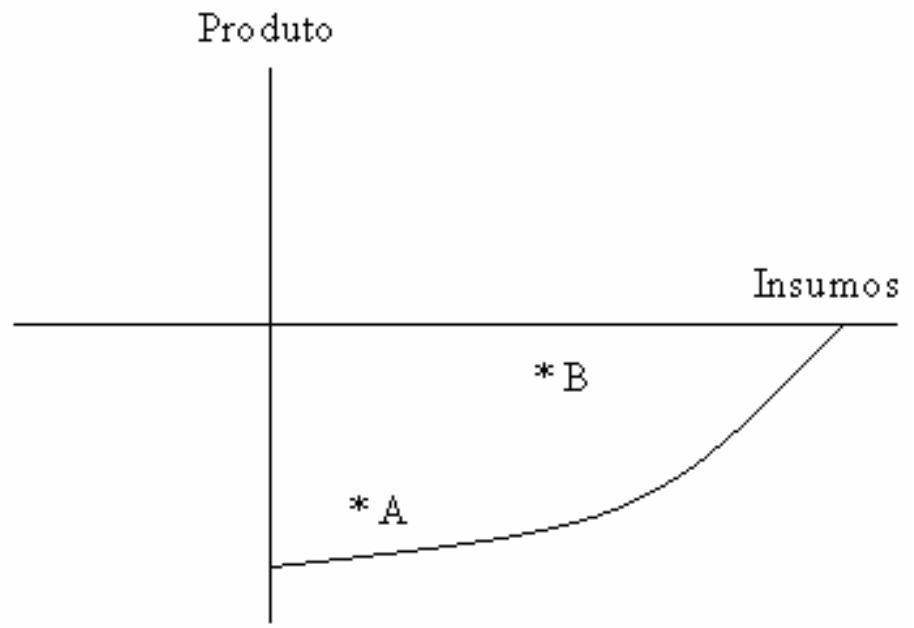

Dessa forma, a medida de eficiência também deve ser invertida, sendo que na comparação entre dois pontos o mais eficiente é aquele que está localizado a uma distância maior da fronteira. No exemplo ilustrado acima, é visualmente notável que o ponto B é mais eficiente do que o A, pois está claramente mais afastado da fronteira.

Dadas essas alterações, o termo $\mathrm{TE}_{\mathrm{i}}=\mathrm{y}_{\mathrm{i}} / \mathrm{f}\left(\mathrm{x}_{\mathrm{i}}\right) \mathrm{e}^{\mathrm{vi}}$, que compara o produto do iésimo produtor com o máximo que poderia ser produzido com os seus insumos $\left(\mathrm{x}_{\mathrm{i}}\right)$, usualmente tido como o termo de eficiência, no caso da estimativa da fronteira para mortalidade infantil tem uma interpretação invertida, uma vez que, conforme discutido nos parágrafos anteriores, quanto mais próximo da fronteira pior. Por isso pode-se dizer que um município com $\mathrm{TE}_{\mathrm{i}}=0,30$ é mais eficiente do que outro com $\mathrm{TE}_{\mathrm{i}}=0,90$.

Feitas as devidas considerações, vejamos agora os resultados da análise de eficiência obtida através desses critérios descritos. Um primeiro ponto que merece comentário é que entre os 15 municípios mais bem posicionados no ranking geral, 11 são de pequeno porte (até 10.000 habitantes $)^{24}$. A princípio isso poderia sinalizar algum indício de viés, contudo, vale lembrar que os municípios desse porte representam $50 \%$ da amostra.e, além disso, que a variável tamanho da população foi incluída nas fronteiras. Ainda assim parece mais apropriado dividir a amostra por porte dos municípios, para facilitar a comparação.

Entre os municípios de pequeno porte o de melhor desempenho é Dilermando de Aguiar (que também lidera o ranking geral), localizado no Rio Grande do Sul (Tabela 30), seguido de perto por Salgado Filho no Paraná. A comparação dos dados disponíveis na tabela 30 desses dois municípios pode gerar algum questionamento uma vez que o índice de mortalidade infantil de Salgado Filho é ligeiramente inferior ao de Dilermando de Aguiar e os gastos municipais do município paranaense também são inferiores, o que pode causar certa desconfiança em relação a

\footnotetext{
${ }^{24}$ O Ranking utilizado foi o gerado pela distribuição normal truncada.
} 
posição relativa desses dois municípios - aparentemente Dilermando de Aguiar utiliza mais insumo e produz menos (tem mortalidade infantil maior), mas ainda assim aparece como mais eficiente. Contudo, não devemos esquecer que existem outros insumos, como por exemplo a alfabetização da população, que aliás, é maior em Salgado Filho, de forma que essa comparação não pode ser feita levando em consideração apenas um dos insumos considerados nas equações.

Nota-se que entre os 15 primeiros municípios dessa categoria aparecem apenas municípios localizados em três estados: São Paulo, Paraná e Rio Grande do Sul, com 5 aparições de cada um desses. Já entre os municípios de pior classificação chama a atenção o fato de que 8 dos 15 são mineiros, inclusive o pior colocado deles: Antônio Prado de Minas.

\begin{tabular}{|c|c|c|c|c|c|c|c|c|}
\hline Estado & Municípios & População & TEi & $\begin{array}{c}\text { Ranking } \\
\text { Geral }\end{array}$ & $\begin{array}{c}\text { Rnking } \\
\text { ajustado* }\end{array}$ & $\begin{array}{l}\text { Mortalidade } \\
\text { Infantil }\end{array}$ & $\begin{array}{c}\text { Índice } \\
\text { desempenho }\end{array}$ & $\begin{array}{l}\text { Gastos por } \\
\text { habitante }\end{array}$ \\
\hline \multicolumn{9}{|c|}{ MELHORES COLOCADOS } \\
\hline RS & Dilermando de Aguiar & 3200 & 0,40 & 1 & 1 & 8,9 & 95,0 & 85,6 \\
\hline PR & Salgado Filho & 5338 & 0,40 & 2 & 2 & 8,7 & 93,8 & 54,2 \\
\hline PR & Barra do Jacaré & 2723 & 0,43 & 3 & 3 & 7,2 & 96,7 & 131,6 \\
\hline $\mathrm{SP}$ & Santo Expedito & 2526 & 0,45 & 4 & 4 & 7,7 & 95,2 & 112,9 \\
\hline PR & Tamboara & 4255 & 0,47 & 6 & 5 & 7,6 & 95,9 & 77,3 \\
\hline RS & São Vicente do Sul & 8336 & 0,48 & 7 & 6 & 8,8 & 95,3 & 99,3 \\
\hline $\mathrm{SP}$ & Santa Lúcia & 7853 & 0,48 & 9 & 7 & 7,6 & 95,4 & 121,7 \\
\hline PR & Pranchita & 6260 & 0,49 & 12 & 8 & 7,5 & 96,0 & 78,0 \\
\hline SP & Alfredo Marcondes & 3697 & 0,49 & 13 & 9 & 7,9 & 94,9 & 88,2 \\
\hline $\mathrm{SP}$ & Caiabu & 4077 & 0,49 & 14 & 10 & 8,0 & 94,8 & 89,2 \\
\hline PR & Miraselva & 1961 & 0,49 & 15 & 11 & 7,7 & 95,7 & 217,7 \\
\hline RS & São José do Herval & 2530 & 0,50 & 16 & 12 & 11,3 & 91,1 & 91,1 \\
\hline $\mathrm{SP}$ & Paulistânia & 1779 & 0,50 & 18 & 13 & 7,7 & 95,4 & 158,0 \\
\hline RS & Barra do Guarita & 2987 & 0,50 & 19 & 14 & 10,8 & 91,9 & 68,1 \\
\hline RS & Bossoroca & 7757 & 0,50 & 20 & 15 & 11,0 & 91,5 & 89,4 \\
\hline \multicolumn{9}{|c|}{ PIORES COLOCADOS } \\
\hline MT & Juruena & 5448 & 0,93 & 3332 & 1683 & 26,4 & 73,1 & 133,8 \\
\hline MT & Itaúba & 8565 & 0,93 & 3337 & 1684 & 30,2 & 68,5 & 118,3 \\
\hline MT & Ribeirẫo Cascalheira & 8866 & 0,93 & 3341 & 1685 & 45,6 & 51,5 & 43,3 \\
\hline$M G$ & Lagoa Grande & 7610 & 0,94 & 3342 & 1686 & 39,8 & 60,2 & 92,4 \\
\hline TO & Divinópolis do Tocantins & 5776 & 0,94 & 3343 & 1687 & 63,2 & 31,1 & 56,4 \\
\hline$M G$ & Fortuna de Minas & 2437 & 0,94 & 3344 & 1688 & 42,5 & 57,3 & 157,5 \\
\hline MG & Durandé & 7005 & 0,94 & 3345 & 1689 & 45,8 & 53,8 & 51,8 \\
\hline MT & Porto Alegre do Norte & 8623 & 0,94 & 3346 & 1690 & 45,6 & 51,5 & 68,4 \\
\hline MG & Ewbank da Câmara & 3608 & 0,94 & 3350 & 1691 & 41,8 & 58,0 & 58,2 \\
\hline MT & Nova Marilândia & 2354 & 0,94 & 3352 & 1692 & 45,1 & 52,0 & 119,5 \\
\hline MG & Lagamar & 7710 & 0,94 & 3355 & 1693 & 37,9 & 62,2 & 111,8 \\
\hline MG & Santana do Manhuaçu & 8607 & 0,94 & 3359 & 1694 & 45,8 & 53,8 & 64,8 \\
\hline $\mathrm{SC}$ & Novo Horizonte & 3101 & 0,94 & 3360 & 1695 & 31,7 & 68,1 & 121,9 \\
\hline MG & Arceburgo & 8035 & 0,94 & 3364 & 1696 & 33,5 & 67,0 & 69,8 \\
\hline$M G$ & Antônio Prado de Minas & 1794 & 0,95 & 3368 & 1697 & 41,3 & 58,5 & 177,6 \\
\hline
\end{tabular}

Entre os municípios de médio porte (Tabela 31) a freqüência de aparições dos municípios de Minas Gerais entre os de pior classificação é ainda mais alarmante: 10 em 15, sendo os 5 mais ineficientes desse estado - Cláudio, Vazante, Extrema, Cabo Verde e Nova Resende. Um município gaúcho, Mostardas, também lidera o ranking de eficiência dos municípios com população entre 10 e 15 mil habitantes.

Já o ranking dos municípios de grande porte (Tabela 32) é liderado por um município paranaense, Pato Branco. Se destaca nessa categoria o estado de São Paulo, que tem 7 municípios 
entre os mais bem colocados - em que pese o fato de que os municípios de São Paulo representam quase $30 \%$ da amostra de municípios com mais de 50 mil habitantes, enquanto os gaúchos e os paranaenses respondem por aproximadamente $10 \%$ cada -, estando entre eles a capital paulista e também o município de São Caetano do Sul (que conforme já foi dito nos capítulos anteriores é o município com as melhores condições de saúde). O pior classificado dessa amostra (e segundo pior no ranking geral) é a capital capixaba, Vitória.

\begin{tabular}{|c|c|c|c|c|c|c|c|c|}
\hline Estado & Municípios & População & TEi & $\begin{array}{c}\text { Ranking } \\
\text { Geral }\end{array}$ & $\begin{array}{c}\text { Rnking } \\
\text { ajustado* }\end{array}$ & $\begin{array}{l}\text { Mortalidade } \\
\text { Infantil }\end{array}$ & $\begin{array}{c}\text { Índice } \\
\text { desempenho }\end{array}$ & $\begin{array}{l}\text { Gastos por } \\
\text { habitante }\end{array}$ \\
\hline \multicolumn{9}{|c|}{ MELHORES COLOCADOS } \\
\hline RS & Mostardas & 11658 & 0,45 & 5 & 1 & 9,2 & 94,7 & 78,9 \\
\hline $\mathrm{SP}$ & Colina & 16664 & 0,48 & 8 & 2 & 7,2 & 96,3 & 142,6 \\
\hline RS & Itaqui & 39770 & 0,48 & 10 & 3 & 9,1 & 94,7 & 53,7 \\
\hline $\mathrm{PR}$ & Antonina & 19174 & 0,48 & 11 & 4 & 11,8 & 88,4 & 25,9 \\
\hline SP & Cajati & 29227 & 0,50 & 17 & 5 & 11,3 & 88,5 & 118,3 \\
\hline RS & Sấo Francisco de Assis & 20810 & 0,51 & 22 & 6 & 11,2 & 91,2 & 30,8 \\
\hline $\mathrm{SC}$ & Abelardo Luz & 16440 & 0,52 & 23 & 7 & 11,9 & 93,0 & 54,6 \\
\hline $\mathrm{SP}$ & Pedregulho & 14994 & 0,53 & 29 & 8 & 8,4 & 93,8 & 85,8 \\
\hline $\mathrm{PR}$ & Capanema & 18239 & 0,54 & 31 & 9 & 7,6 & 95,8 & 65,7 \\
\hline PR & Salto do Lontra & 12757 & 0,54 & 33 & 10 & 11,9 & 88,1 & 28,3 \\
\hline GO & Nerópolis & 18578 & 0,54 & 36 & 11 & 10,7 & 91,7 & 87,3 \\
\hline RS & Osório & 36131 & 0,55 & 38 & 12 & 8,3 & 96,2 & 84,0 \\
\hline MG & Sẫo Joẫo das Missốes & 10230 & 0,55 & 45 & 13 & 31,6 & 69,1 & 52,8 \\
\hline $\mathrm{SP}$ & Cordeirópolis & 17591 & 0,56 & 50 & 14 & 7,1 & 96,5 & 185,3 \\
\hline RN & Santo Antônio & 20107 & 0,56 & 52 & 15 & 31,2 & 69,7 & 50,4 \\
\hline \multicolumn{9}{|c|}{ PIORES COLOCADOS } \\
\hline PE & Sanharó & 15879 & 0,93 & 3336 & 1297 & 78,2 & 30,8 & 99,8 \\
\hline MG & Além Paraíba & 33610 & 0,93 & 3338 & 1298 & 31,4 & 69,3 & 73,0 \\
\hline ES & Baixo Guandu & 27819 & 0,93 & 3339 & 1299 & 39,9 & 55,2 & 45,1 \\
\hline MG & Mário Campos & 10535 & 0,93 & 3340 & 1300 & 46,0 & 53,7 & 52,3 \\
\hline $\mathrm{BA}$ & lbititá & 17905 & 0,94 & 3348 & 1301 & 73,2 & 19,5 & 29,2 \\
\hline MG & São José da Lapa & 15000 & 0,94 & 3349 & 1302 & 34,4 & 65,9 & 100,5 \\
\hline MG & Santa Margarida & 13713 & 0,94 & 3354 & 1303 & 44,8 & 54,9 & 71,0 \\
\hline MT & Campo Novo do Parecis & 17638 & 0,94 & 3356 & 1304 & 26,2 & 73,3 & 129,5 \\
\hline MG & Monte Belo & 13142 & 0,94 & 3357 & 1305 & 33,5 & 67,0 & 53,7 \\
\hline MT & Nova Canaẫ do Norte & 11516 & 0,94 & 3358 & 1306 & 42,1 & 55,2 & 60,7 \\
\hline MG & Cláudio & 22522 & 0,94 & 3361 & 1307 & 36,6 & 63,5 & 57,6 \\
\hline MG & Vazante & 18928 & 0,94 & 3362 & 1308 & 38,2 & 61,8 & 58,0 \\
\hline MG & Extrema & 19219 & 0,94 & 3363 & 1309 & 29,8 & 71,2 & 46,3 \\
\hline MG & Cabo Verde & 13727 & 0,95 & 3365 & 1310 & 33,5 & 67,0 & 38,0 \\
\hline MG & Nova Resende & 13887 & 0,95 & 3366 & 1311 & 33,5 & 67,0 & 71,9 \\
\hline
\end{tabular}


Tabela 32. Ranking de eficiência dos municípios com população maior de 50000 habitantes

\begin{tabular}{|c|c|c|c|c|c|c|c|c|}
\hline Estado & Municípios & População & TEi & $\begin{array}{c}\text { Ranking } \\
\text { Geral }\end{array}$ & $\begin{array}{c}\text { Rnking } \\
\text { ajustado* }\end{array}$ & $\begin{array}{l}\text { Mortalidade } \\
\text { Infantil }\end{array}$ & ID & $\begin{array}{l}\text { Gastos por } \\
\text { habitante }\end{array}$ \\
\hline \multicolumn{9}{|c|}{ MELHORES COLOCADOS } \\
\hline PR & Pato Branco & 62234 & 0,55 & 41 & 1 & 8,1 & 94,9 & 156,3 \\
\hline $\mathrm{SP}$ & São Joẫo da Boa Vista & 77387 & 0,56 & 58 & 2 & 6,9 & 96,8 & 72,5 \\
\hline RS & Viamấo & 227429 & 0,57 & 65 & 3 & 11,3 & 91,1 & 19,2 \\
\hline $\mathrm{PR}$ & Cianorte & 57401 & 0,58 & 79 & 4 & 8,3 & 94,6 & 61,6 \\
\hline SP & Embu-Guaçu & 56916 & 0,59 & 95 & 5 & 10,5 & 90,1 & 86,8 \\
\hline $\mathrm{SP}$ & Caçapava & 76130 & 0,63 & 149 & 6 & 9,7 & 91,4 & 127,9 \\
\hline $\mathrm{SP}$ & São Paulo & 10434252 & 0,63 & 152 & 7 & 21,7 & 76,6 & 106,2 \\
\hline $\mathrm{SP}$ & Bebedouro & 74815 & 0,63 & 157 & 8 & 10,4 & 90,3 & 45,0 \\
\hline MG & Alfenas & 66957 & 0,64 & 171 & 9 & 11,4 & 94,5 & 30,9 \\
\hline RS & Bento Gonçalves & 91486 & 0,64 & 175 & 10 & 7,5 & 97,6 & 40,0 \\
\hline $\mathrm{SP}$ & Fernandópolis & 61647 & 0,64 & 177 & 11 & 8,4 & 93,9 & 63,0 \\
\hline SP & Sẫo Caetano do Sul & 140159 & 0,64 & 180 & 12 & 5,4 & 100,0 & 170,7 \\
\hline RJ & Itaperuna & 86720 & 0,64 & 189 & 13 & 12,8 & 86,1 & 149,2 \\
\hline PR & Pinhais & 102985 & 0,65 & 211 & 14 & 10,8 & 90,1 & 65,7 \\
\hline $\mathrm{SC}$ & Chapecó & 146967 & 0,65 & 214 & 15 & 11,0 & 94,3 & 105,0 \\
\hline \multicolumn{9}{|c|}{ PIORES COLOCADOS } \\
\hline $\mathrm{BA}$ & Conceiçẫo do Coité & 56317 & 0,92 & 3231 & 346 & 69,7 & 23,0 & 26,7 \\
\hline RS & Sẫo Leopoldo & 193547 & 0,92 & 3235 & 347 & 23,8 & 72,7 & 139,2 \\
\hline $\mathrm{SC}$ & Criciúma & 170420 & 0,92 & 3243 & 348 & 22,7 & 78,7 & 112,9 \\
\hline RJ & Macaé & 132461 & 0,92 & 3246 & 349 & 23,5 & 69,3 & 91,9 \\
\hline PE & Caruaru & 253634 & 0,92 & 3251 & 350 & 47,7 & 58,3 & 41,8 \\
\hline ES & Vila Velha & 345965 & 0,92 & 3256 & 351 & 26,2 & 71,5 & 20,6 \\
\hline$M G$ & Itajubá & 84135 & 0,92 & 3272 & 352 & 26,1 & 75,5 & 23,8 \\
\hline PR & Arapongas & 85428 & 0,92 & 3280 & 353 & 23,9 & 69,9 & 37,0 \\
\hline SE & Aracaju & 461534 & 0,92 & 3283 & 354 & 39,0 & 64,3 & 29,7 \\
\hline $\mathrm{BA}$ & Jacobina & 76492 & 0,93 & 3307 & 355 & 65,3 & 27,4 & 25,3 \\
\hline RS & Passo Fundo & 168458 & 0,93 & 3308 & 356 & 25,0 & 71,1 & 42,8 \\
\hline$M G$ & Araxá & 78997 & 0,94 & 3347 & 357 & 28,4 & 72,8 & 65,5 \\
\hline $\mathrm{BA}$ & Irecê & 57436 & 0,94 & 3351 & 358 & 62,2 & 30,5 & 35,0 \\
\hline $\mathrm{BA}$ & Barreiras & 131849 & 0,94 & 3353 & 359 & 46,9 & 46,9 & 53,2 \\
\hline $\mathrm{ES}$ & Vitória & 292304 & 0,95 & 3367 & 360 & 26,7 & 75,5 & 112,9 \\
\hline
\end{tabular}

A seguir a tabela 33 explicita a melhor e a pior colocação dentro de cada estado, tendo o intuito de ilustrar a disparidade de eficiência dentro de cada unidade da federação. No Paraná, por exemplo, onde está localizado o $2^{\circ}$ município mais bem classificado no ranking geral, está também o município de Virmond, que ocupa a $3329^{a}$ posição. 
Tabela 33. Municípios com melhor e pior classificação por Estado

\begin{tabular}{|c|c|c|c|c|c|c|}
\hline \multicolumn{4}{|c|}{ Melhor Classificação } & \multicolumn{3}{|c|}{ Pior Classificação } \\
\hline UF & Município & TEi & Ranking & Município & TEi & Ranking \\
\hline $\mathrm{AC}$ & Jordẫo & 0,54 & 30 & Rio Branco & 0,86 & 2172 \\
\hline $\mathrm{AL}$ & Igreja Nova & 0,56 & 53 & Major Isidoro & 0,87 & 2396 \\
\hline $\mathrm{AM}$ & Novo Aripuanẫ & 0,69 & 326 & Juruá & 0,89 & 2657 \\
\hline $\mathrm{BA}$ & Glória & 0,63 & 159 & Barreiras & 0,94 & 3353 \\
\hline $\mathrm{CE}$ & Ipu & 0,61 & 126 & Icapuí & 0,91 & 2998 \\
\hline ES & Santa Teresa & 0,67 & 259 & Vitória & 0,95 & 3367 \\
\hline $\mathrm{GO}$ & Nerópolis & 0,54 & 36 & Turvelândia & 0,92 & 3209 \\
\hline $\mathrm{MA}$ & Morros & 0,75 & 620 & Riachẫo & 0,92 & 3264 \\
\hline$M G$ & São Joẫo das Missốes & 0,55 & 45 & Antônio Prado de Minas & 0,95 & 3368 \\
\hline MS & Guia Lopes da Laguna & 0,70 & 397 & Bataguassu & 0,93 & 3319 \\
\hline MT & Acorizal & 0,66 & 241 & Nova Canaấ do Norte & 0,94 & 3358 \\
\hline PA & Anajás & 0,56 & 57 & Marabá & 0,91 & 3003 \\
\hline PB & Bananeiras & 0,65 & 199 & Bonito de Santa Fé & 0,92 & 3271 \\
\hline $\mathrm{PE}$ & Chẫ de Alegria & 0,69 & 329 & Sanharó & 0,93 & 3336 \\
\hline $\mathrm{PI}$ & Miguel Leẫo & 0,56 & 62 & Jurema & 0,92 & 3204 \\
\hline $\mathrm{PR}$ & Salgado Filho & 0,40 & 2 & Virmond & 0,93 & 3329 \\
\hline RJ & Quatis & 0,61 & 125 & Varre-Sai & 0,93 & 3306 \\
\hline RN & Santo Antônio & 0,56 & 52 & Pureza & 0,91 & 3089 \\
\hline $\mathrm{RO}$ & Espigẫo D'Oeste & 0,77 & 852 & Corumbiara & 0,92 & 3192 \\
\hline $\mathrm{RR}$ & Boa Vista & 0,91 & 3096 & Boa Vista & 0,91 & 3096 \\
\hline RS & Dilermando de Aguiar & 0,40 & 1 & Passo Fundo & 0,93 & 3308 \\
\hline $\mathrm{SC}$ & Abelardo Luz & 0,52 & 23 & Novo Horizonte & 0,94 & 3360 \\
\hline SE & Campo do Brito & 0,64 & 166 & Aracaju & 0,92 & 3283 \\
\hline $\mathrm{SP}$ & Santo Expedito & 0,45 & 4 & Uru & 0,92 & 3258 \\
\hline $\mathrm{TO}$ & Sucupira & 0,65 & 192 & Divinópolis do Tocantins & 0,94 & 3343 \\
\hline
\end{tabular}

O fato da medida de ineficiência ter interpretação inversa no caso da fronteira de mortalidade infantil não causa maiores problemas na elaboração do ranking, pois permite a comparação entre municípios, entretanto, dificulta a avaliação da magnitude da ineficiência (os valores relativos são confiáveis, mas o absoluto não tem significado direto). Por esse motivo, com o intuito de obter uma estimativa do grau de eficiência dos municípios, foi calculada a eficiência máxima e mínima dentro de cada unidade da federação, através da utilização de uma fronteira de mortalidade infantil ajustada. Para isso foi criado um índice de mortalidade infantil invertido, onde:

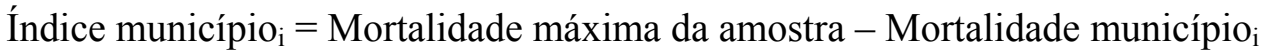

Estimando a fronteira estocástica a partir desse índice o termo TEi volta a ter a interpretação usual, sendo que quanto mais próximo de 1 é esse termo mais eficiente é o município, uma vez que se encontra mais próximo da fronteira de possibilidade de produção. Ademais, vale dizer que o ranking gerado pela fronteira estimada por esse índice apresenta correlação relativamente alta com a estimada via indicador de mortalidade infantil (feitas as adaptações descritas nos parágrafos anteriores), de 0,87 - dessa forma, podemos concluir que estimar a fronteira com o índice de mortalidade infantil normal e depois inverter a interpretação do TEi gerado $\left(1^{\circ}\right.$ procedimento 
adotado); ou inverter o índice de mortalidade infantil e dar a interpretação usual para o TEi ( $2^{\circ}$ procedimento adotado), produz rankings relativamente similares.

Tabela 34. Eficiêcia Máxima e Mínima em cada Estado

Via Fronteira Estocástica com índice de mortalidade infantil invertido como produto

\begin{tabular}{|c|c|c|c|c|c|}
\hline UF & Eficiência Máxima & Eficiência Mínima & Total & Amostra & $\begin{array}{c}\text { Representatividade } \\
\text { da amostra }\end{array}$ \\
\hline $\mathrm{AC}$ & 0.99 & 0.95 & 22 & 8 & $36.4 \%$ \\
\hline $\mathrm{AL}$ & 0.99 & 0.39 & 102 & 46 & $45.1 \%$ \\
\hline $\mathrm{AM}$ & 0.97 & 0.51 & 62 & 7 & $11.3 \%$ \\
\hline AP & - & - & 16 & 0 & $0.0 \%$ \\
\hline $\mathrm{BA}$ & 0.99 & 0.41 & 418 & 201 & $48.1 \%$ \\
\hline $\mathrm{CE}$ & 0.99 & 0.62 & 187 & 64 & $34.2 \%$ \\
\hline ES & 0.97 & 0.76 & 80 & 55 & $68.8 \%$ \\
\hline GO & 0.98 & 0.78 & 246 & 149 & $60.6 \%$ \\
\hline MA & 0.96 & 0.46 & 217 & 29 & $13.4 \%$ \\
\hline MG & 0.99 & 0.51 & 853 & 643 & $75.4 \%$ \\
\hline MS & 0.98 & 0.80 & 77 & 41 & $53.2 \%$ \\
\hline MT & 0.98 & 0.73 & 139 & 67 & $48.2 \%$ \\
\hline PA & 0.99 & 0.81 & 143 & 11 & $7.7 \%$ \\
\hline PB & 0.98 & 0.51 & 223 & 99 & $44.4 \%$ \\
\hline PE & 0.98 & 0.33 & 185 & 69 & $37.3 \%$ \\
\hline $\mathrm{PI}$ & 0.99 & 0.45 & 222 & 80 & $36.0 \%$ \\
\hline PR & 0.99 & 0.77 & 403 & 365 & $90.6 \%$ \\
\hline $\mathrm{RJ}$ & 0.98 & 0.79 & 93 & 61 & $65.6 \%$ \\
\hline RN & 0.99 & 0.39 & 167 & 59 & $35.3 \%$ \\
\hline $\mathrm{RO}$ & 0.96 & 0.84 & 52 & 29 & $55.8 \%$ \\
\hline $\mathrm{RR}$ & 0.88 & 0.88 & 15 & 1 & $6.7 \%$ \\
\hline $\mathrm{RS}$ & 0.99 & 0.82 & 496 & 402 & $81.0 \%$ \\
\hline $\mathrm{SC}$ & 0.98 & 0.79 & 293 & 266 & $90.8 \%$ \\
\hline SE & 0.99 & 0.56 & 75 & 35 & $46.7 \%$ \\
\hline $\mathrm{SP}$ & 0.98 & 0.82 & 646 & 529 & $81.9 \%$ \\
\hline $\mathrm{TO}$ & 0.99 & 0.34 & 139 & 51 & $36.7 \%$ \\
\hline Brasil & 0.99 & 0.33 & 5572 & 3367 & $60.4 \%$ \\
\hline
\end{tabular}

A tabela 34 também explicita as disparidades de eficiência dentro de uma mesma Unidade da Federação. No Alagoas, por exemplo, o grau de eficiência $\left(\mathrm{TE}_{\mathrm{i}}\right)$ oscila desde 0,99 até 0,39. Alguns estados mostram um intervalo de oscilação menor, contudo deve ser levado em consideração o tamanho da amostra de municípios: no Acre, por exemplo, a eficiência máxima é de 0,99 e a mínima de 0,95 , porém, são considerados apenas 8 municípios, que correspondem a apenas 36,4\% do total de seus municípios. Já em São Paulo a cobertura amostral é bastante ampla (529 municípios que correspondem a $81,9 \%$ do total do estado), e ainda assim o intervalo de oscilação de eficiência é relativamente estreito (o mesmo pode ser dito do Rio Grande do Sul, com $81 \%$ de cobertura e intervalo de oscilação idêntico ao dos municípios paulistas).

É importante frisar que não foi mostrado nesse estudo nenhum indicador de ineficiência média (nem nacional e nem estadual). Essa decisão foi tomada pois é muito provável que esse indicador seria distorcido por um viés de seleção, uma vez que o fato de alguns municípios não 
declararem (ou retardarem a declaração) seus gastos pode estar correlacionado a um grau menor de eficiência, sendo assim, estados que possuem representatividade pequena na amostra provavelmente teriam sua eficiência superestimada.

\section{6 - CONCLUSÕES}

A maior motivação desse trabalho foi comparar a eficiência dos municípios na produção de saúde. Para isso foi utilizado o método de fronteiras estocásticas. Esse método se mostrou adequado uma vez que sua maior limitação - necessidade de assumir hipóteses distributivas sobre o termo de ineficiência - aparentemente não foi um problema relevante, pois os resultados se mostraram robustos em relação a diferentes escolhas de distribuição.

Uma dificuldade encontrada foi a decisão a respeito do índice que deveria ser tomado como produto para a construção da fronteira, já que dependendo dessa escolha os resultados encontrados são significativamente afetados. A opção aqui adotada foi o índice de mortalidade infantil, motivada por dois fatores principais: (i) os modelos estimados para essa variável apresentaram poder explicativo mais elevado; e (ii) a significância dos gastos com saúde é mais elevada nas equações dessa variável.

O principal receio em relação ao uso da mortalidade infantil como "termômetro" da eficiência do sistema de saúde é o fato de que esse indicador está altamente correlacionado a uma série de outros fatores, como por exemplo as condições de saneamento e educação. Contudo, como foram incluídas diversas variáveis de controle, esse efeito foi dissolvido. Além disso, tanto a expectativa de vida como a probabilidade de se atingir 60 anos são indicadores que se alteram lentamente. Dessa forma, é de se esperar que a ampliação dos gastos em saúde, mesmo que feita de forma eficiente, leve um tempo considerável para produzir melhorias nesses indicadores. Assim, levando todos esses argumentos em consideração, a escolha do indicador de mortalidade infantil parece ter sido de fato a mais apropriada.

Ainda assim, é forçoso reconhecer que existe o problema de abrangência do indicador, uma vez que a mortalidade infantil está relacionada a uma parcela muito específica da população, além de não levar em conta a saúde dos indivíduos em vida. Nesse sentido, seria muito útil construir um índice de expectativa de vida ajustada, mas infelizmente, com os dados disponíveis até o momento da elaboração desse trabalho, essa tarefa muito dificilmente poderia ser executada. Esse, aliás, é um caminho que pode ser explorado em uma obra posterior, visando aprimorar os resultados encontrados aqui.

Quanto aos resultados observados no ranking gerado, destacaram-se positivamente alguns municípios de São Paulo (incluindo a capital), do Rio Grande do Sul e do Paraná. Já do lado 
negativo, chama a atenção o número de municípios mineiros que se encontram entre os piores colocados.

Quanto às variáveis selecionadas para explicar a ineficiência, os principais resultados encontrados foram: (i) a utilização mais intensiva em tecnologia reduz tanto a variância quanto a média da ineficiência; (ii) a maior participação das transferências na receita do município está associada a uma maior variância e também a uma ineficiência mais elevada esses dois primeiros resultados vão na mesma linha que os encontrados por Sousa, CribariNeto, Stosic e Borko (2003) que concluíram que o grau de utilização de computadores aumenta a eficiência e o recebimento de royalties reduz; (iii) os programas Saúde da Família e Agentes Comunitários da Saúde aparentemente não alcançam os objetivos desejáveis, uma vez que a proporção da população coberta por esses programas está positivamente correlacionada com a ineficiência e a variância; e (iv) a parceria com o setor privado parece trazer alguns benefícios, uma vez que o porcentual de hospitais/leitos privados que atendem ao SUS em relação ao total de hospitais/leitos que fazem esse atendimento está associado a uma menor variância da ineficiência.

\section{BIBLIOGRAFIA}

Afonso, A. e M. St Aubyn 2004. Non-parametric approaches to education and health : expenditure efficiency in OECD countries. Mimeo. Technical University of Lisbon.

Afonso, A., L. Schuknecht e V. Tanzi 2003. Public sector efficiency : an international comparison. Working paper 242, European Central Bank.

Afonso, A., L. Schuknecht e V. Tanzi 2006. "Public Sector Efficiency Evidence for New EU Member States and Emerging Markets". Working paper 581, European Central Bank.

Aigner, D., C. A. K. Lovell and P. Schmidt. (1977). "Formulation and Estimation of Stochastic Frontier Production Function Models." Journal of Econometrics 6, 21-37.

Andrade, M. V. (2000). Ensaios em economia da saúde. Tese de doutorado - EPGE, Rio de Janeiro.

Miranda R. B. (2006). Uma avaliação de eficiência dos municípios brasileiros na provisão de serviços públicos usando "Data Envelopment Analisys". Ipea, boletim de desenvolvimento fiscal 03.

Battese, G. and T.J. Coelli. (1995). "A Model for Technical Inefficiency Effects in a Stochastic Frontier Production Function for Panel Data." Empirical Economics 20(2), 325332. 
Coelli, T.J., D. S. P. Rao and G. Battese. (1998). An Introduction to Efficiency and Productivity Analysis. Kluwer Academic Publishers, Boston.

Debreu. G (1951). “The Coefficient of Resource Utilization.” Econometrica 19(3), 273-292.

Evans, D., A. Tandon, C. JL Murria e J.A. Lauer. 2000. The comparative efficiency of national health systems in producing health : an analysis of 191 countries. World Health Organization GPE Discussion Paper Series no. 29.

Farrell, M. J. (1957). "The Measurement of Productive Efficiency." Journal of the Royal Statistical Society Series A, General, 120, 253-81.

Greene, W. (2000) A Gamma Distributed Stochastic Frontier Model. Journal of Econometrics,46:141-164.

Greene, W. (2003) Distinguishing between heterogeneity and inefficiency : stochastic frontier analysis of the World Health Organization's panel data on national health care systems. Mimeo. NYU.

Greene, W. 2005. Reconsidering heterogeneity in panel data estimators of the stochastic frontier model. Journal of Econometrics, v. 126, pp 282-283.

Gupta, S. e M. Verhoeven. 2001. The efficiency of government expenditures experiences from África. Journal of Policy Modeling, 23, 433-467.

Herrera, S. e G. Pang. 2005. Efficiency of public spending in developing countries: an efficiency frontier approach, Mimeo.

Jayasuriya, R. e Q. Wodon. 2002. Measuring and explaining country efficiency in improving health and education indicators. The World Bank.

Kumbhakar,S. and Lovell,K. 2000. Sthocastic Frontier Analysis. Cambridge University Press. Cambridge.

Lovell, C.1993. Production Frontiers and Productive Efficiency, in Fried, H. Lovell, C. and Schmidt, S. (eds). The Measurement of Productive Efficiency - Techniques and Applications. New York, Oxford University Press.

Lovell, C.2000. Measuring Efficiency in the Public Sector, in Blank, Jos L.T, (eds) Public Provision and Performance. Amsterdam, North-Holland.

Mathers C, Sadana R, Salomon J. et al. Estimates of DALE for 191 countries: methods and results. Geneva, Switzerland. World Health Organization, 2000 (Global Programme on Evidence for Health Policy Discussion Paper No.16.)

Meuse, W. and Van de Broeck, J. 1977. Efficiency estimation from Cobb-Douglas production functions with composed error. International Economic Review, 18, 435-444.

Mendonça, M. J. C e Motta R. S.(2005).Saúde e Saneamento no Brasil. IPEA. Texto para discussão 1081, Rio de Janeiro. 
Moesen, W. 1994. The need for performance auditing in the Public Sector and the BestPractice Frontier. European Journal of Law Economics, 1(4),263-274.

Pan American Health Organization (2003). Techniques to Meausere the impact of mortality: Years of Potential Life Lost. Epidemiological Bulletin. Vol. 24 No. 2

Peixoto H. C. G. e Souza M. L. (1999). O indicador Anos Potenciais de Vida Perdidos e as desigualdades regionais em Santa Catarina, no ano de 1995. Universidade Federal de Santa Catarina.

Pires, M. C. C. e Oliveira Neto, J. C. C. (2006). Indicador municipal de saúde: Uma análise dos sistemas municipais de saúde brasileiros. IPEA. Texto para discussão 1216, Brasília.

Pitt, M. e Lee,L. 1981 The measurement and sources of technical inefficiency in Indonesian weaving industry. Journal of Development Economics, 9:43-64.

Ravallion, M. 2003. On measuring aggregate social efficiency. Policy Research Working Paper 3166. The World Bank. November.

Sousa, M. C. S, F. Cribari-Neto e B. D. Stosic 2005. Explaining DEA Technical Efficiency Scores in an Outlier Corrected Environment: The Case of Public Services in Brazilian Municipalities. Brazilian Review of Econometrics.

Stevenson, R. (1980). "Likelihood Functions for Generalized Stochastic Frontier Functions". Journal of Econometrics 13, 57-66.

WHO, World Health Report 2000. Geneva, Switzerland. World Health Organization, 2000 
ANEXOS

Tabela 35. Ranking dos municípios com até $\mathbf{1 0}$ mil habitantes

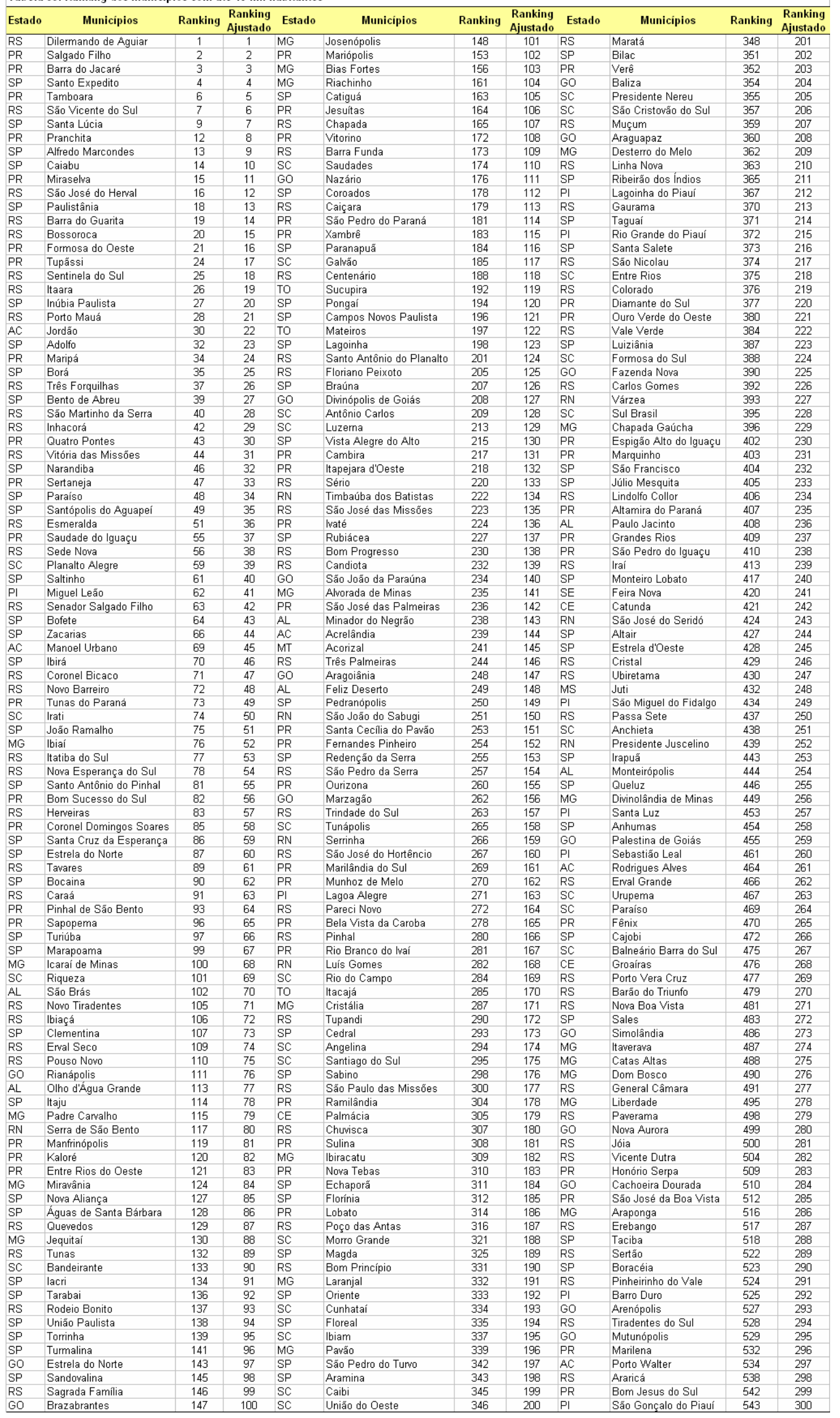


Tabela 35. Ranking dos municípios com até 10 mil habitantes - Fronteira estimada com indice de mortalidade infantil como produto Continua

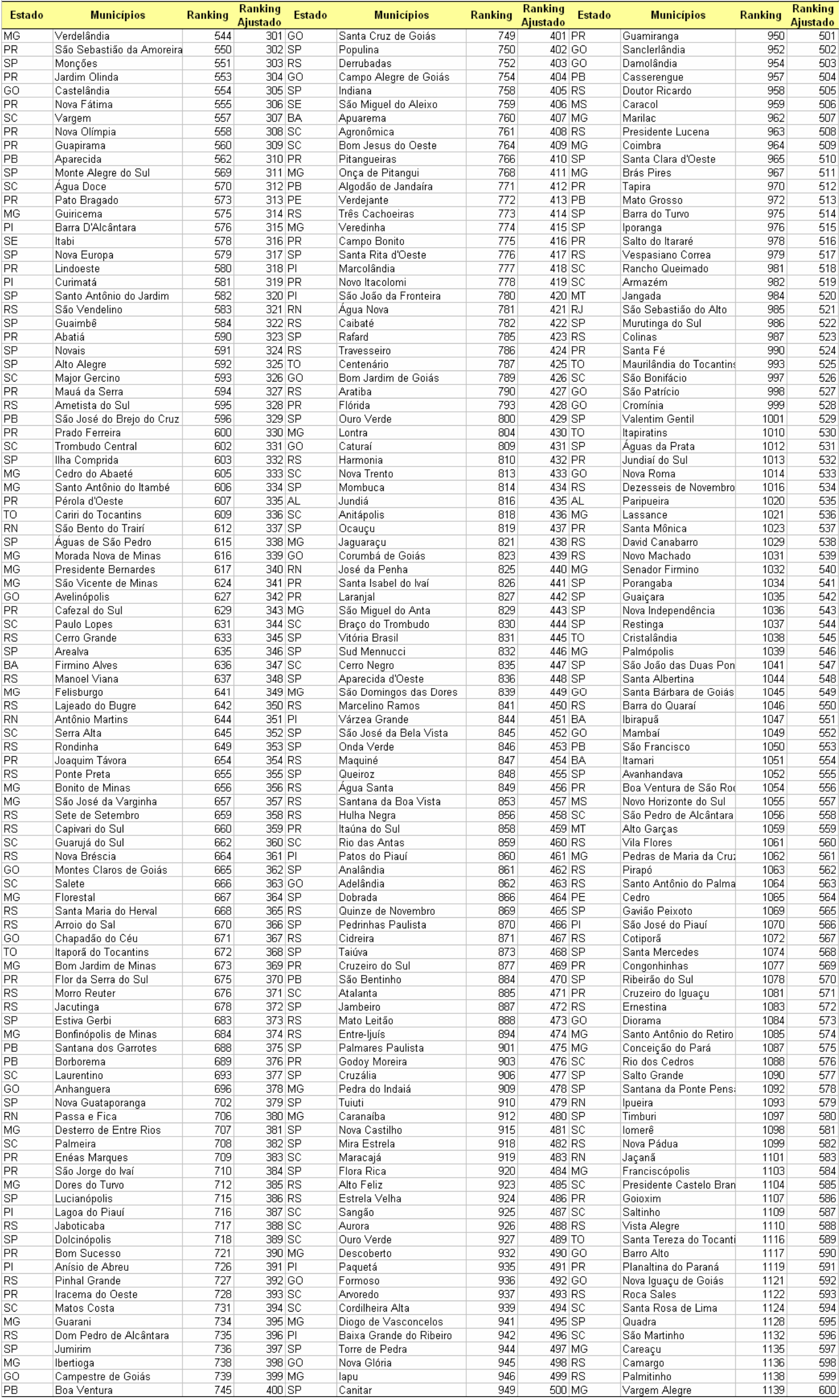




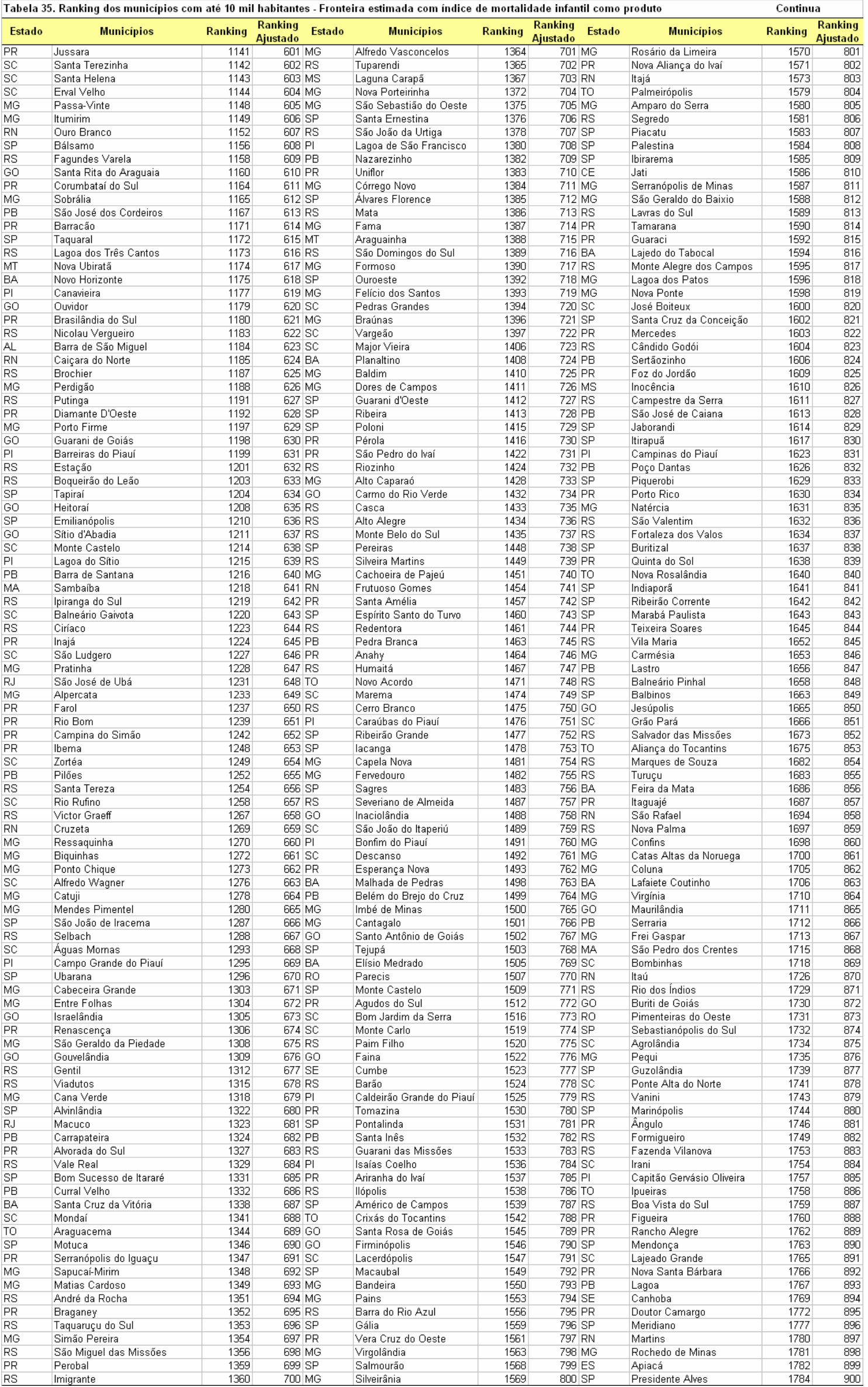


Tabela 35. Ranking dos municipios com até $10 \mathrm{mil}$ habitantes - Fronteira estimada com indice de mortalidade infantil como produto

Continua

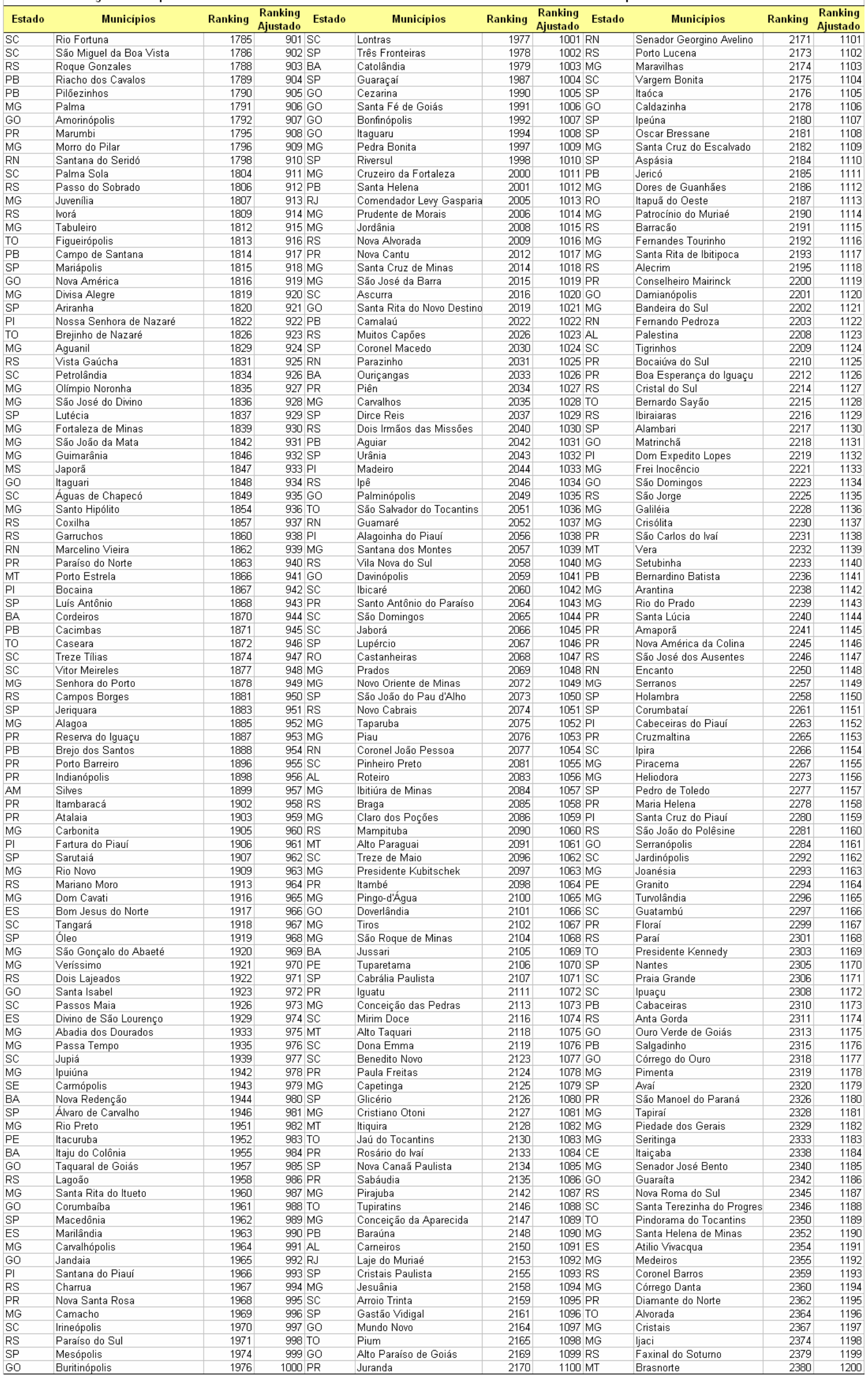




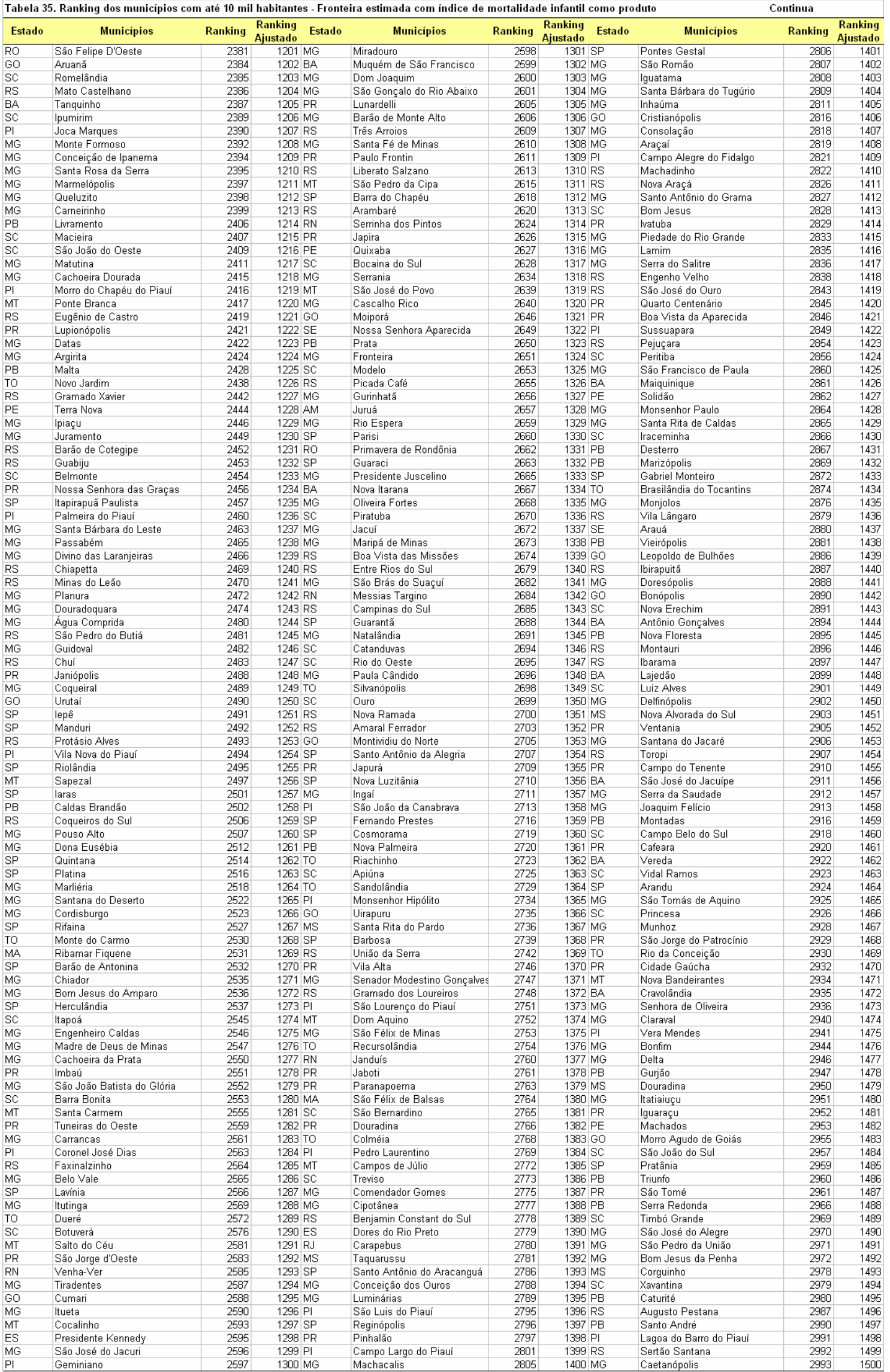


Tabela 35. Ranking dos municipios com até $\mathbf{1 0}$ mil habitantes - Fronteira estimada com indice de mortalidade infantil como produto

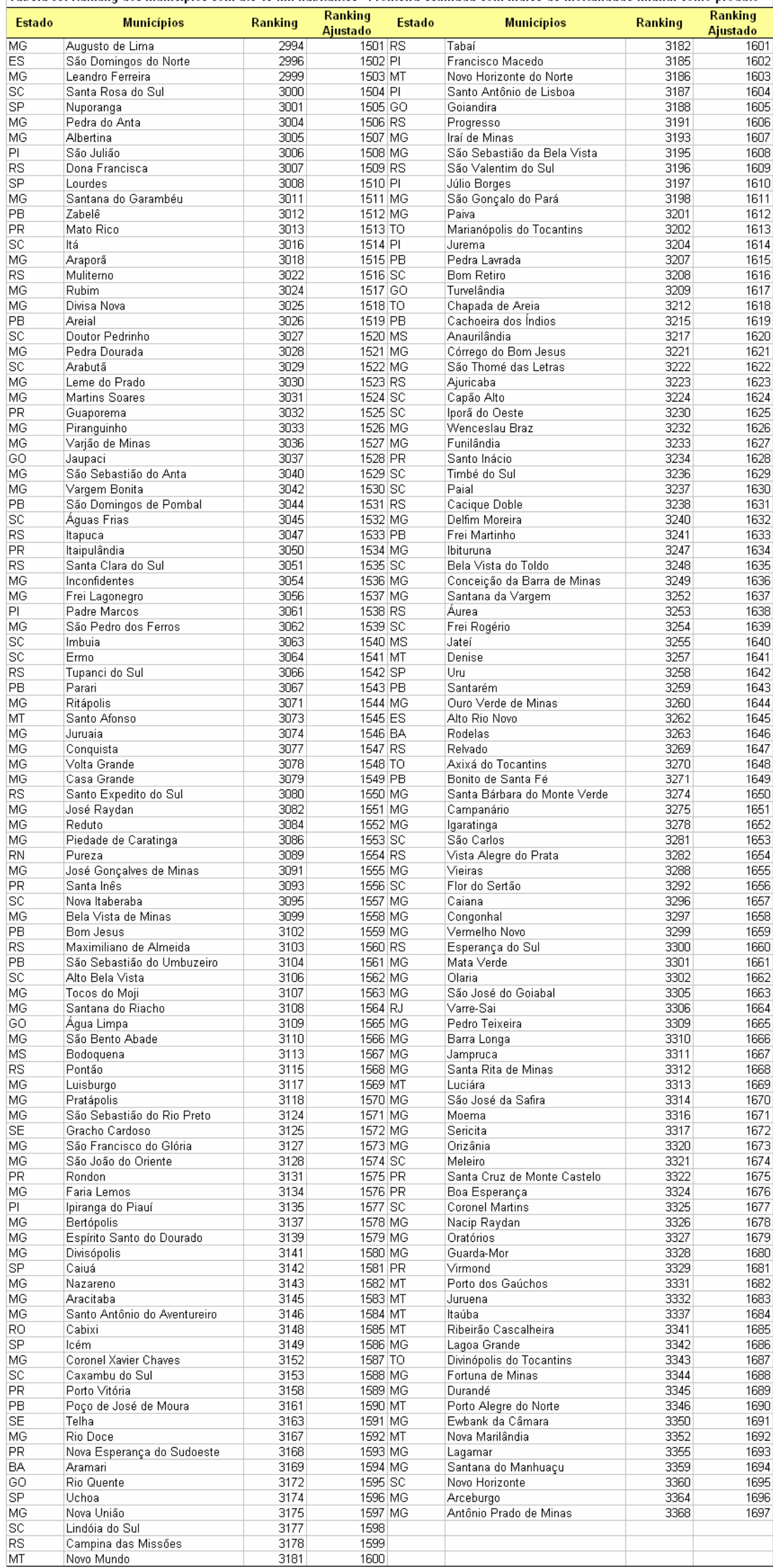


Tabela 36. Ranking dos municipios entre 10 e 15 mil habitantes - Fronteira estimada com indice de mortalidade infantil como produto

Continua

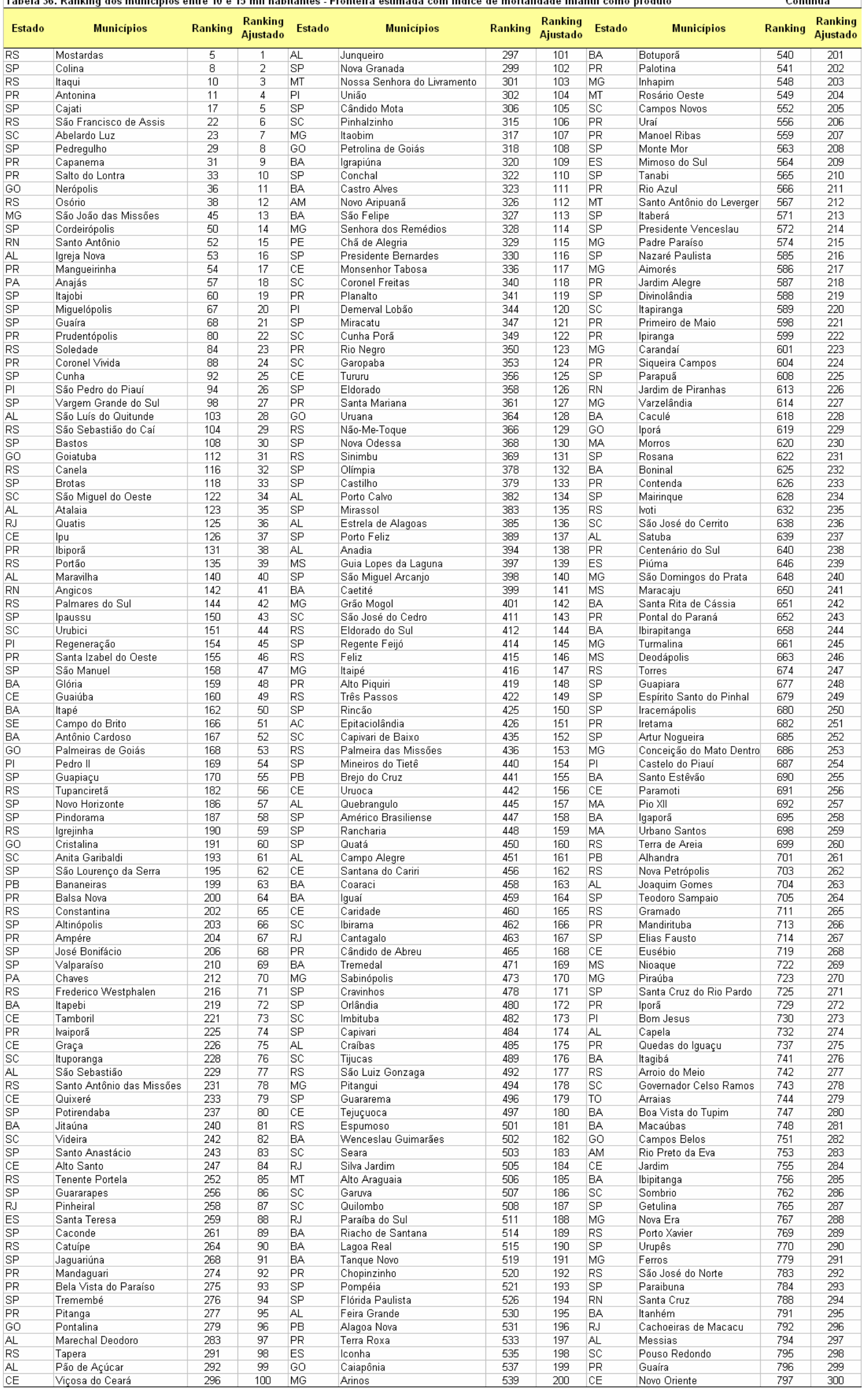




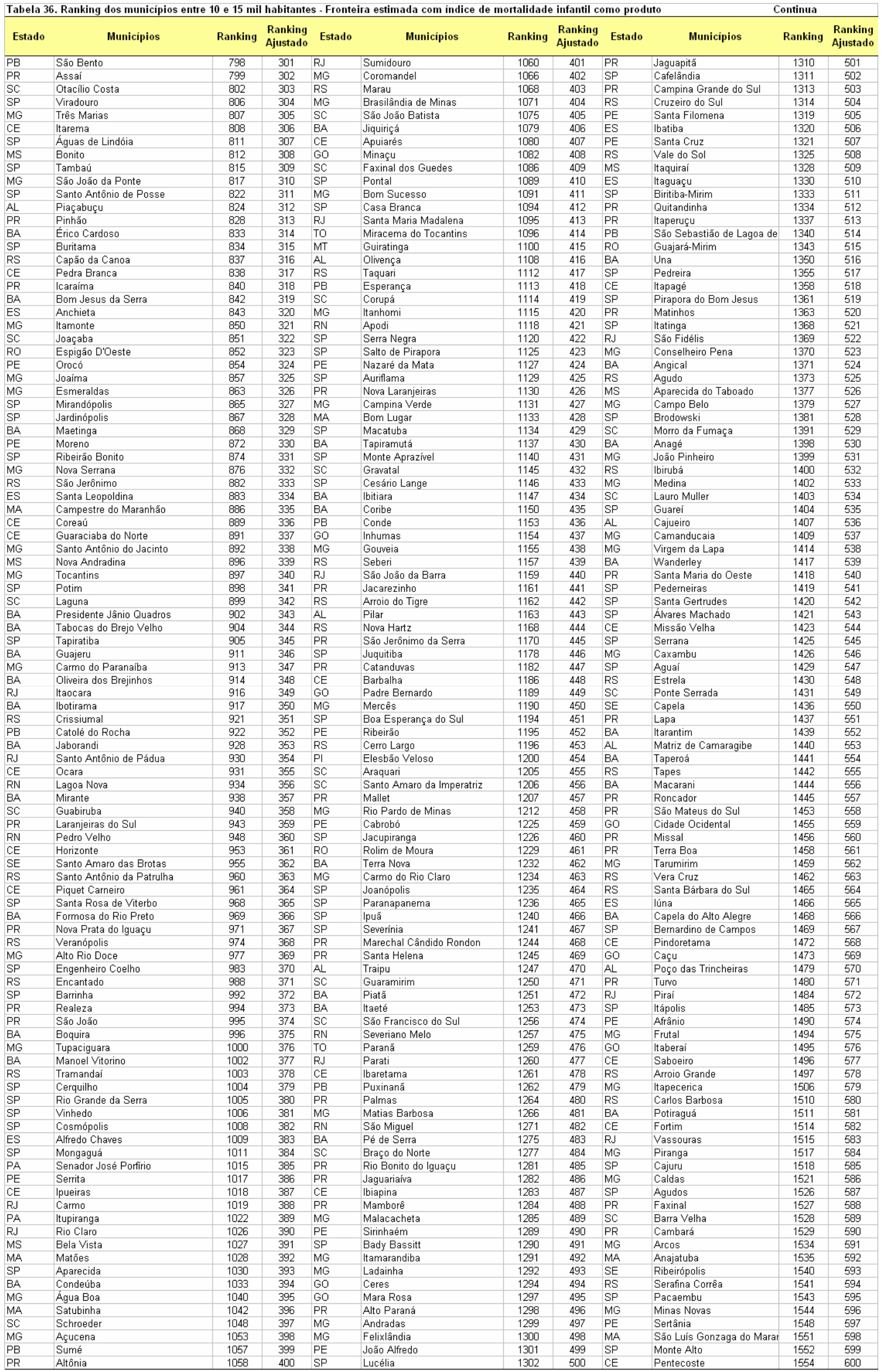




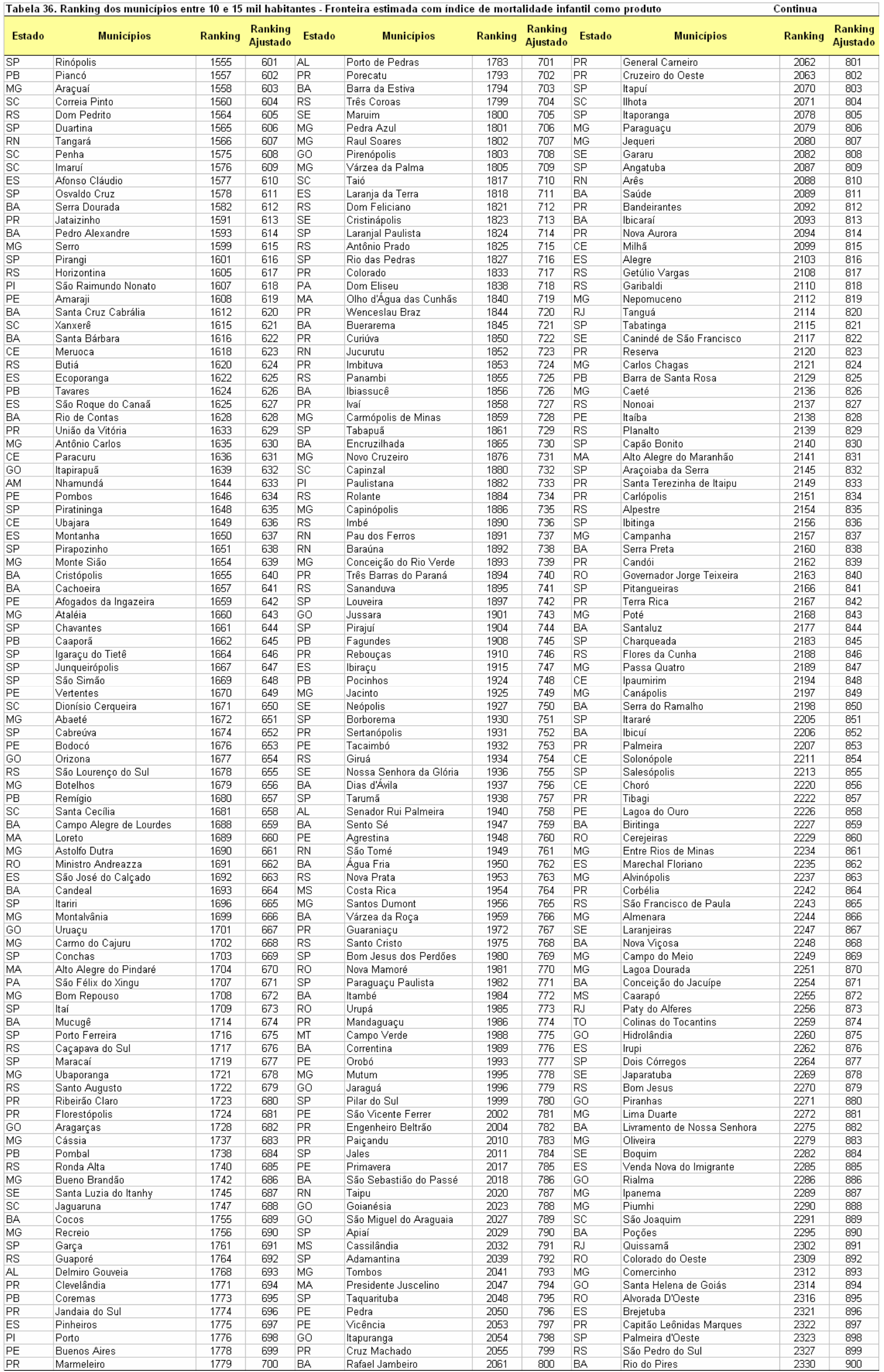


Tabela 36. Ranking dos municipios entre 10 e 15 mil habitantes - Fronteira estimada com indice de mortalidade infantil como produto Continua

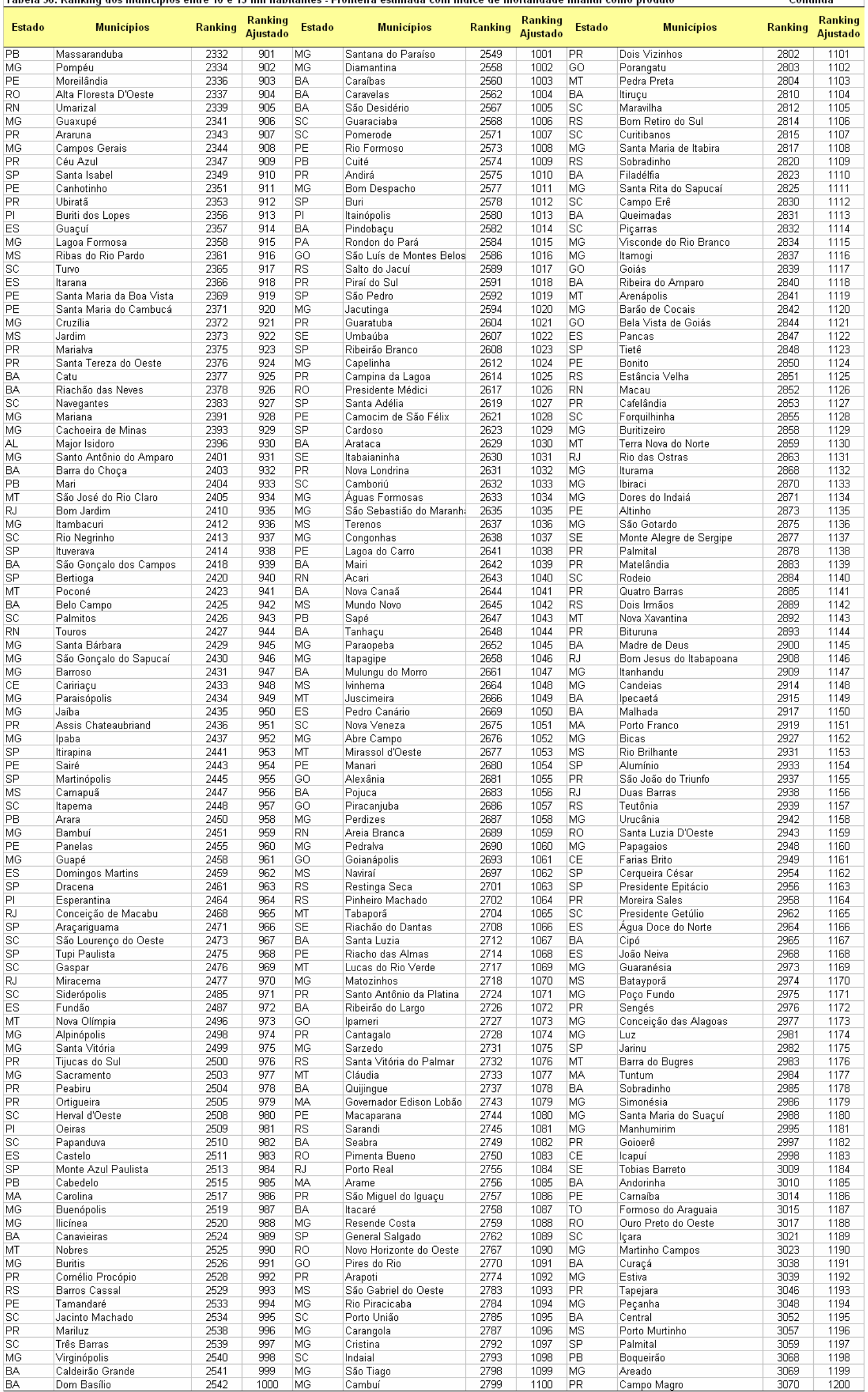


Tabela 36. Ranking dos municipios entre 10 e 15 mil habitantes - Fronteira estimada com índice de mortalidade infantil como produto

\begin{tabular}{|c|c|c|c|c|c|c|c|c|c|c|c|}
\hline Estado & Municipios & Ranking & $\begin{array}{l}\text { Ranking } \\
\text { Ajustado }\end{array}$ & Estado & Municipios & Ranking & $\begin{array}{l}\text { Ranking } \\
\text { Ajustado }\end{array}$ & Estado & Municipios & Ranking & $\begin{array}{l}\text { Ranking } \\
\text { Ajustado }\end{array}$ \\
\hline MT & Juara & 3072 & 1201 & MG & Santo Antônio do Monte & 3213 & 1251 & BA & Ibititá & 3348 & 1301 \\
\hline MT & Primavera do Leste & 3075 & 1202 & $\mathrm{BA}$ & Ibicoara & 3214 & 1252 & MG & Săo José da Lapa & 3349 & 1302 \\
\hline BA & Jussiape & 3076 & 1203 & MG & Presidente Olegário & 3216 & 1253 & MG & Santa Margarida & 3354 & 1303 \\
\hline $\mathrm{BA}$ & Canudos & 3081 & 1204 & MG & Borda da Mata & 3218 & 1254 & MT & Campo Novo do Parecis & 3356 & 1304 \\
\hline PE & Bom Conselho & 3083 & 1205 & SP & Vera Cruz & 3219 & 1255 & MG & Monte Belo & 3357 & 1305 \\
\hline MG & Rio Casca & 3085 & 1206 & MS & Brasilândia & 3220 & 1256 & MT & Nova Canaă do Norte & 3358 & 1306 \\
\hline GO & Nova Crixás & 3087 & 1207 & ES & Vila Valério & 3226 & 1257 & MG & Cláudio & 3361 & 1307 \\
\hline RO & Nova Brasilândia D'Oeste & 3088 & 1208 & RS & Jaguarẳo & 3227 & 1258 & MG & Vazante & 3362 & 1308 \\
\hline BA & Uauá & 3092 & 1209 & $\mathrm{PE}$ & Săo Caitano & 3228 & 1259 & MG & Extrema & 3363 & 1309 \\
\hline MG & Monte Alegre de Minas & 3094 & 1210 & MG & Teixeiras & 3229 & 1260 & MG & Cabo Verde & 3365 & 1310 \\
\hline MG & Muzambinho & 3098 & 1211 & ES & Itapemirim & 3239 & 1261 & MG & Nova Resende & 3366 & 1311 \\
\hline PR & São João do lvaí & 3100 & 1212 & MG & Porteirinha & 3242 & 1262 & & & & \\
\hline MG & Machado & 3105 & 1213 & $\mathrm{PE}$ & Itapetim & 3244 & 1263 & & & & \\
\hline $\mathrm{PR}$ & Rolândia & 3114 & 1214 & $\mathrm{BA}$ & Mucuri & 3245 & 1264 & & & & \\
\hline MT & Alta Floresta & 3116 & 1215 & MG & Rio Paranaíba & 3250 & 1265 & & & & \\
\hline RS & Lagoa Vermelha & 3119 & 1216 & $\mathrm{BA}$ & Nordestina & 3261 & 1266 & & & & \\
\hline MG & Divino & 3120 & 1217 & MA & Riachăo & 3264 & 1267 & & & & \\
\hline BA & Araças & 3122 & 1218 & MG & Brumadinho & 3265 & 1268 & & & & \\
\hline $\mathrm{SC}$ & Itaiópolis & 3123 & 1219 & $\mathrm{BA}$ & Antas & 3266 & 1269 & & & & \\
\hline PB & São Joăo do Rio do Peixe & 3126 & 1220 & MT & Nova Mutum & 3267 & 1270 & & & & \\
\hline MG & Raposos & 3132 & 1221 & PR & Nova Esperança & 3268 & 1271 & & & & \\
\hline MT & Aripuană & 3136 & 1222 & MG & Lagoa Santa & 3273 & 1272 & & & & \\
\hline RJ & Miguel Pereira & 3138 & 1223 & MT & Marcelândia & 3276 & 1273 & & & & \\
\hline MA & Pedreiras & 3140 & 1224 & $\mathrm{BA}$ & Abaré & 3277 & 1274 & & & & \\
\hline MG & Alterosa & 3144 & 1225 & MT & São Félix do Araguaia & 3279 & 1275 & & & & \\
\hline TO & Dianópolis & 3147 & 1226 & MG & Prata & 3284 & 1276 & & & & \\
\hline PE & Lagoa Grande & 3150 & 1227 & BA & Sítio do Quinto & 3285 & 1277 & & & & \\
\hline BA & Nilo Peçanha & 3151 & 1228 & MG & Monte Santo de Minas & 3286 & 1278 & & & & \\
\hline PB & Itaporanga & 3156 & 1229 & $\mathrm{BA}$ & Alcobaça & 3287 & 1279 & & & & \\
\hline $\mathrm{BA}$ & Chorrochó & 3159 & 1230 & MG & Maria da Fé & 3289 & 1280 & & & & \\
\hline SE & Propriá & 3162 & 1231 & RS & Tapejara & 3290 & 1281 & & & & \\
\hline MG & Itaguara & 3164 & 1232 & MG & Itabirito & 3291 & 1282 & & & & \\
\hline $\mathrm{BA}$ & Andaraí & 3165 & 1233 & MG & Nanuque & 3293 & 1283 & & & & \\
\hline $\mathrm{BA}$ & Belmonte & 3166 & 1234 & $\mathrm{BA}$ & lbipeba & 3294 & 1284 & & & & \\
\hline BA & Miguel Calmon & 3171 & 1235 & MG & Lagoa da Prata & 3295 & 1285 & & & & \\
\hline MG & lbiá & 3173 & 1236 & $\mathrm{BA}$ & Barro Alto & 3298 & 1286 & & & & \\
\hline MG & Sẩo Joăo Nepomuceno & 3176 & 1237 & MG & Dionísio & 3303 & 1287 & & & & \\
\hline RJ & Engenheiro Paulo de Frontin & 3179 & 1238 & MG & Itaú de Minas & 3304 & 1288 & & & & \\
\hline TO & Paraiso do Tocantins & 3180 & 1239 & MG & Espera Feliz & 3315 & 1289 & & & & \\
\hline PE & Barra de Guabiraba & 3184 & 1240 & ES & Jaguaré & 3318 & 1290 & & & & \\
\hline $\mathrm{BA}$ & Caém & 3189 & 1241 & MS & Bataguassu & 3319 & 1291 & & & & \\
\hline ES & Muqui & 3190 & 1242 & MG & Carmo da Mata & 3323 & 1292 & & & & \\
\hline $\mathrm{RO}$ & Corumbiara & 3192 & 1243 & MG & Brasópolis & 3330 & 1293 & & & & \\
\hline MG & Lajinha & 3194 & 1244 & ES & Jerônimo Monteiro & 3333 & 1294 & & & & \\
\hline PB & Monteiro & 3199 & 1245 & MT & Colíder & 3334 & 1295 & & & & \\
\hline PR & Medianeira & 3200 & 1246 & $\mathrm{BA}$ & Ribeira do Pombal & 3335 & 1296 & & & & \\
\hline PR & Astorga & 3203 & 1247 & $\mathrm{PE}$ & Sanharó & 3336 & 1297 & & & & \\
\hline BA & Banzaê & 3205 & 1248 & MG & Além Paraíba & 3338 & 1298 & & & & \\
\hline MG & Monte Carmelo & 3206 & 1249 & ES & Baixo Guandu & 3339 & 1299 & & & & \\
\hline MG & Belo Oriente & 3211 & 1250 & MG & Mário Campos & 3340 & 1300 & & & & \\
\hline
\end{tabular}




\begin{tabular}{|c|c|c|c|c|c|c|c|c|c|c|c|}
\hline Estado & Municipios & Ranking & $\begin{array}{l}\text { Ranking } \\
\text { Ajustado }\end{array}$ & Estado & Municipios & Ranking & $\begin{array}{l}\text { Ranking } \\
\text { Ajustado }\end{array}$ & Estado & Municípios & Ranking & $\begin{array}{l}\text { Ranking } \\
\text { Ajustado }\end{array}$ \\
\hline$\overline{P R}$ & Pato Branco & 41 & 1 & RS & Sapucaia do Sul & 697 & 61 & GO & Aparecida de Goiânia & 1222 & 121 \\
\hline SP & São Joẫo da Boa Vista & 58 & 2 & MG & Divinópolis & 700 & 62 & SP & Itapevi & 1230 & 122 \\
\hline RS & Viamão & 65 & 3 & RS & Esteio & 720 & 63 & SP & Taboẫo da Serra & 1238 & 123 \\
\hline PR & Cianorte & 79 & 4 & PA & Santarém & 724 & 64 & RJ & Săo Joăo de Meriti & 1243 & 124 \\
\hline SP & Embu-Guaçu & 95 & 5 & AL & Rio Largo & 733 & 65 & GO & Jataí & 1246 & 125 \\
\hline $\mathrm{SP}$ & Caçapava & 149 & 6 & $\mathrm{SP}$ & Lins & 740 & 66 & $\mathrm{SP}$ & Cotia & 1255 & 126 \\
\hline SP & Săo Paulo & 152 & 7 & RJ & Nova Friburgo & 746 & 67 & CE & Boa Viagem & 1263 & 127 \\
\hline $\mathrm{SP}$ & Bebedouro & 157 & 8 & $\mathrm{SP}$ & Bragança Paulista & 757 & 68 & $\mathrm{CE}$ & Maracanaú & 1265 & 128 \\
\hline MG & Alfenas & 171 & 9 & CE & Maranguape & 763 & 69 & PR & Ponta Grossa & 1268 & 129 \\
\hline RS & Bento Gonçalves & 175 & 10 & MG & Ituiutaba & 801 & 70 & RS & Cachoeirinha & 1274 & 130 \\
\hline SP & Fernandópolis & 177 & 11 & PE & Jaboatão dos Guararapes & 803 & 71 & $\mathrm{PI}$ & Picos & 1279 & 131 \\
\hline SP & São Caetano do Sul & 180 & 12 & SP & Carapicuíba & 805 & 72 & SP & Piracicaba & 1286 & 132 \\
\hline RJ & Itaperuna & 189 & 13 & $\mathrm{SP}$ & Hortolândia & 820 & 73 & $\mathrm{SP}$ & Peruibe & 1307 & 133 \\
\hline $\mathrm{PR}$ & Pinhais & 211 & 14 & MG & Pedro Leopoldo & 855 & 74 & SE & Itabaiana & 1316 & 134 \\
\hline SC & Chapecó & 214 & 15 & SP & Atibaia & 864 & 75 & RJ & Nova Iguaçu & 1317 & 135 \\
\hline $\mathrm{CE}$ & Cascavel & 245 & 16 & MG & São Joẫo del Rei & 875 & 76 & RS & Lajeado & 1326 & 136 \\
\hline $\mathrm{PR}$ & Araucária & 246 & 17 & MA & São Luís & 878 & 77 & MA & Santa Luzia & 1335 & 137 \\
\hline $\mathrm{PR}$ & Apucarana & 273 & 18 & MG & Patrocínio & 879 & 78 & $\mathrm{SP}$ & São Carlos & 1336 & 138 \\
\hline SP & Catanduva & 286 & 19 & SP & Caieiras & 880 & 79 & $\mathrm{SP}$ & Itatiba & 1339 & 139 \\
\hline AL & Palmeira dos Índios & 288 & 20 & $\mathrm{PE}$ & São Lourenço da Mata & 881 & 80 & RS & Cachoeira do Sul & 1342 & 140 \\
\hline SP & Mococa & 289 & 21 & SP & Campo Limpo Paulista & 890 & 81 & RJ & Itaboraí & 1345 & 141 \\
\hline CE & Russas & 303 & 22 & SP & Votorantim & 893 & 82 & TO & Gurupi & 1357 & 142 \\
\hline AL & Săo Miguel dos Campos & 313 & 23 & GO & Luziânia & 895 & 83 & $\mathrm{SP}$ & lbiúna & 1362 & 143 \\
\hline $\mathrm{SC}$ & Joinville & 319 & 24 & $\mathrm{SP}$ & Limeira & 900 & 84 & $\mathrm{SP}$ & Jaú & 1366 & 144 \\
\hline SP & Pirassununga & 324 & 25 & SP & Itapecerica da Serra & 907 & 85 & SP & Poá & 1374 & 145 \\
\hline RS & Santa Rosa & 338 & 26 & RJ & Săo Pedro da Aldeia & 908 & 86 & $\mathrm{SP}$ & Tatuí & 1395 & 146 \\
\hline RS & Campo Bom & 381 & 27 & SP & Várzea Paulista & 929 & 87 & $\mathrm{SP}$ & Embu & 1401 & 147 \\
\hline PR & Toledo & 386 & 28 & CE & Aquiraz & 933 & 88 & PA & Belém & 1405 & 148 \\
\hline MG & São Francisco & 391 & 29 & RS & Canguçu & 947 & 89 & $\mathrm{SP}$ & Barueri & 1427 & 149 \\
\hline RS & Guaíba & 400 & 30 & SC & Araranguá & 951 & 90 & RS & Santo Ângelo & 1438 & 150 \\
\hline MG & Januária & 418 & 31 & SP & Mogi Guaçu & 956 & 91 & AM & Manaus & 1443 & 151 \\
\hline SP & Araras & 423 & 32 & PR & Fazenda Rio Grande & 966 & 92 & RJ & Três Rios & 1446 & 152 \\
\hline $\mathrm{PA}$ & Acará & 431 & 33 & RS & Vacaria & 973 & 93 & MG & Ribeirẫo das Neves & 1447 & 153 \\
\hline SP & Araçatuba & 433 & 34 & MG & Itaúna & 980 & 94 & $\mathrm{SC}$ & São José & 1450 & 154 \\
\hline GO & Catalẵo & 452 & 35 & RS & Sapiranga & 989 & 95 & MG & Itabira & 1452 & 155 \\
\hline PR & Sarandi & 457 & 36 & $\mathrm{BA}$ & Santo Antônio de Jesus & 991 & 96 & $\mathrm{PI}$ & Teresina & 1470 & 156 \\
\hline $\mathrm{CE}$ & Canindé & 468 & 37 & $\mathrm{SP}$ & São Roque & 1007 & 97 & RJ & Săo Gonçalo & 1486 & 157 \\
\hline $\mathrm{CE}$ & Caucaia & 474 & 38 & $\mathrm{SP}$ & Ferraz de Vasconcelos & 1024 & 98 & SC & Tubarẫo & 1504 & 158 \\
\hline MG & Joẫo Monlevade & 493 & 39 & $\mathrm{SP}$ & Assis & 1025 & 99 & RJ & Duque de Caxias & 1508 & 159 \\
\hline SP & Matẵo & 513 & 40 & MG & Pará de Minas & 1043 & 100 & RS & Caxias do Sul & 1513 & 160 \\
\hline $\mathrm{RJ}$ & Barra Mansa & 536 & 41 & SP & Lençóis Paulista & 1067 & 101 & $\mathrm{SP}$ & Guarujá & 1562 & 161 \\
\hline SP & Birigui & 545 & 42 & SP & Avaré & 1073 & 102 & SP & Osasco & 1567 & 162 \\
\hline SP & Sertăozinho & 546 & 43 & MG & Manhuaçu & 1076 & 103 & RO & Cacoal & 1572 & 163 \\
\hline SP & Sumaré & 547 & 44 & GO & Valparaíso de Goiás & 1102 & 104 & RJ & Saquarema & 1574 & 164 \\
\hline SP & Pindamonhangaba & 561 & 45 & $\mathrm{SP}$ & Indaiatuba & 1105 & 105 & $\mathrm{SP}$ & Paulínia & 1597 & 165 \\
\hline SP & Ourinhos & 568 & 46 & $\mathrm{SP}$ & Jundiaí & 1106 & 106 & MT & Várzea Grande & 1619 & 166 \\
\hline $\mathrm{SP}$ & Santa Bárbara d'Oeste & 577 & 47 & $\mathrm{SP}$ & Franca & 1111 & 107 & RS & Erechim & 1621 & 167 \\
\hline SC & Concórdia & 597 & 48 & $\mathrm{BA}$ & Paulo Afonso & 1123 & 108 & GO & Itumbiara & 1627 & 168 \\
\hline AM & Itacoatiara & 610 & 49 & $\mathrm{SP}$ & Jandira & 1126 & 109 & $\mathrm{SP}$ & Jaboticabal & 1647 & 169 \\
\hline $\mathrm{SP}$ & Leme & 611 & 50 & MG & Montes Claros & 1151 & 110 & RJ & Angra dos Reis & 1668 & 170 \\
\hline PR & Cambé & 621 & 51 & CE & Tianguá & 1166 & 111 & $\mathrm{SP}$ & Sorocaba & 1684 & 171 \\
\hline SP & São José do Rio Pardo & 623 & 52 & MG & Formiga & 1169 & 112 & BA & Valença & 1685 & 172 \\
\hline SC & São Bento do Sul & 630 & 53 & $\mathrm{SP}$ & Franco da Rocha & 1176 & 113 & $\mathrm{PR}$ & Umuarama & 1695 & 173 \\
\hline $\mathrm{SP}$ & Batatais & 634 & 54 & $\mathrm{SP}$ & Francisco Morato & 1181 & 114 & MG & Teófilo Otoni & 1720 & 174 \\
\hline RS & São Borja & 643 & 55 & RJ & Belford Roxo & 1193 & 115 & RS & Venâncio Aires & 1725 & 175 \\
\hline AL & Penedo & 647 & 56 & GO & Nowo Gama & 1202 & 116 & CE & Aracati & 1727 & 176 \\
\hline RS & Santiago & 653 & 57 & RJ & Japeri & 1209 & 117 & RJ & Araruama & 1733 & 177 \\
\hline MG & Timóteo & 669 & 58 & $\mathrm{AC}$ & Cruzeiro do Sul & 1213 & 118 & PR & São José dos Pinhais & 1736 & 178 \\
\hline ES & Guarapari & 681 & 59 & $\mathrm{CE}$ & Sobral & 1217 & 119 & RJ & Volta Redonda & 1748 & 179 \\
\hline RS & Cruz Alta & 694 & 60 & $\mathrm{SP}$ & Itanhaém & 1221 & 120 & $\mathrm{~PB}$ & Cajazeiras & 1750 & 180 \\
\hline
\end{tabular}


Tabela 37. Ranking dos municípios com mais de 50 mil habitantes - Fronteira estimada com índice de mortalidade infantil como produto

\begin{tabular}{|c|c|c|c|c|c|c|c|c|c|c|c|}
\hline Estado & Municípios & Ranking & $\begin{array}{l}\text { Ranking } \\
\text { Ajustado }\end{array}$ & Estado & Municípios & Ranking & $\begin{array}{l}\text { Ranking } \\
\text { Ajustado }\end{array}$ & Estado & Municípios & Ranking & $\begin{array}{l}\text { Ranking } \\
\text { Ajustado }\end{array}$ \\
\hline$\overline{\mathrm{MG}}$ & Poços de Caldas & 1751 & 181 & MA & Codó & 2288 & 241 & $\mathrm{PE}$ & Petrolina & 2794 & 301 \\
\hline SC & Lages & 1752 & 182 & RS & Camaquã & 2298 & 242 & SP & Moji das Cruzes & 2800 & 302 \\
\hline SP & Piedade & 1770 & 183 & MG & Sabará & 2300 & 243 & PR & Irati & 2813 & 303 \\
\hline RS & Alvorada & 1787 & 184 & SP & Ribeirão Pires & 2304 & 244 & BA & Porto Seguro & 2824 & 304 \\
\hline RO & Jaru & 1797 & 185 & SP & Americana & 2307 & 245 & MG & Nova Lima & 2857 & 305 \\
\hline PR & Maringá & 1808 & 186 & SP & Mauá & 2317 & 246 & $\mathrm{BA}$ & Alagoinhas & 2882 & 306 \\
\hline CE & Camocim & 1810 & 187 & PR & Castro & 2324 & 247 & SP & Santos & 2898 & 307 \\
\hline $\mathrm{RJ}$ & Teresópolis & 1811 & 188 & MG & Curvelo & 2325 & 248 & TO & Araguaína & 2904 & 308 \\
\hline SP & Moji-Mirim & 1828 & 189 & RJ & Petrópolis & 2331 & 249 & RS & Novo Hamburgo & 2921 & 309 \\
\hline $\mathrm{PE}$ & Salgueiro & 1830 & 190 & $\mathrm{SP}$ & Andradina & 2335 & 250 & $\mathrm{SP}$ & São José do Rio Preto & 2945 & 310 \\
\hline $\mathrm{CE}$ & Juazeiro do Norte & 1832 & 191 & MS & Campo Grande & 2348 & 251 & RS & Porto Alegre & 2963 & 311 \\
\hline BA & Ilhéus & 1841 & 192 & MG & Ipatinga & 2363 & 252 & ES & Cariacica & 2967 & 312 \\
\hline MG & Barbacena & 1843 & 193 & RO & Ariquemes & 2368 & 253 & BA & Vitória da Conquista & 2989 & 313 \\
\hline $\mathrm{BA}$ & Brumado & 1851 & 194 & $\mathrm{BA}$ & Feira de Santana & 2370 & 254 & MG & Viçosa & 3002 & 314 \\
\hline PR & Londrina & 1864 & 195 & sc & Blumenau & 2382 & 255 & PA & Marabá & 3003 & 315 \\
\hline MG & Patos de Minas & 1869 & 196 & SP & Arujá & 2388 & 256 & MG & Ubá & 3019 & 316 \\
\hline SP & Cajamar & 1873 & 197 & PR & Campo Largo & 2400 & 257 & SE & Lagarto & 3020 & 317 \\
\hline GO & Anápolis & 1875 & 198 & RJ & Barra do Piraí & 2402 & 258 & $\mathrm{RN}$ & Natal & 3034 & 318 \\
\hline MA & Timon & 1879 & 199 & RJ & Valença & 2408 & 259 & MT & Cáceres & 3035 & 319 \\
\hline ES & Colatina & 1889 & 200 & $\mathrm{SP}$ & Tupã & 2432 & 260 & RS & ljuí & 3041 & 320 \\
\hline RJ & Itaguaí & 1900 & 201 & MG & Araguari & 2439 & 261 & RS & Rio Grande & 3043 & 321 \\
\hline RJ & Queimados & 1911 & 202 & $\mathrm{SP}$ & Suzano & 2440 & 262 & PR & Curitiba & 3049 & 322 \\
\hline RN & Mossoró & 1912 & 203 & BA & Tucano & 2462 & 263 & $\mathrm{SP}$ & Amparo & 3053 & 323 \\
\hline SE & Nossa Senhora do Socorro & 1914 & 204 & SC & Caçador & 2467 & 264 & $\mathrm{BA}$ & Lauro de Freitas & 3055 & 324 \\
\hline BA & Jequié & 1928 & 205 & MG & Conselheiro Lafaiete & 2478 & 265 & MG & Três Corações & 3058 & 325 \\
\hline RS & Farroupilha & 1941 & 206 & $\mathrm{PR}$ & Paranavaí & 2479 & 266 & RJ & Nilópolis & 3060 & 326 \\
\hline $\mathrm{SP}$ & Araraquara & 1945 & 207 & MT & Sinop & 2484 & 267 & ES & Cachoeiro de Itapemirim & 3065 & 327 \\
\hline SP & Campinas & 1973 & 208 & $\mathrm{BA}$ & Campo Formoso & 2486 & 268 & ES & Viana & 3090 & 328 \\
\hline MG & Muriaé & 1983 & 209 & SP & Itapira & 2521 & 269 & $\mathrm{RR}$ & Boa Vista & 3096 & 329 \\
\hline $\mathrm{PE}$ & Cabo de Santo Agostinho & 2003 & 210 & MS & Três Lagoas & 2543 & 270 & MG & Juiz de Fora & 3097 & 330 \\
\hline $\mathrm{SP}$ & Penápolis & 2007 & 211 & PR & Campo Mourão & 2544 & 271 & $\mathrm{SP}$ & Bauru & 3101 & 331 \\
\hline SP & Diadema & 2013 & 212 & MG & Sete Lagoas & 2548 & 272 & PB & Patos & 3111 & 332 \\
\hline $\mathrm{SP}$ & Itaquaquecetuba & 2021 & 213 & $\mathrm{SP}$ & Valinhos & 2554 & 273 & BA & Teixeira de Freitas & 3112 & 333 \\
\hline GO & Senador Canedo & 2024 & 214 & MG & Caratinga & 2556 & 274 & RS & Santa Cruz do Sul & 3121 & 334 \\
\hline MG & Coronel Fabriciano & 2025 & 215 & SP & Rio Claro & 2557 & 275 & PB & Sousa & 3129 & 335 \\
\hline SC & Brusque & 2028 & 216 & BA & Itapetinga & 2570 & 276 & MG & Passos & 3130 & 336 \\
\hline RS & Alegrete & 2036 & 217 & PR & Cascavel & 2579 & 277 & $\mathrm{SP}$ & Barretos & 3133 & 337 \\
\hline SP & Santana de Parnaíba & 2038 & 218 & MG & Uberaba & 2602 & 278 & MG & Governador Valadares & 3154 & 338 \\
\hline SP & Mairiporã & 2045 & 219 & MT & Rondonópolis & 2603 & 279 & sc & Balneário Camboriú & 3155 & 339 \\
\hline SP & Itapetininga & 2095 & 220 & PR & Almirante Tamandaré & 2616 & 280 & MG & Belo Horizonte & 3157 & 340 \\
\hline PE & Recife & 2109 & 221 & MG & Três Pontas & 2622 & 281 & $\mathrm{PE}$ & Bezerros & 3160 & 341 \\
\hline MG & Paracatu & 2122 & 222 & PR & Paranaguá & 2625 & 282 & ES & São Mateus & 3170 & 342 \\
\hline MG & Leopoldina & 2131 & 223 & PR & Francisco Beltrão & 2636 & 283 & MT & Tangará da Serra & 3183 & 343 \\
\hline SP & Guarulhos & 2132 & 224 & SP & Cubatão & 2654 & 284 & MG & Contagem & 3210 & 344 \\
\hline PB & Guarabira & 2143 & 225 & BA & Candeias & 2671 & 285 & $\mathrm{PE}$ & Surubim & 3225 & 345 \\
\hline $\mathrm{CE}$ & Fortaleza & 2144 & 226 & sc & Rio do Sul & 2678 & 286 & BA & Conceição do Coité & 3231 & 346 \\
\hline SP & Itu & 2152 & 227 & PR & Piraquara & 2692 & 287 & RS & São Leopoldo & 3235 & 347 \\
\hline AC & Rio Branco & 2172 & 228 & SP & Praia Grande & 2706 & 288 & SC & Criciúma & 3243 & 348 \\
\hline PR & Guarapuava & 2179 & 229 & $\mathrm{SP}$ & São Bernardo do Campo & 2715 & 289 & RJ & Macaé & 3246 & 349 \\
\hline $\mathrm{sc}$ & Itajaí & 2196 & 230 & MG & Varginha & 2721 & 290 & $\mathrm{PE}$ & Caruaru & 3251 & 350 \\
\hline PR & Telêmaco Borba & 2199 & 231 & RO & Ji-Paraná & 2722 & 291 & ES & Vila Velha & 3256 & 351 \\
\hline SP & Itapeva & 2204 & 232 & $\mathrm{SC}$ & Jaraguá do Sul & 2730 & 292 & MG & Itajubá & 3272 & 352 \\
\hline RS & Uruguaiana & 2224 & 233 & MG & Santa Luzia & 2738 & 293 & $\mathrm{PR}$ & Arapongas & 3280 & 353 \\
\hline MG & Pirapora & 2252 & 234 & $\mathrm{PE}$ & Vitória de Santo Antão & 2740 & 294 & SE & Aracaju & 3283 & 354 \\
\hline RJ & Resende & 2253 & 235 & BA & Euclides da Cunha & 2741 & 295 & BA & Jacobina & 3307 & 355 \\
\hline $\mathrm{PE}$ & Escada & 2268 & 236 & RS & Carazinho & 2771 & 296 & RS & Passo Fundo & 3308 & 356 \\
\hline $\mathrm{SP}$ & Marília & 2274 & 237 & MG & Lavras & 2776 & 297 & MG & Araxá & 3347 & 357 \\
\hline SP & Votuporanga & 2276 & 238 & $\mathrm{sc}$ & Canoinhas & 2782 & 298 & $\mathrm{BA}$ & Irecê & 3351 & 358 \\
\hline SE & Estância & 2283 & 239 & MG & Vespasiano & 2790 & 299 & BA & Barreiras & 3353 & 359 \\
\hline MG & São Sebastião do Paraíso & 2287 & 240 & PR & Foz do Iguaçu & 2791 & 300 & ES & Vitória & 3367 & 360 \\
\hline
\end{tabular}

